\title{
Comparison of expression pattern and localization of iron transport proteins in rat liver, brain and spleen during acute phase response: in-vivo and in-vitro studies
}

\author{
Dissertation \\ zur Erlangung des Doktorgrades \\ der Mathematisch-Naturwissenschaftlichen Fakultäten \\ der Georg-August-Universität zu Göttingen
}

vorgelegt von

Naila Naz

Aus Lahore, Pakistan

Göttingen 2011 
D7

Referent: Prof. Dr. Jürgand Wienands

Korreferent: Prof. Dr. Lutz Walter

Tag der mündlichen Prüfung: 12.01.2012 


\section{Table of Contents}

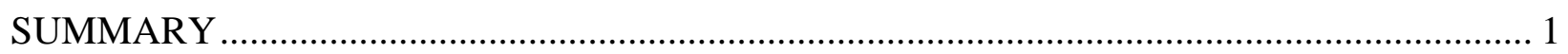

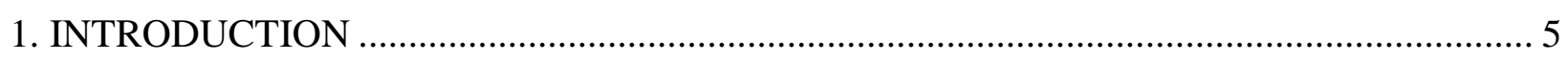

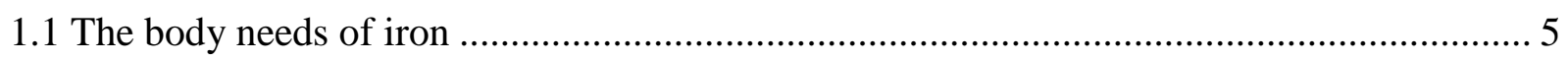

1.2 The iron metabolism proteins and normal iron homeostasis ............................................ 5

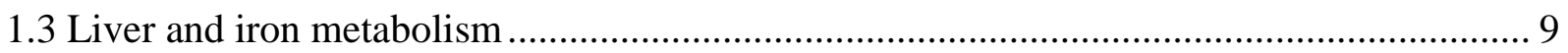

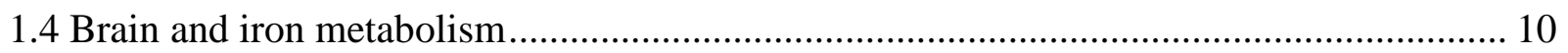

1.5 The acute phase response, liver and acute phase proteins ............................................... 12

1.6 The model of acute phase study and iron metabolism.................................................... 13

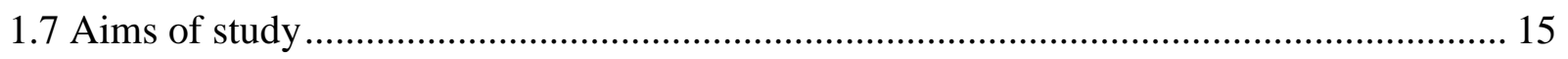

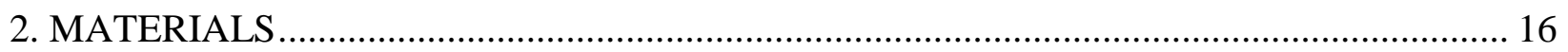

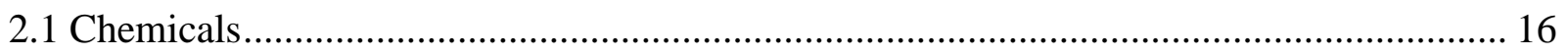

2.2 Animals and experimental models of acute-phase reaction.............................................. 17

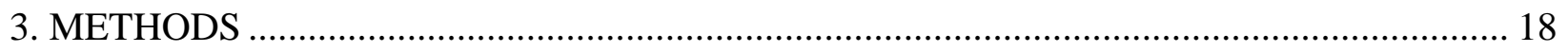

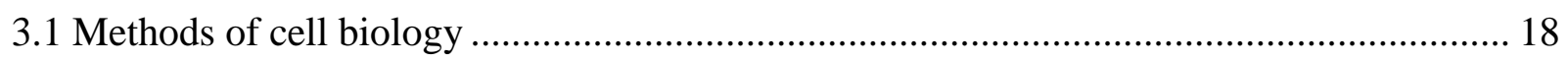

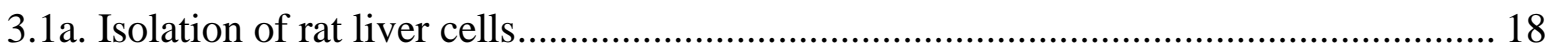

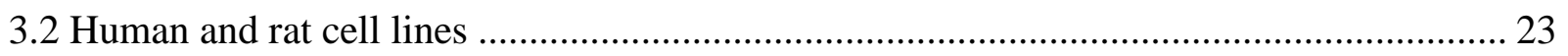

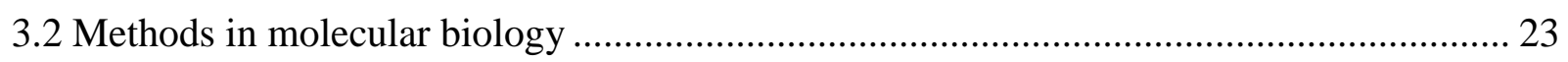

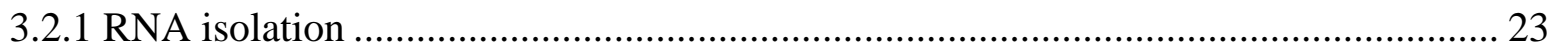

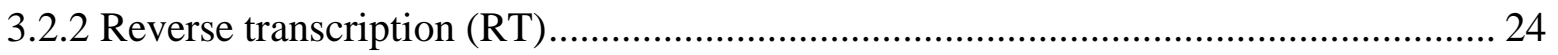

3.2.3 Real time quantitative Polymerase chain reaction .................................................... 24

3.2.4 Southern blot analysis of PCR products. ................................................................. 25

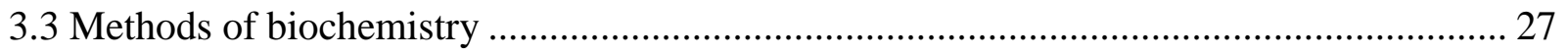

3.3.1 Protein extraction from liver tissue and cultured hepatocytes ..................................... 27

3.3.2 Proteins isolation and Western Blot..................................................................... 28

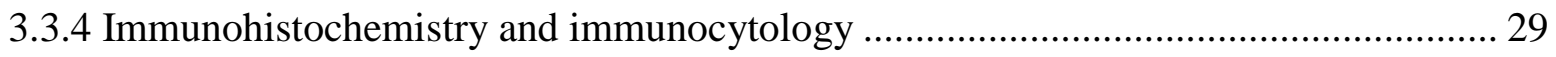

3.3.5 Prussian blue iron staining in liver and spleen....................................................... 30

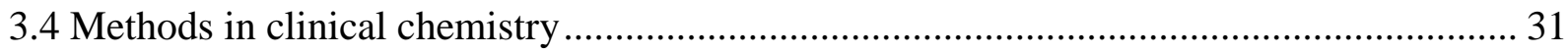

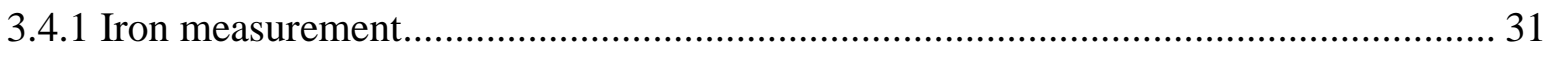

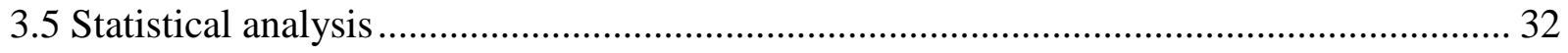

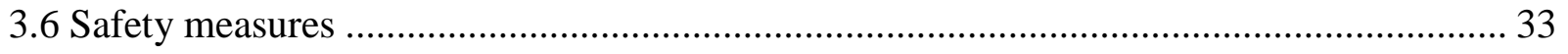

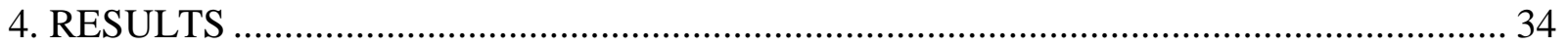


4.1 Changes in mRNA expression of acute-phase cytokines in injured muscle, liver and brain 34

4.2 Expressional change in hemeoxygenase-1 (positive acute phase protein) in liver and brain 36

4.3 Changes in serum and tissue iron levels 37

4.4 Changes in mRNA expressions of hepcidin, Hjv, HFE, hephastin Fpn-1 in rat liver, brain and spleen. 39

4.5 Changes in mRNA expressions of iron import proteins (Tf, TfR1, TfR2 and DMT-1) in rat liver, brain and spleen. 43

4.6 Changes in mRNA expressions of iron storage proteins (Ferritin $\mathrm{H}$ and $\mathrm{L}$ ) in rat liver, brain

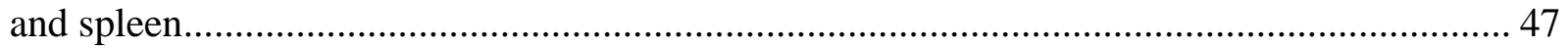

4.7 mRNA expression of other iron regulatory proteins in the rat liver, brain and spleen ....... 47

4.8 Changes in protein expression of iron transport proteins during APR .............................. 50

4.8a Western blot analysis of iron transport proteins in rat liver during APR ....................... 50

4.8b Densitometry analysis of changes in protein expression in rat liver APR ..................... 51

4.8c Comparative analysis of TfR1 protein expression in rat liver and brain ........................ 53

4.9 Immunohistochemical identification of iron transport proteins in rat liver, brain and spleen

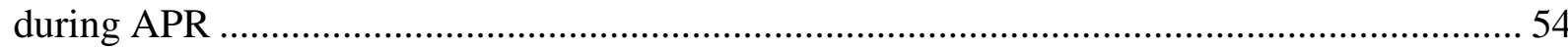

4.9a Immunohistochemical detection of TfR1 protein localization in rat liver, brain and

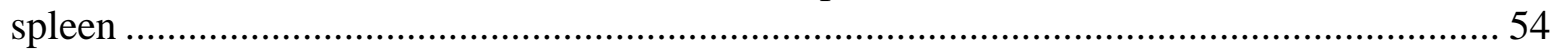

4.9b Detection of TfR1 localization in liver cells (confirmation of TfR 1 membranous

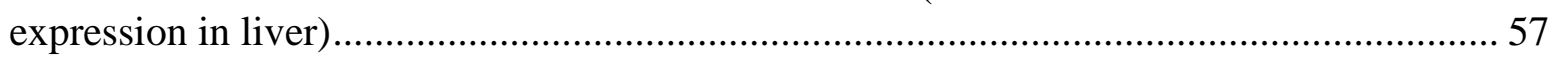

4.9c Immunohistochemical detection of TfR1 expression in brain cell lines (confirmation of TfR1nuclear expression) .............................................................................................. 59

4.9d Immunohistochemical detection of TfR2 localization in rat liver, brain and spleen.... 60 4.9e Immunofloresence detection of DMT-1 localization in rat liver, brain and spleen ...... 62 4.9f Detection of Fpn-1 protein localization in rat liver, brain and spleen .......................... 64

4.9g Blocking of Fpn-1, DMT-1 and TfR2 immunoexpression using blocking peptide...... 66 4.9g Immunohistochemical detection of iron transport proteins in isolated rat liver cells ... 66 4.9h Detection of iron transport proteins in isolated liver cells and tissue fraction by means

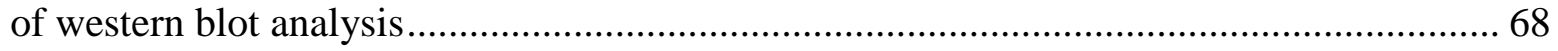

4.10 Changes in mRNA expression of ribonuclease reductase (RNR) and Cyclin E in rat liver during acute phase response............................................................................................ 70

4.11 Changes in cyclin E protein expression in rat liver during acute phase response ............ 70 4.12 mRNA Expression pattern of hepcidin Fpn-1, Fpn-1a and Fpn-1b in mice liver during APR 73

4.13 Changes in protein expression of Fpn-1 in wild type and IL-6 knock-out mice during acute phase response 74 
4.14 Changes in mRNA expression of Fpn-1 and hepcidin in rat hepatocytes after cytokine

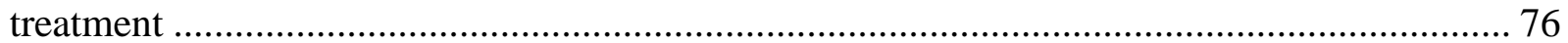

4.15 Changes in protein expression of acute phase protein and Fpn-1 in rat hepatocytes after

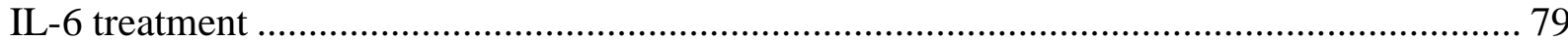

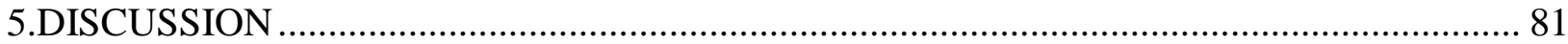

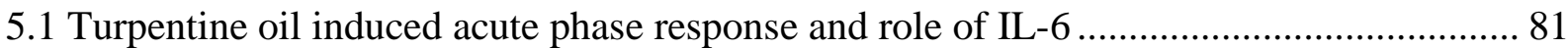

5.2 Changes in serum and tissue iron concentration; a significant role of liver under APR .... 82

5.3 Expressional changes of iron transport proteins during APR; a comparison between liver,

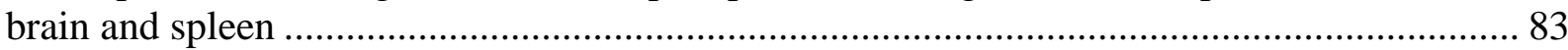

5.4 The differential cellular localization of iron transport proteins in rat liver, brain and spleen 86

5.5 Ferroportin-1, a negative acute phase protein; role of IL-6 cytokine ................................ 88

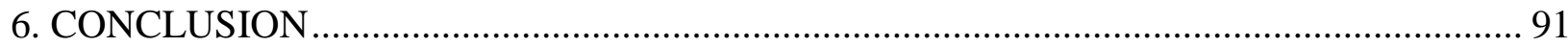

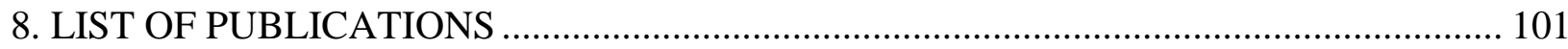

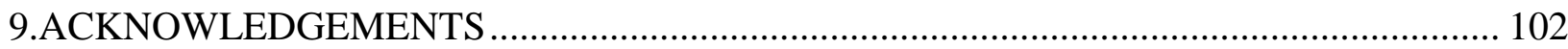

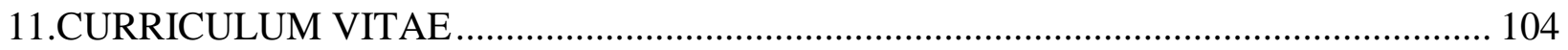




\section{LIST OF FIGURES}

Figure 1: A model of iron absorption pathways by duodenal enterocyte. The figure shows uptake of ionic iron and haem iron from the gut lumen and transfer of iron to blood. DMT1: divalent metal transporter 1; HFE, haemochromatosis protein, TfR1, transferrin receptor 1; TfR2, transferrin receptor 2. Source: (Trinder et al. 2002) .......................................................... 6 Figure 2: Schematic diagram illustrating the mechanisms involved in iron uptake. Diferric Tf undergoes endocytosis after binding to TfR1. Iron is released from Tf mediated by a decrease in $\mathrm{pH}$ and is exported out of the endosome by DMT1, where it enters the labile iron pool (LIP). Iron in the LIP can subsequently be incorporated into ferritin for iron storage or into iron-containing proteins. Source: (Kalinowski and Richardson 2005) ....................................................... 8

Figure 3: Hepcidin down-regulates ferroportin expression. Ferroportin (FPN) is expressed in enterocytes, hepatocytes, and tissue macrophages. The binding of hepcidin to Fpn-1 leads to its phosphorylation, internalization, and degradation. Low levels of Fpn-1 expression reduce iron absorption in the gut, lower iron release from the liver, and prevent iron recycling by tissue macrophages. Source: (Cui et al. 2009) ......................................................................... 10

Figure 4: Brain iron uptake and mobilization; the main areas of iron entry to the brain are the blood-brain barrier (BBB) and the blood-cerebrospinal fluid barrier (choroid plexuses). At the $\mathrm{BBB}$ level, iron is transferred to the brain by plasma transferrin (Tf) through an interaction between circulatory $\mathrm{Tf}$ and transferrin receptors (TfR) in the brain microvasculature. The release of iron from the endothelial cell is presumed to occur by a process similar to the one in the basolateral side of the enterocyte, but direct evidence is lacking. Some studies have shown transcytosis of transferrin suggesting that Tf may transport iron trough the BBB. Once across the blood-brain-barrier, iron is transported by $\mathrm{Tf}$ (synthesized by choroid plexus or by oligodendrocytes) and taken up by different cell types. Source : (Pi+!ero and Connor 2000)..... 11 Figure 5: The acute phase model of study. Turpentine injection into the limb muscle results cytokine production at the site of injury. These cytokines are released into the blood and when they reach to the liver, liver becomes metabolically active and release acute phase mediators to start the healing process at the site of injury. The decreased iron concentration in the serum is the hallmarks of APR. The fever and illness behavior during acute phase response is induced by local production of cytokines and prostaglandins by brain. 14 Figure 6: mRNA expression of acute-phase cytokines (IL-6, IL1- $\beta$ and TNF- $\alpha$ ) in rat muscle, liver and brain after TO-administration. RT-PCR analysis of total RNA from muscle, liver and brain tissue shows gene expression of acute phase cytokines. $\mathrm{Ct}$ values were normalized with UBC as a housekeeping gene. The results represent the fold changes of mRNA expression where control values are normalized to one. Results represent mean value \pm S.E.M. $\left({ }^{*} \mathrm{P} \leq 0.05, * * \mathrm{P} \leq 0.01\right.$ analyzed by one way ANOVA, $n=4)$. 35

Figure 7: Changes of heme oxygenase-1-(HO-1) transcript amount in the liver and brain tissue during APR. a) RT-PCR analysis of total RNA from rat liver and brain during APR. RT-PCR was normalized by using UBC as housekeeping gene Results show the fold changes in the mRNA expression of HO-1 where control values are normalized to one. Results represent mean value \pm S.E.M. ( $* * * P<0.0001$, analyzed by one way ANOVA; $n=3)$. b) Western blot analysis of total protein lysates $(50 \mu \mathrm{g})$ from rat liver during APR at various time-points with antibodies specific for HO-1 and $\beta$-actin. Published: (Malik et al. 2010). 36 
Figure 8: Changes of serum and tissue iron concentration during APR. Iron concentrations of serum, liver, spleen, brain tissue lysates and liver tissue fractions were determined by ferrozine based assay as described in materials and methods. Control values were normalized to 100 percent. Results represent mean value \pm S.E.M. $(* * \mathrm{P}<0.01 * \mathrm{P}<0.05$ analyzed by one way

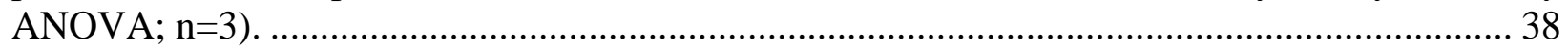

Figure 9: RT-PCR analysis of total liver RNA to demonstrate the changes of hepcidin-, Fpn1-, Fpn-1a-, Fpn-1b-, hephastin-, HFE- and Hjv-transcript amount in the liver tissue during APR. The mRNA expression of each gene was analyzed by real-time PCR and normalized using UBC as housekeeping gene. Result shows the fold changes where control values are normalized to one. Results represent mean value \pm S.E.M. $(* P<0.05$, $* * \mathrm{P}<0.01$ analyzed by one way ANOVA; $\mathrm{n}=3$ ). 40

Figure 10: RT-PCR of total RNA from brain to demonstrate the changes of hepcidin-, Fpn-1-, Fpn-1a, Fpn-1b, hephastin-, HFE- and Hjv-transcript amount in the brain tissue during APR (upper panel). The mRNA expression was analyzed by RT-PCR and normalized using UBC as housekeeping gene. Data show the fold changes in comparison to controls where the control values are normalized to one. Results represent mean value \pm S.E.M. $(* P<0.05, * * \mathrm{P}<0.01$, analyzed by one way ANOVA; $n=3$ ). The lower panel: Change in gene expression of hepcidin at transcriptional concentration showed by Southern blot analysis using $\beta$-actin as loading control.

Figure 11: RT-PCR analysis of total RNA from spleen to demonstrate the changes of hepcidin-, Fpn1-, Fpn-1a-, Fpn-1b-, hephastin-, HFE- and Hjv-transcript amount during APR. The mRNA expression was analyzed by RT-PCR and normalized using UBC as housekeeping gene. Data shows fold changes of gene expression where the control values were normalized to one. Results represent mean value \pm S.E.M. $(* P<0.05$, $* * \mathrm{P}<0.01$, $* * * \mathrm{P}<0.001$ analyzed by one way ANOVA;

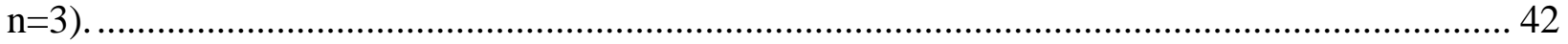

Figure 12: RT-PCR analysis of total RNA from rat liver to show the changes of TfR1, TfR2, Tfand DMT-1 (the iron import proteins) transcript amount during APR. The mRNA expression of transferrin (Tf), transferrin receptor1 (TfR1) and transferrin receptor2 (TfR2) was analyzed by real time PCR and normalized with ubiquitin $\mathrm{C}$ as housekeeping gene. Data shows the fold changes of respective gene compared to controls where the control values are normalized to one. Results represent mean value \pm S.E.M. ( ${ }^{*} P<0.05$, analyzed by one way ANOVA; $\left.n=3\right)$......... 44 Figure 13: RT-PCR analysis of total RNA from brain to demonstrate the changes of Tf-, TfR1, TfR2, and DMT-1 (the iron import proteins) transcript amount in the brain tissue during APR. The mRNA expression of transferrin (Tf), transferrin receptor1 (TfR1) and transferrin receptor2 (TfR2) was analyzed by real time PCR and normalized with UBC as housekeeping. Data represents the fold changes in comparison to controls where the control values are normalized to one. Results represent mean value \pm S.E.M. $(* * P<0.001$, analyzed by one way ANOVA; $n=3)$.

Figure 14: RT-PCR analysis of total RNA from spleen to demonstrate the changes of Tf, TfR1, TfR2 and DMT-1 (the iron import proteins) transcript amount in the spleen tissue during APR. The mRNA expression of transferrin (Tf), transferrin receptor 1 (TfR1) and transferrin receptor 2 (TfR2) was analyzed by real time PCR and normalized with UBC as housekeeping. Data represents the fold changes of respective gene where the control values were normalized to one. Results represent mean value \pm S.E.M. $(* \mathrm{P}<0.05, * * P<0.001$, $* * * \mathrm{P}<0.001$ analyzed by one way ANOVA; $n=3$ ). 46 
Figure 15: RT-PCR of total RNA from liver, brain and spleen to demonstrate the changes of ferritin-H and ferritin-L (the iron storage proteins) transcript amount during acute-phase response. Fold change in mRNA expression was normalized with UBC as housekeeping gene as revealed by real-time PCR. The data shows fold changes in comparison to controls where control values are normalized to one. Results represent mean value \pm S.E.M. ( $* \mathrm{P}<0.05$ analyzed by one way ANOVA; $n=3$ ). 48

Figure 16: RT-PCR of total RNA from liver, brain and spleen to demonstrate the changes of IRP-1 and IRP-2 (the iron regulatory proteins) transcript amount in the liver, brain and spleen during APR. Fold change in mRNA expression was normalized with UBC as housekeeping gene as revealed by real-time PCR. The data shows fold changes in comparison to controls where control values are normalized to one. Results represent mean value \pm S.E.M.

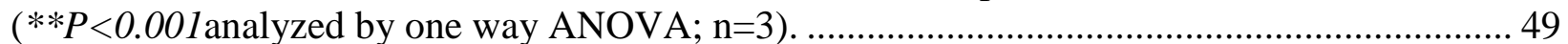
Figure 17: Western blot analysis of total rat liver lysates $(50 \mu \mathrm{g})$ for iron transport proteins. Western blot analysis of iron export proteins (Fpn-1 and hephastin) and iron import proteins (DMT-1, Tf, TfR1, TfR2) in rat liver during APR. The results show representative figure from three technical replicates. 51

Figure 18: Densitometry analysis of western blots performed for rat liver during APR. The result shows the percentage changes of protein amount in comparison to controls where the control values were normalized to 100 percent. Densitometry was performed using Image J software. Results represent mean values \pm SEM $(* * * \mathrm{P}<0.0001$ analyzed by one-way ANOVA; $\mathrm{n}=3)$. 52

Figure 19: Identification and comparison of TfR1 protein in rat liver, brain and serum at different time points during acute phase response. Western blot analysis of TfR1 (95-kDa) from total protein lysates $(50 \mu \mathrm{g})$ of rat liver, brain and serum. $\beta$-actin $(43 \mathrm{kDa})$ was used as equal loading control. Densitometry analysis of western blots was also performed to show the changes in the protein expression of TfR1. Results represent mean value \pm S.E.M. $(* * * P<0.0001$ analyzed by one way ANOVA; n=3). Published: (Malik et al. 2011) ...................................... 54 Figure 20: Immunofluorescence detection of TfR 1 and ED-1 in the rat liver. TfR 1 and ED-1 positive cells in sequential sections of rat liver tissue at different time points during acute phase response. Right panel: ED-1+DAPI, the left panel TfR1+ DAPI. a) and c) are control rat liver b) and d) 6 hours after TO administration. Insets show the higher magnification of TfR1 positive cells in the liver tissue. Results are representative of 3 animals (original magnification x100, scale bar $100 \mu \mathrm{m})$. 55

Figure 21: Microscopic demonstration of immunofluorescence detection of TfR1 on cryostat sections of rat brain. TfR1 positive cells in rat brain during acute phase response. a) TfR1 immunoexpression in control brain (b) 4 hours, white arrow in insets, lower right indicates the TfR1-positive cells in the brain (c) 6 hours and (d) 24 hours after TO treatment. Results are

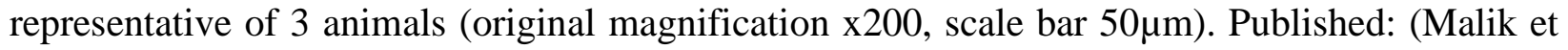
al. 2011) 56

Figure 22: Microscopic demonstration of immunofluorescence detection of TfR1 on cryostat sections of rat spleen. TfR1 positive cells in rat spleen during acute phase response. a) TfR1 immunoexpression in spleen of control rats (b) 6 hours, the inset demonstrates the higher magnification (c) 12 hours and (d) 24 hours white pulp area in spleen. Results are representative of 3 animals (original magnification x200, scale bar $100 \mu \mathrm{m}$ ). 57

Figure 23: Microscopic demonstration of immunofluorescence detection of TfR1 in isolated rat (a) hepatocytes, (b) Kupffer cells and (c) human hepatoma cell line (HepG2). Results are 
representative of three experiments for each cell type (original magnification $\mathrm{x} 400$, scale bar $20 \mu \mathrm{m})$. Published: (Malik et al. 2011) ................................................................................. 58

Figure 24: (a) Western blot analysis of TfR1 (95 kDa) in rat liver isolated cells using $\beta$-actin (43 $\mathrm{kDa}$ ) as loading control. (b) Western blot analysis of TfR 1 in protein $(50 \mu \mathrm{g})$ extracted from different fractions of hepatoma cell line (Hep G2). Results represent one of three experiments.

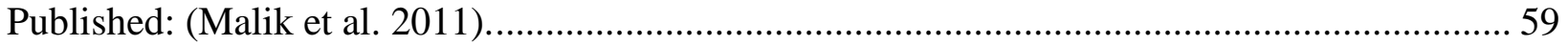

Figure 25: Microscopic demonstration of immunofluorescence detection of TfR1 in (a) rat neural stem cells (NSC) and (b) human glioblastoma cell line (U373MG). Results are representative of three experiments for each cell type (original magnification x200, scale bar 10 $\mu \mathrm{m}$ ). Published: (Malik et al. 2011).

Figure 26: Microscopic demonstration of immunofluorescence detection of TfR2 on cryostat sections of rat liver, brain and spleen. The upper most panel: Double immunofloresence staining of TfR2 (red) and ED-1(green) in rat liver. The white arrow and insets indicate the co-expression of both proteins. The middle panel: immunofloresence detection of TfR2 in rat brain. The lower panel: immunolocalization of TfR2 in rat spleen. The inset indicates the higher magnification. Co (control), WP (white pulp), RP (red pulp). Results are representative of 3 animals (original magnification $\mathrm{x} 200$, scale bar $100 \mu \mathrm{m})$.

61

Figure 27: Microscopic demonstration of immunofluorescence detection of DMT-1 on cryostat sections of rat liver, brain and spleen. The upper most panel: Double immunofloresence staining of DMT-1 (red) and ED-1(green) in rat liver. DMT-1 is localized in the nuclei of liver hepatocytes and Kupffer cells. The middle panel: Immunofloresence detection of DMT-1 in rat brain indicates nuclear localization of DMT-1. The lower panel: immunolocalization of DMT-1 in control rat spleen and at $6 \mathrm{~h}$ of acute phase response. DMT-1 is more intense in the cell population of white pulp area. Insets indicate the higher magnification. Co (control), WP (white pulp), RP (red pulp). Results are representative of 3 animals (original magnification x200, scale bar $100 \mu \mathrm{m})$. 63

Figure 28: Microscopic demonstration of immunofluorescence detection of Fpn-1 on cryostat sections of rat liver, brain and spleen. The upper most panel: Double immunofloresence staining

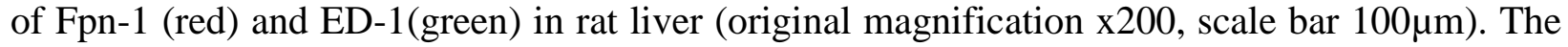
middle panel: Immunofloresence detection of Fpn-1 in rat brain (Original magnification x100, scale bar $200 \mu \mathrm{m})$. The lower panel: immunolocalization of Fpn-1 in control rat spleen and at $24 \mathrm{~h}$ of acute phase response (original magnification $\mathrm{x} 400$, scale bar $50 \mu \mathrm{m}$ ). Co (control, WP (white pulp), RP (red pulp). The insets indicate the higher magnification. Results are representative of 3 animals.

Figure 29: Microscopic demonstration of blocking of immunohistochemical expression of Fpn1, DMT-1 and TfR2 protein. The immunoreactivity of primary antibodies was blocked using antisera against specific antibody provided by the manufacturer. The experiment was performed parallel in the presence of antibody alone and with the mixture of antibody and blocking peptide (antisera). The antigens were visualized using rhodamine conjugated secondary antibody. Results are representative of 3 animals (original magnification x200, scale bar $100 \mu \mathrm{m}$ )..... 67 Figure 30: Microscopic demonstration of immunodetection of TfR1, TfR2, DMT-1, and Fpn-1 on cryostat sections of rat liver. Indirect immunostaining was performed using peroxidase conjugated secondary antibodies. The antigens were developed with a horse-reddish- peroxidase conjugated secondary antibody with a counterstaining of nuclei by hematoxylin. Results are representative of 3 animals (original magnification x200, scale bar $100 \mu \mathrm{m}$ ). 68 
Figure 31: Microscopic demonstration of immunohistochemical detection of TfR2, DMT-1, and Fpn-1 in cultured rat liver cells. Rat hepatocytes and Kupffer cells isolated and cultured under normal conditions and immunocytology was performed as described in methods. The left panel; detection of TfR2 (a), DMT-1 (e) and Fpn-1 (i) in isolated rat Kupffer cells. The right panel; detection of TfR2 (b-d), DMT-1 (f-h) and Fpn-1 (j,k) in isolated hepatocytes. The small insets in right panel are taken from different areas of cultured cells in lab-tecs. Results are representative of 3 experiments (original magnification $\mathrm{x} 400$, scale bar $50 \mu \mathrm{m}$ ). 69

Figure 32: Western blot analysis of DMT-1,Tf, TfR1, TfR2 and Fpn-1. a) Expression of iron

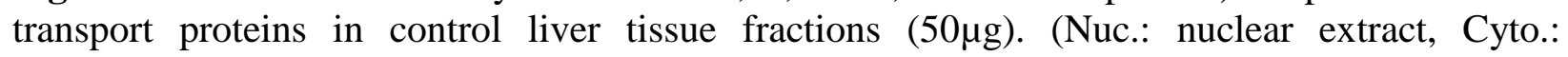
cytoplasmic extract, Memb.: membrane extract). b) Comparative expression of iron transport proteins in major cell population of rat liver in (HC: hepatocytes, MF: Myofibroblasts, KC: Kupffer cells). $\beta$-actin was used as a loading control. Result demonstrates the representative figure of three experiments. 71

Figure 33: RT-PCR analysis of total RNA from rat liver tissue to demonstrate the changes of RNR and cyclin E mRNA amount. Changes of RNR and cyclin E transcript amount in the liver tissue during acute-phase reaction. Fold change in mRNA expression was normalized with UBC as housekeeping gene at different time points after intramuscular TO administration as revealed by real-time PCR. The data shows fold changes in comparison to controls where control values are normalized to one. Results represent mean value \pm S.E.M. $(* \mathrm{P}<0.05, * * P<0.001$, $* * * \mathrm{P}<0.001$ analyzed by one way ANOVA; $\mathrm{n}=3$ ) 72

Figure 34: Changes in the protein expression of cyclin $\mathrm{E}$ in rat liver during acute phase response. Upper panel; microscopic demonstration of indirect immunofloresence of cyclin $\mathrm{E}$ in control (Co.) and TO-injected rat liver at $24 \mathrm{~h}$ (original magnification x200, scale bar $100 \mu \mathrm{m}$ ). The lower panel; Western blot analysis of total protein lysates $(50 \mu \mathrm{g})$ from rat liver for cyclin $\mathrm{E}$ protein during APR. Results are representative of three experiments. 73

Figure 35: RT-PCR analysis of total RNA from mice liver during APR. Gene expression of hepcidin, Fpn-1, Fpn-1a and Fpn-1b in wild type (black bars) and IL-6 knock-out (gray bars) mice liver during acute phase response. RT-PCR was normalized by using GAPDH as housekeeping gene. Results represent the fold changes of mRNA expression of respective gene where, the control values were normalized to one. Data show the results of three animals (mean values \pm SEM. $* \mathrm{P}<0.05$ analyzed by one-way ANOVA). 75

Figure 36: Fpn-1 protein expression in the livers of wild type and IL-6 knock-out mice during acute phase response. Western blot analysis of total protein lysates $(50 \mu \mathrm{g})$ for Fpn-1 protein in wild type and IL-6 knock-out during acute phase response. The result indicates representative figure of three experiments. 77

Figure 37: RT-PCR analysis of total RNA from rat hepatocytes after IL-6 stimulation. Quantification of Fpn-1, Fpn-1a, Fpn-1b and hepcidin gene expression in isolated rat hepatocytes after IL-6 treatment. The mRNA expression was analyzed by real time PCR and was normalized by using UBC as housekeeping gene. Results represent the fold changes of mRNA expression of respective gene where, the control values were normalized to one. Data show the results of three technical replicates (mean values \pm SEM. $* * * \mathrm{P}<0.0001$ analyzed by one-way ANOVA)........... 78 Figure 38: RT-PCR analysis of total RNA from rat hepatocytes after IL-1 $\beta$ and TNF- $\alpha$ stimulation. Quantification of Fpn-1, Fpn-1a, Fpn-1b and hepcidin gene expression in isolated rat hepatocytes after IL-1 $\beta$ and TNF- $\alpha$ treatment. The mRNA expression was analyzed by real time PCR and was normalized by using UBC as housekeeping gene. Results represent the fold changes of mRNA expression of respective gene where, the control values were normalized to 
one. Data show the results of three experiments (mean values $\pm \mathrm{SEM},{ }^{*} \mathrm{P}<0.05$ analyzed by oneway ANOVA).

Figure 39: Western blot analysis of total cellular lysates $(50 \mu \mathrm{g})$ from control and IL-6 treated rat hepatocytes for $\alpha-2 \mathrm{M}$, Fpn-1 and albumin protein. Changes in protein expression of $\alpha 2 \mathrm{M}$ (alpha2-macroglobulin; a positive acute phase protein), albumin (a negative acute phase protein) and Fpn-1 (the iron export protein) in control and IL-6 treated hepatocytes. Data represents results from three experiments. 80

Figure 40: The proposed mechanism of iron metabolism in liver cells (HC: hepatocytes, KC: Kupffer cells) under physiological and acute phase conditions. The iron absorbed at intestinal level seeps into blood and is taken up by Tf which translocates iron inside the cell by TfR1 mediated endocytosis. TfR2 and DMT-1 adds to serve the iron transportation into the cell nuclei (N). During APR, the increased level of serum cytokine (IL-6) induces a downregulation of nuclear iron exporter (Fpn-1) and aids the cells to retain iron inside the cell and cell nuclei to meet the higher metabolic requirements under APR. 92

\section{LIST OF TABLES}

Table 1a: Mice primer sequences used for real-time PCR analysis.

Table 1b: Rat primer sequences used for real-time PCR analysis.

Table 2: Comparison of changes in mRNA amount of Fpn-1 and its isoforms in wild type and IL-6 knock-out mice liver during APR.

Table 3: Comparison of changes in mRNA amount of Fpn-1 and its isoforms in rat hepatocytes after cytokine treatment. 


\section{Abbreviations}

$\mathrm{Ab}$

APP

APR

BBB

BCA

BSA

cDNA

CNS

CRP

$\mathrm{Ct}$

dd $\mathrm{H}_{2} \mathrm{O}$

DMSO

dNTP

DTT

Dcytb

DMT1

DTT

EDTA

FCS

Fpn1

$\mathrm{g}$

GFP

gp

GRE

HIF

HRP

Hepc

Heph

HFE

Hjv
Antibody

Acute phase proteins

Acute phase response

Blood brain barrier

Bicinchoninic acid

Bovine serum albumin

Copy desoxyribonucleic acid

Central Nervous System

C-reactive protein

Threshold cycle

Double distilled water

Dimethylsulfoxide

Deoxyribonucleoside triphosphate

Dithiothreitol

Duodenal cytochrome B reductase

Divalent metal transporter 1

Dithiothreitol

Ethylendiaminetetraacetic acid

Fetal calf serum

Ferroportin 1

Gravity

Green fluorescent protein

Glycoprotein

Glucocorticoid response element

Hypoxia induced factor

Horseradish peroxidase

Hepcidin

Hephaestin

Hemochromatosis gene

Hemojuvelin 


\begin{tabular}{ll} 
IgG & Immunoglobulin G \\
IL & Interleukin \\
IRP & Iron regulatory protein \\
IFN- $\gamma$ & Interferon gamma \\
IL-1B & Interleukin 1 Beta \\
IL-6 & Interleukin 6 \\
IRE & Iron responsive elements \\
IRE-BP1 & Iron responsive element binding protein 1 \\
IRE-BP2 & Iron responsive element binding protein 2 \\
kDa & Kilodalton \\
LPS & Lipopolysaccharide \\
MOPS & 3-(N-Morpholino)-propanesulfonic acid \\
Min & Minutes \\
OD & Optical density \\
PBS & Phosphate buffered saline \\
PCR & Polymerase chain reaction \\
PMSF & Phenylmethyl sulfonylfluoride \\
PBS & Phosphate buffered saline \\
PCR & Polymerase chain reaction \\
PMSF & Phenylmethyl sulfonylfluoride \\
rpm & Revolutions per minute \\
RT & Room temperature \\
RT-PCR & Reverse transcriptase-PCR \\
RNase & Ribonuclease \\
ROS & Reactive oxygen species \\
rpm & Revolutions per minute \\
RT-PCR & Reverse transcriptase-PCR \\
SDS & Sodium dodecylsulfate \\
SDS-PAGE & SDS-polyacrylamide gel electrophoresis \\
SEM & Standard error of the mean \\
TEMED & Nenediamine \\
\hline
\end{tabular}


TNF- $\alpha$

Tris

TAE

$\mathrm{Tf}$

TfR1

TfR2

TO

Tris

UTR

UV
Tumor necrosis factor $\alpha$

Tris-(hydroxymethyl)-aminomethane

Tris acetate EDTA buffer

Transferrin

Transferrin receptor 1

Transferrin receptor 2

Turpentine oil

Tris-(hydroxymethyl)-aminomethane

Untranslated region

Ultraviolet 


\section{SUMMARY}

Acute phase is clinically characterized by homeostatic alterations such as somnolence, adinamia, fever, muscular weakness and leucocytosis. Dramatic changes in iron metabolism are observed under acute-phase conditions. Under conditions inducing non-hepatic tissue damage, serum iron level decreases. Liver is the central organ for iron homeostasis under physiological conditions. However, brain also requires iron for higher metabolic work under stress conditions. The exact mechanism and the changes of the gene expression and localization of the proteins involved in the iron regulation are not yet fully clarified. Current study aimed to compare the expressional changes and differential localization of the iron transport proteins; Transferrin receptor (TfR)-1 and 2, divalent-metal-transpoter-1 (DMT-1) and ferroportin-1(Fpn-1) in rat liver, brain and spleen during acute phase response due to experimental tissue damage. Muscle damage was induced by injecting turpentine-oil (TO) in hind limbs of rat and mice (wild type and IL-6 knock-out). Serum, liver, brain and spleen were removed. Serum and tissues were used for iron measurement. Moreover, tissues were evaluated by RT-PCR, immunobloting and immunohistochemical analysis. Rat hepatocytes were stimulated with cytokines and lysed to get protein and RNA.

As a result of TO administration, at the site of injury; the muscle, mRNA amount of acute phase cytokines (IL-6, IL-1 $\beta$ and TNF- $\alpha$ ) increased significantly with the highest expression of IL-6. Similarly, in the liver, an increase in gene expression of IL-1 $\beta$ and TNF- $\alpha$ was observed however, no significant changes in IL-6 gene expression were observed. Moreover, in the brain the mRNA expression of IL-6 and TNF- $\alpha$ was upregulated whereas, IL-1 $\beta$ showed 
downregulation. In the liver and brain, an upregulation of HO-1(positive acute phase protein) expression was observed.

Serum iron concentration decreased significantly after TO-administration with a progressive increase in liver (significant) and brain (non-significant) iron concentration. Furthermore, for liver, an increase of cytoplasmic and an even stronger increase of nuclear iron concentration was observed. However, the spleen iron concentration decreased during the course of study.

In liver, mRNA amount of Fpn-1-, Fpn-1-a, Fpn-1-b, HFE-, hemojuvelin-, and hephastingenes showed a rapid decrease. Hepcidin, DMT-1, transferrin and TfR1, TfR2, ferritin $\mathrm{H}$ and ferritin L gene-expression was increased. Immunobloting confirmed the changes observed at mRNA indicating an increase in protein amount of iron importers (Tf, TfR1, TfR2 and DMT-1) and a decrease in iron export protein's amount (Fpn-1 and hephastin) with an almost diminished expression of Fpn-1 by $24 \mathrm{~h}$ of APR. In brain, with a difference in magnitude, the mRNA expressional changes of Tf, TfR1, TfR2, hepcidin, Fpn-1, ferritin H, ferritin L and IRPs were comparable to that of the liver. However, DMT-1 was slightly downregulated. In spleen, a rapid decrease of Fpn-1, Fpn-1-a, Fpn-1-b, DMT-1, Tf, TfR1, TfR2 gene expression was observed with an increase in hepcidin gene expression. However, the changes in hephastin, HFE, hemojuvelin transcript were non-significant.

By means of immunohistology, an abundant expression of TfR1 was detected in the membrane of the liver and spleen, in contrast to, almost only, nuclear expression of TfR 1 in the brain tissue. In vitro experiments confirmed TfR1 membranous protein expression in the liver cells whereas nuclear and slightly cytoplasmic TfR1-protein was detectable in brain cells. DMT1 and TfR2 protein was mainly localized to the cell nuclei of liver, brain and spleen. Similarly, in 
liver and brain Fpn-1 was localized to the nuclei of cells whereas, in spleen Fpn-1 showed a strong membrane expression. Immunohistochemical results were further confirmed by western blot analysis of liver tissue fractionated proteins.

RT-PCR of total RNA from liver tissue showed a significant upregulation of an iron dependent cytoplasmic enzyme; ribonucleotide reductase (RNR) and a nuclear enzyme involved in DNA replication; cyclin E. The increase in cyclin E expression was further confirmed at protein level by means of immunohistochemistry and western blot analysis.

In wild type mice, RT-PCR demonstrated a downregulation of Fpn-1, Fpn-1-a and Fpn-1b whereas hepcidin gene expression was upregulated. However, in IL-6 knock-out mice the changes in Fpn-1, Fpn-1-a, Fpn-1-b and hepcidin gene expression were less pronounced. Western blot analysis of wild type mice showed an early downregulation of Fpn-1 protein expression which was almost diminished at 24h (as was observed for rat liver). However, in IL-6 knockout mice, Fpn-1 protein showed a slight tendency of downregulation.

RT-PCR of cytokine (IL-6, IL- $\beta$ and TNF- $\alpha$ ) treated rat hepatocytes showed an upregulation of hepcidin gene expression while Fpn-1 was downregulated. These changes were more evident after IL-6 treatment. Western blot analysis of IL-6 treated hepatocytes showed an increase of $\alpha 2$-macroglobulin (major positive acute phase protein) while albumin (major negative acute phase protein) and Fpn-1 (the iron export protein) were downregulated.

From the present work, we conclude that in the rat model of the sterile abscess-induced systemic acute phase response, the changes of gene expression of the main proteins involved in iron metabolism taking place in the liver are qualitatively similar to those observed in brain possibly by locally produced acute-phase cytokines. The iron content in the liver and brain increased together with the expression of TfR1. Moreover, liver behaves as a "sponge" for iron 
under acute phase conditions and Fpn-1 behaves as a nuclear-negative acute-phase-protein in rat hepatocytes comparable to mediated mainly by IL-6. These changes could explain iron retention in hepatocytes during acute-phase-situation. 


\section{INTRODUCTION}

\subsection{The body needs of iron}

Iron is a fundamental element for almost every organism. It contributes in a wide variety of metabolic processes including oxygen transport, heme and nonheme iron proteins, electron transfer, neurotransmitter synthesis, myelin production energy metabolism and mitochondrial function in the organs (Camaschella 2005;Hentze et al. 2004;Napier et al. 2005; Stankiewicz et al. 2007). Ribonucleotide reductase (the rate-limiting enzyme of DNA synthesis), and succinate dehydrogenase and aconitase of the TCA cycle are also iron dependent enzymes (Crowe and Morgan 1992). However, the excess of iron can lead to the production of oxygen free radicals, which can damage various cellular components. In contrast to many other nutrients, the body has no defined excretory mechanism for iron, for this reason, organisms must regulate the body iron at intestinal absorption levels to provide the body with sufficient iron for cellular needs without developing the toxicity due to iron excess (Frazer and Anderson 2005).

\subsection{The iron metabolism proteins and normal iron homeostasis}

Iron homeostasis is controlled by a large group of iron regulatory proteins. Haem iron is transported across the apical membrane of enterocytes and is converted into ferrous iron by heme-oxygenase-1 (HO-1). However, absorption of dietary iron begins by its transport across the duodenal brush-border membrane mediated by duodenal metal transporter-1 (DMT-1) and a ferroreductase known as duodenum cytochrome B (Dcytb) that is thought to reduce ferric $\left(\mathrm{Fe}^{3+}\right)$ to ferrous $\left(\mathrm{Fe}^{2+}\right)$ iron (McKie et al. 2001) for transport by DMT1. DMT-1 is also essential for iron acquisition necessary for erythropoiesis (Gunshin et al. 1997). DMT-1 has been detected in the endosomal compartment of different cell types, suggesting that it may also participate in transport of transferrin-bound iron across the membrane of acidified endosomes and into the 
cytoplasm (Gruenheid et al. 1999; Tabuchi et al. 2000). After entering the enterocytes, iron is used for metabolic purposes, stored in ferritin subunits (heavy and light chain), or translocated to the plasma by ferroportin-1 (Fpn-1; Figure 1)

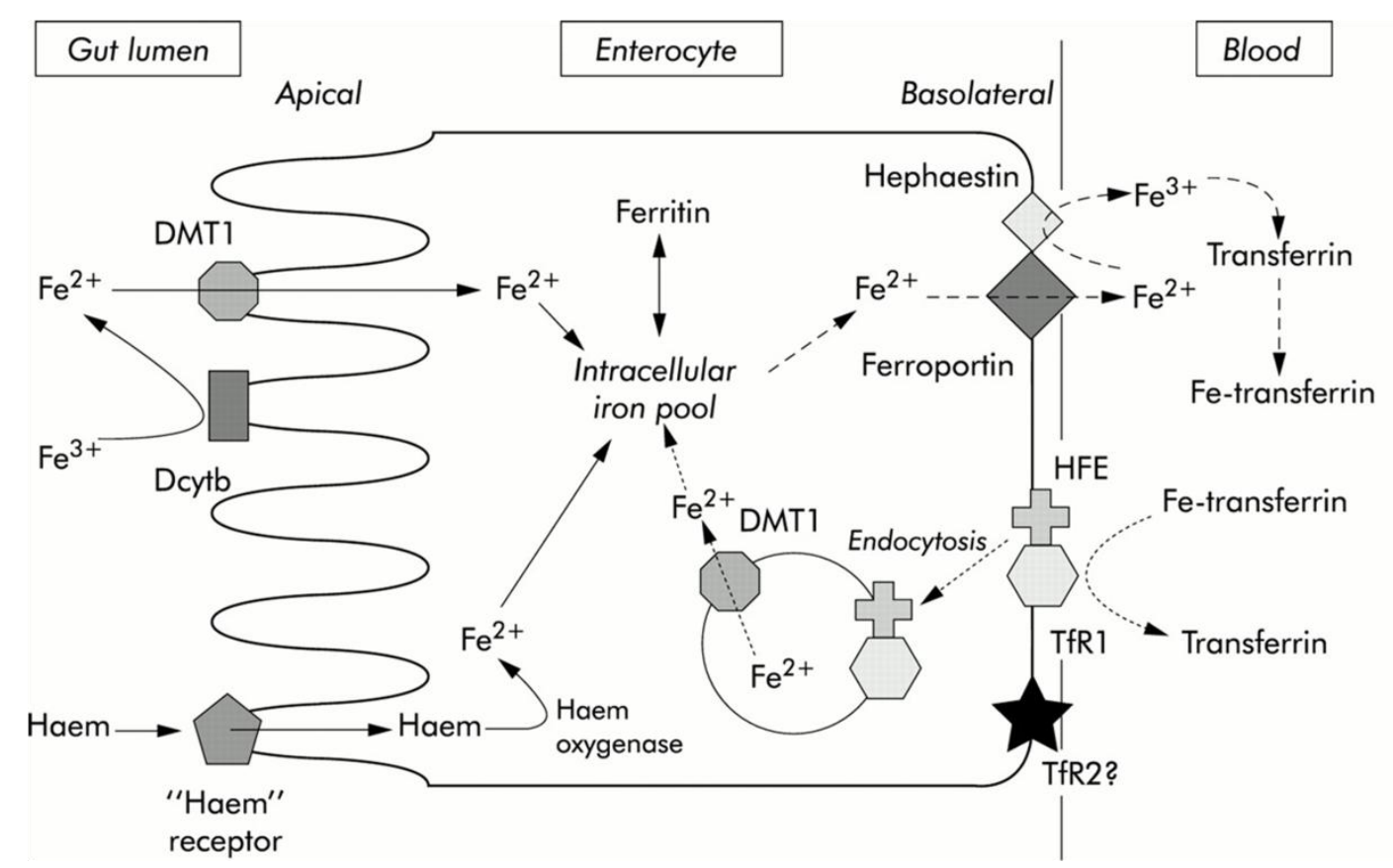

Figure 1: A model of iron absorption pathways by duodenal enterocyte. The figure shows uptake of ionic iron and haem iron from the gut lumen and transfer of iron to blood. DMT1: divalent metal transporter 1; HFE, haemochromatosis protein, TfR1, transferrin receptor 1; TfR2, transferrin receptor 2. Source: (Trinder et al. 2002)

Ferroportin-1 (Fpn-1, also known as MTP1, IREG-1, or SLC11A3) is the main ironexport-protein. It was first characterized as an iron exporter in Zebrafish where embryos carrying mutations in the Fpn-1 ortholog showed a lack of iron transfer ability from the yolk sac to embryo (Donovan et al. 2000). It is highly expressed in numerous cells, including duodenal enterocytes, reticuloendothelial macrophages, and Kupffer cells (Donovan et al. 2000;Ganz 2005). It is also suggested that Fpn-1 mediates iron export in hepatocytes (Abboud and Haile 2000). In the presence of an iron exporter (Fpn-1) and a ferroxidase; hephastin, the newly 
released ferrous iron could be oxidized to its ferric form, allowing binding to transferrin (Song et al. 2010). Hephastin is proposed to have a multi-copper oxidase activity due to its homology with ceruloplasmin, and to be located on the basolateral membrane in intestinal enterocytes because it has a single predicted transmembrane domain (Anderson et al. 2002; Vulpe et al. 1999). The previous study showed that hephastin protein was located on the basolateral membrane of small intestine in mice (Han and Kim 2007;Kuo et al. 2004; Yeh et al. 2009). The co-localization of Fpn-1 and hephastin suggested a collaborative role of both proteins in transport of iron out of enterocytes, but it is not known whether these two proteins interact during iron absorption.

Transferrin (Tf) carries plasma iron to the reticuloendothelial system (spleen, liver and bone marrow) and to all proliferating cells in the body. It binds to the exported iron and transfers it through portal blood to the liver by TfR1 mediated iron uptake mechanism (Hentze et al. 2010) or Tf-independent mechanism (Prus and Fibach 2011). Tf binds to iron in a diferric form ( $\mathrm{Fe}_{2} \mathrm{Tf}$ ), interaction of this diferric $\mathrm{Tf}$ with the TfR1 and internalization of the complex by receptormediated endocytosis leads to iron uptake in the cells (Frazer and Anderson 2005) (Figure 2). The synthesis of the TfR1 is generally known to be regulated at the mRNA level through iron responsive elements (IRE) present in the untranslated region of the mRNA. If the cellular iron level is low, these IRE's interact with iron regulatory proteins to protect mRNA from cleavage and degradation and thereby increase protein synthesis (Casey et al. 1989; Rouault 2006).

A second transferrin-mediated route of iron uptake is via TfR2. Although, the role of TfR1 is well defined for transporting iron across the plasma membrane, the role of TfR2 is not yet clearly understood. TfR2 knockout mice results in embryonic lethality due to severe anemia (Levy et al. 1999). Because TfR2 mutation or knockout results in hepatic iron overload, TfR2 
appears to function, not principally in cellular iron uptake and delivery, but rather in systemic iron homeostasis (Roetto et al. 2010).

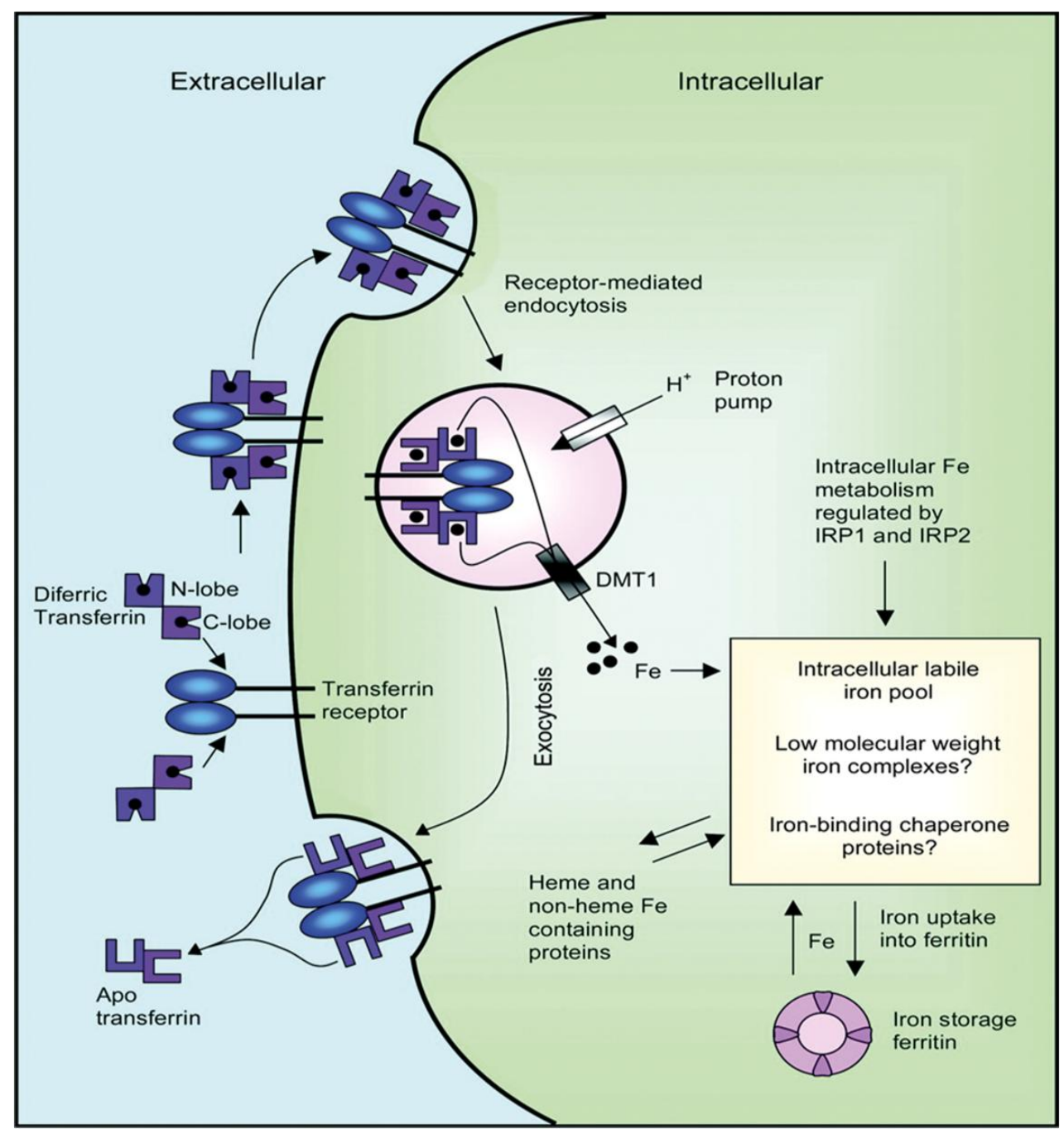

Figure 2: Schematic diagram illustrating the mechanisms involved in iron uptake. Diferric Tf undergoes endocytosis after binding to TfR1. Iron is released from Tf mediated by a decrease in $\mathrm{pH}$ and is exported out of the endosome by DMT1, where it enters the labile iron pool (LIP). Iron in the LIP can subsequently be incorporated into ferritin for iron storage or into iron-containing proteins. Source: (Kalinowski and Richardson 2005) 


\subsection{Liver and iron metabolism}

Liver is a major organ in iron homeostasis. Hepatocytes (the major; 70\%, cell population of liver) are key cells to regulate absorption of dietary iron and reutilization of iron after senescent red cells are phagocytosed and digested by macrophages by secreting the regulatory peptide hormone, hepcidin. Hepcidin, a liver derived hormone (Krause et al. 2000); is a 25amino acid, 2-3 kDa, cationic peptide (McGrath and Rigby 2004). Hepatocytes judge the totalbody iron stores and secrete hepcidin in direct proportion to hepatocytic iron stores.

Kupffer cells regulate the return of iron to the circulation by regulating expression of ferroportin, which appears to be the major mammalian iron exporter (Ganz 2005). The expression of Fpn-1 is supposed to be regulated by liver derived hormone, hepcidin. Hepcidin is reported to cause internalization and degradation of Fpn-1; as a result the cells lack the iron exporter (Figure 3). Decreased expression of intestinal Fpn-1 reduces intestinal iron absorption, and decreased expression of Fpn-1 in macrophages simultaneously reduces return of iron to the circulation. By decreasing iron absorption from the intestine and increasing macrophage iron sequestration, hepcidin causes a decrease in serum iron levels (Cairo et al. 2011;Ganz and Nemeth 2006).

In hepcidin knock-out mice, hepcidin deficiency induces periportal Fpn-1 stabilization, and thus iron is exported along the peri-central axis and progressively accumulated in the centrolobular region where it is trapped due to the absence of Fpn-1 in this area (Ramey et al. 2010). However, several studies also demonstrated direct iron regulatory effects on Fpn-1 gene expression (Aydemir et al. 2009; Yeh et al. 2009). In addition, a recent study identifies and characterized two isoforms of Fpn-1 (Fpn-1a and Fpn-1b) which differs from each other by existence/lacking of iron regulatory elements proposing that the isoform could escape repression 
by IRE/IRP system in iron deficiency might be expressed in duodenum to allow active export of iron into blood stream to meet systemic iron demands (Zhang et al. 2009).

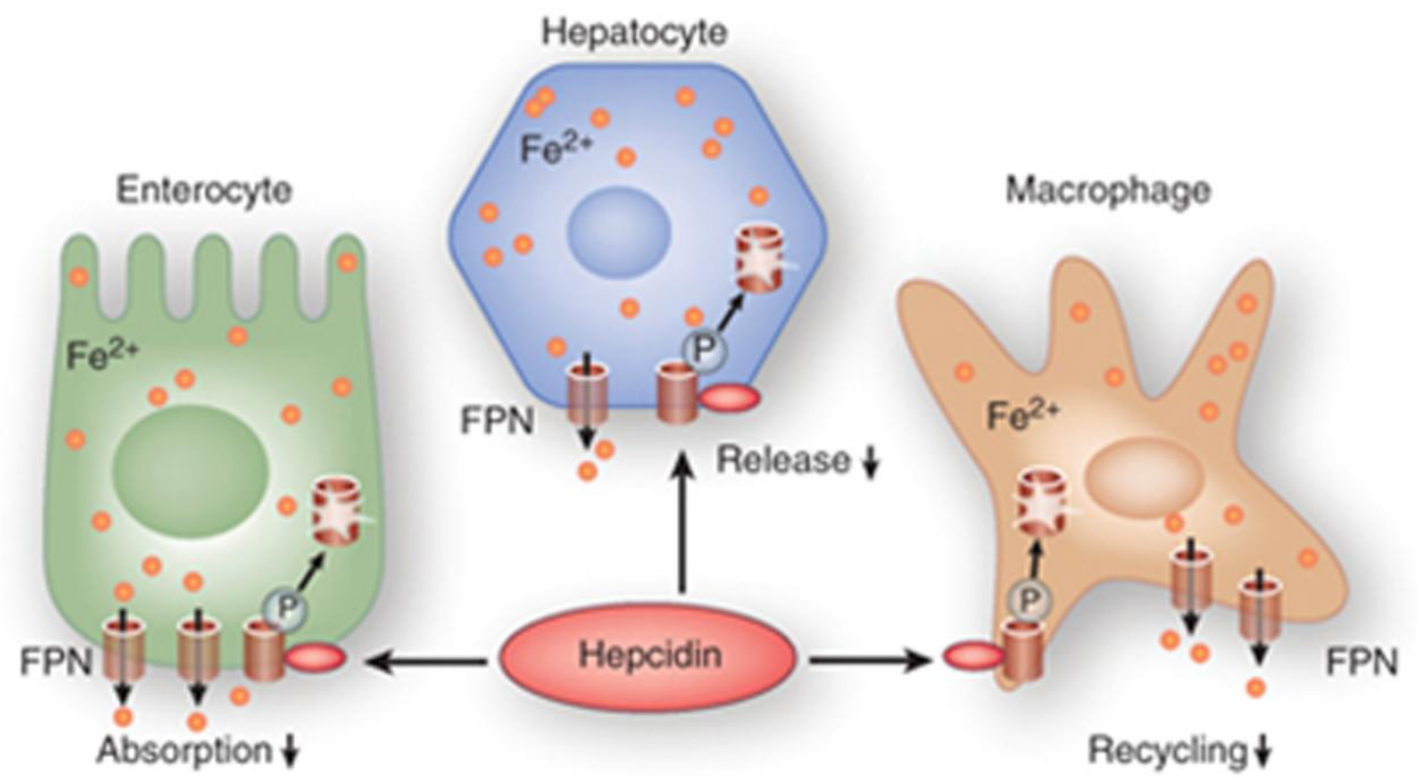

Figure 3: Hepcidin down-regulates ferroportin expression. Ferroportin (FPN) is expressed in enterocytes, hepatocytes, and tissue macrophages. The binding of hepcidin to Fpn-1 leads to its phosphorylation, internalization, and degradation. Low levels of Fpn-1 expression reduce iron absorption in the gut, lower iron release from the liver, and prevent iron recycling by tissue macrophages. Source: (Cui et al. 2009)

\subsection{Brain and iron metabolism}

The iron concentration in the brain is second to the liver among the organs in the body (Benarroch 2009). The iron metabolism proteins and iron homeostasis in the brain is same as in other organs with the exception of a blood brain barrier and the blood-cerebrospinal fluid barrier (choroid plexuses). The brain is protected by the blood brain barrier, before iron approaches the central nervous system (CNS) for metabolic purposes; it has to cross the blood brain barrier. The blood-brain barrier is composed of endothelial cells, a basal lamina, pericytes, and astrocytic foot processes. The endothelial cells in blood brain barrier are connected by tight junctions, which are 
further protected and sealed by pericytes located within the endothelial basement membrane near the endothelial tight junctions (Lai and Kuo 2005) (Figure 4).

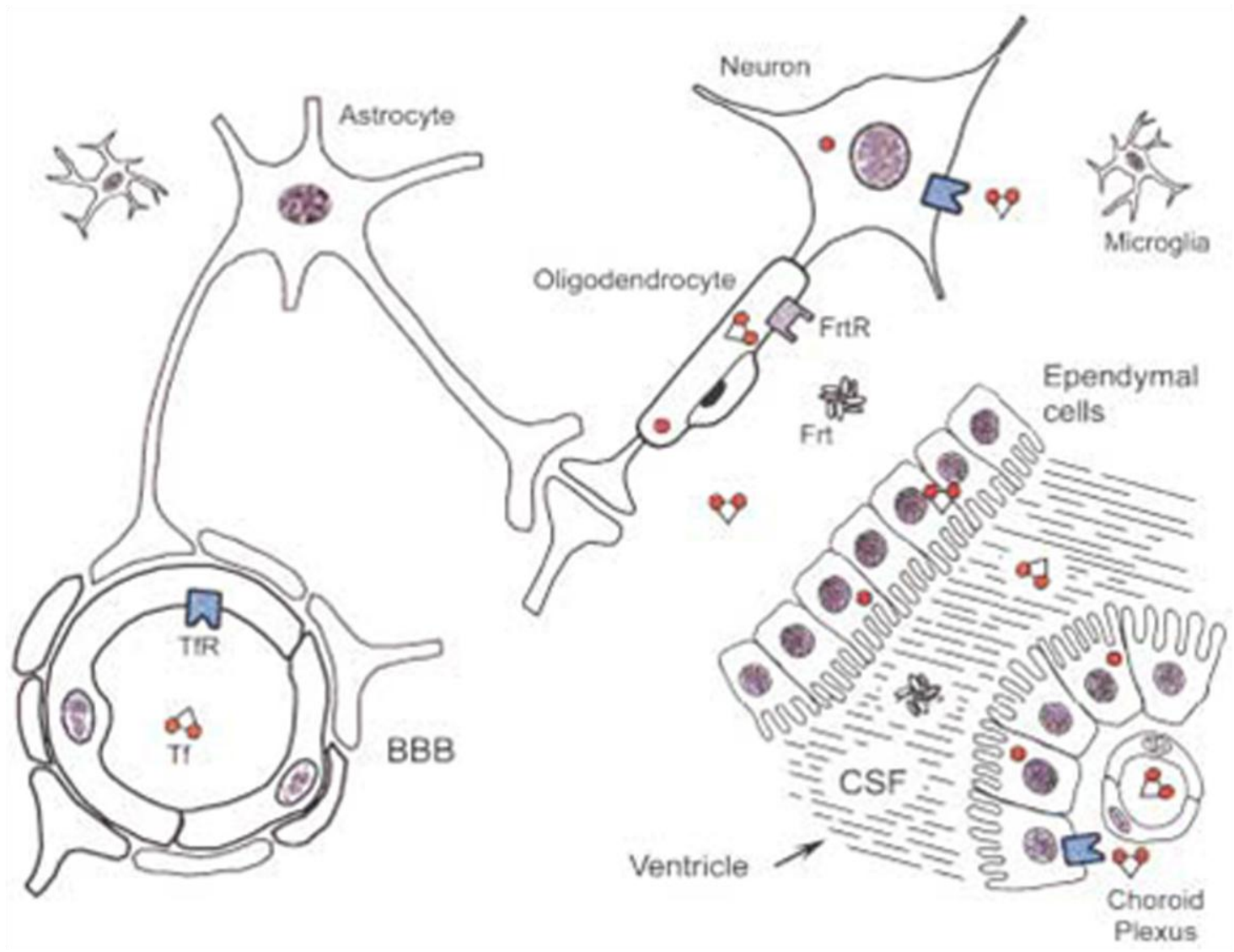

Figure 4: Brain iron uptake and mobilization; the main areas of iron entry to the brain are the blood-brain barrier (BBB) and the blood-cerebrospinal fluid barrier (choroid plexuses). At the $\mathrm{BBB}$ level, iron is transferred to the brain by plasma transferrin (Tf) through an interaction between circulatory $\mathrm{Tf}$ and transferrin receptors (TfR) in the brain microvasculature. The release of iron from the endothelial cell is presumed to occur by a process similar to the one in the basolateral side of the enterocyte, but direct evidence is lacking. Some studies have shown transcytosis of transferrin suggesting that Tf may transport iron trough the BBB. Once across the blood-brain-barrier, iron is transported by $\mathrm{Tf}$ (synthesized by choroid plexus or by oligodendrocytes) and taken up by different cell types. Source : (Pi+'ero and Connor 2000). 
The major source of brain-iron is receptor mediated endocytosis of Tf-TfR in endothelial cells. In CNS, the main source of Tf is oligodendrocytes, cells found throughout the CNS that elaborate the myelin sheathes around axons (Oide et al. 2006). The TfR level on the luminal endothelial surface is controlled by iron concentrations of CNS determines the expressional changes of TfR (Enerson and Drewes 2006;Moos et al. 2000). The blood brain barrier exhibits the well established topology of TfR1 which suggest that parenchymal blood vessels permit iron entry into the CNS, whereas iron likely exits the brain by crossing the cerebrospinal fluid in arachnoid plexuses and entering the venous drainage system (Bradbury 1997). Once iron enters the cytosol of endothelial cells it can be exported into the CNS by Fpn-1. In mature oligodendrocytes iron is also taken up by ferritin receptors (Pi+'ero and Connor 2000).

\subsection{The acute phase response, liver and acute phase proteins}

The acute phase response (APR) is a well-known physiological defence reaction of the organism to local or systemic disturbances caused by infection, tissue injury, trauma or surgery, neoplastic growth or immunological disorders (Gordon and Koy, 1985; Gruys et al., 1999). APR is aimed to remove the injuring noxae and to restore homeostasis. Clinically, it is characterized by fever, somnolence, weakness, muscular joint pain, and adinamia. This reaction is mediated by a large group of cytokines including; interleukin (IL)-1-like cytokines (IL-1, tumor necrosis factor-alpha $[\mathrm{TNF}-\alpha]$ ) and IL-6-like cytokines (IL-6, oncostatin M, and others), through the activation of the transcription factors nuclear factor kappa B, activator protein 1, signal transducer and activator of transcription 3/5, or CCAAT/enhancing-binding protein $\beta$ (Ramadori and Christ 1999). These cytokines are released at the sight of damage by a large group of cells including endothelial cells, fibroblasts, macrophages, granulocytes and lymphocytes. Floating in the systemic circulation, the blood brings these cytokines to the liver and liver regulates different 
kinds of acute phase proteins discriminated as positive and negative acute phase proteins (APP). Proteins with an increased expression and plasma concentration are classified as positive acutephase proteins (APP), e.g., $\alpha 2$-macroglobulin in rats. These APPs support wound healing processes and neutralizes the tissue damage (Ramadori and Christ 1999). The other positive APPs include clotting proteins, transport proteins, antiproteases, and complement factors serum amyloid A (SAA) and either C-reactive protein (CRP) in humans or its homologue in mice, serum amyloid P component (SAP). Furthermore, the decrease of the serum iron level is also a hallmark of APR (Sheikh et al. 2007). Those proteins which are downregulated and are decrease in plasma concentration during APRare categorized as negative (APP) such as albumin (Ramadori and Christ 1999). The major sours of these APPs are the hepatocytes which comes metabolically active during APR (Ramadori et al. 1985;Ramadori and Christ 1999).

\subsection{The model of acute phase study and iron metabolism}

There are two well established animal models to study the APR and acute phase mediated changes in acute phase proteins. Induction of APR by bacterial endotoxin lipopolysaccharide (LPS) administration induces systemic APR together with liver damage (Boelen et al. 2005; Ramadori et al. 1985). The other model of APR is turpentine oil (TO) induced sterile muscle abscess without a detectable injury to liver and other tissues (Boelen et al. 2005; Ramadori et al. 1990; Tron et al. 2005;Wusteman et al. 1990). Thus, the TO-induced acutephase response model allows studying the effect of cytokines produced at distant sites on the liver. It reproduces changes observed in human disease states (Basso et al, 2005; Bodet et al, 2006; Boelen et al, 2005; Gabay and Kushner, 1999; Halter et al, 2005; Kim et al, 2002; Stoeck et al, 2006). 
Under inflammatory conditions induced by microbial attack or during liver injury a diversion of iron traffic from the circulation to storage sites of reticuloendothelial system occurs to minimize the availability of this essential element for the microbial proliferation and growth (Weiss 2005). However, during APR induced by sterile muscle abscess by TO-intramuscular administration, the acute phase cytokines mediates the expressional changes of iron metabolism proteins which in turn leads to serum iron turn over and deposition of iron in metabolically active tissue (Cairo et al. 2011; Sheikh et al. 2007) (Figure 5).

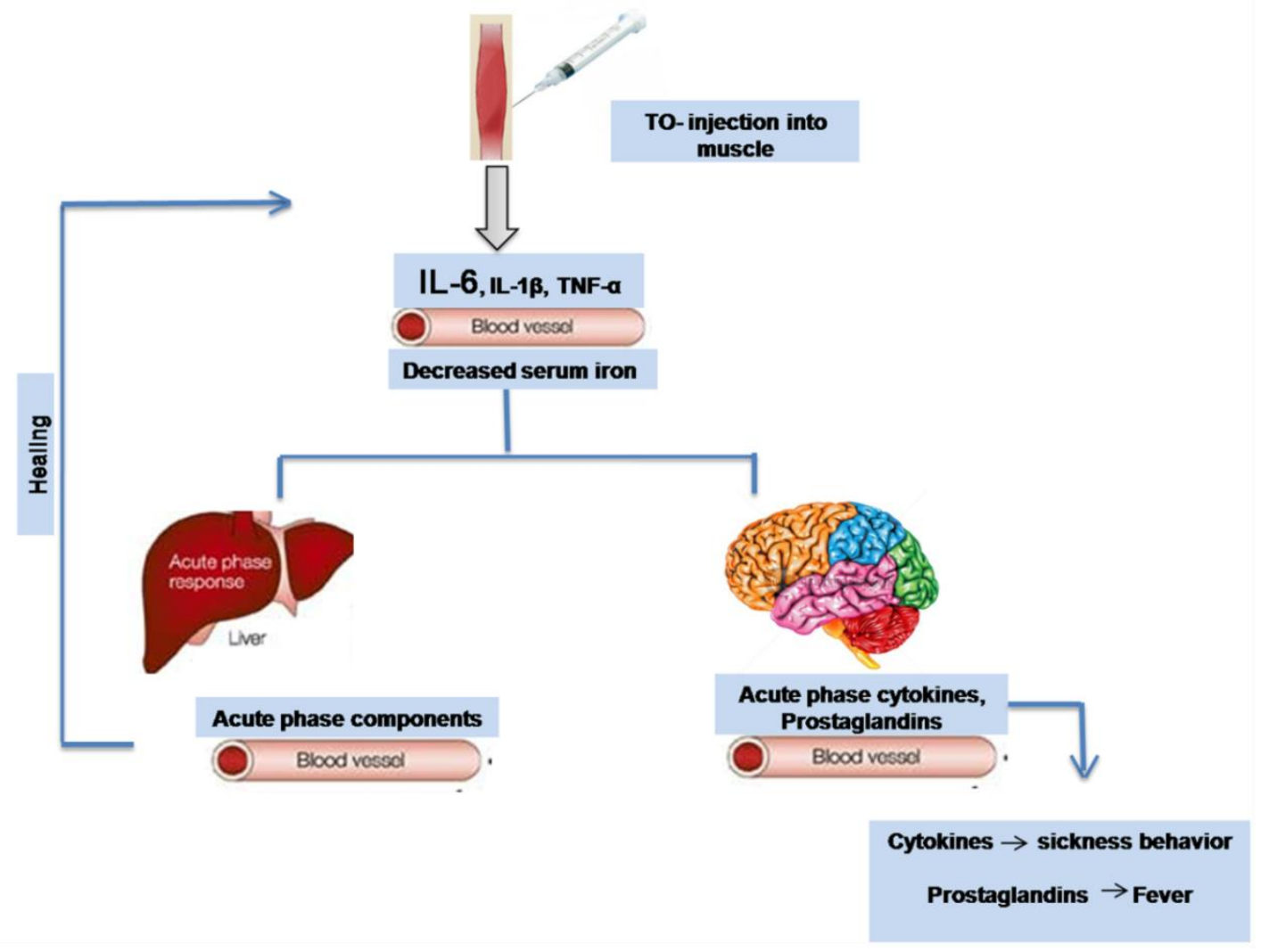

Figure 5: The acute phase model of study. Turpentine injection into the limb muscle results cytokine production at the site of injury. These cytokines are released into the blood and when they reach to the liver, liver becomes metabolically active and release acute phase mediators to start the healing process at the site of injury. The decreased iron concentration in the serum is the hallmarks of APR. The fever and illness behavior during acute phase response is induced by local production of cytokines and prostaglandins by brain. 


\subsection{Aims of study}

This study is based on the previous findings that during sterile muscle abscess, a decrease in serum iron content is observed. Moreover, it has been reported that the intramuscular administration of TO induces the changes in gene expression of several proteins involved in iron metabolism in hepatic and non-hepatic organs (Sheikh et al. 2007). This study is designed to elaborate the previous findings and understanding of role of liver in iron metabolism and to evaluate the expressional changes of iron metabolism proteins in brain during acute phase response.

Therefore, the aims of the present work are to:

1. Investigate and to compare the expressional changes in iron transporter's (Tf, TfR1, TfR2, DMT-1, Fpn-1) gene expression in different organs (liver, brain and spleen) of rat model of acute phase response.

2. Investigate and compare the cellular localization of iron transport proteins (Tf, TfR1, TfR2, DMT-1, Fpn-1) in rat liver, brain and spleen in rat model of acute phase response.

3. Evaluate the role of IL-6, the principle mediator of inflammation, in the regulation of expression pattern of Fpn-1 (the iron export protein) in wild type and IL-6 knock-out mice models of acute phase response; in vivo.

4. Demonstrate the changes in Fpn-1 (the iron export protein) expression using primary cultures of isolated rat hepatocytes stimulated with acute phase cytokines (IL-6, IL- $\beta$ and TNF- $\alpha$ ); in vitro. 


\section{MATERIALS}

\subsection{Chemicals}

All the chemicals used were of analytical grade and were purchased from commercial sources as indicated below: TRIzol reagent (Invitrogen $\mathrm{GmbH}$, Karlsruhe, Germany) for isolation of RNA from the tissues; real-time polymerase chain reaction (PCR) primers, M-MLV reverse transcriptase, reverse transcription buffer and 0.1M DTT, platinum Sybr green qPCRUDG mix from Invitrogen, dNTPs, protector RNase inhibitor, bovine insulin, Klenow enzyme, primer oligo (DT)15 for cDNA synthesis and salmon sperm DNA from Roche (Mannheim, Germany). All other reagents and chemicals were from Sigma-Aldrich (Munich, Germany) or Merck (Darmstadt, Germany).

Mouse anti-human/rat ED-1 antibody from (Serotec Düsseldorf, Germany), Rabbit antitransferrin from Invitrogen (Darmstadt, Germany), Rabbit anti-transferrin receptor-1 from Invitrogen (Darmstadt, Germany), Rabbit anti-transferrin receptor-2 from abcam (Cambridge, UK), Rabbit anti-divalent-metal-transport-1 (NRAMP-2) from Acris (Hiddenhausen, Germany), two Rabbit anti-ferroportin-1 (SLC40A1) from abnova (Heidelberg, Germany) and Novus Biological (Cambridge, UK), Rabbit-anti hephastin from abcam (Cambridge, UK), Rabbit anti Cyclin E from abcam (Cambridge, UK), anti-beta-actin antibody from Sigma Aldrich (Germany) were used in the study. Among secondary antibodies; Horse-reddish-peroxidase-conjugated antimouse and anti-rabbit IgGs from DAKO (Germany) and among Fluorescent Dye Conjugates Alexa Fluor 350 goat anti-mouse IgG and Alexa Fluor 555 goat anti-rabbit IgG from Invitrogen (Darmstadt, Germany), were used in the study. 


\subsection{Animals and experimental models of acute-phase reaction}

Male Wistar rats of about 170-200 g body weight were purchased from HarlanWinkelmann (Brochen, Germany). The animals were kept under standard conditions with $12 \mathrm{~h}$ light/dark cycles and ad libitum access to fresh water and food pellets. All animals were cared for according to the University's guidelines, the German convention for the protection of animals and NIH guidelines. Adult male B6.129S2-Il6tm1Kopf (IL6-knockout) mice and control wild type adult male C57BL/6J mice (25-28 g) were purchased from Jackson Laboratory. The animals were kept under standard conditions with $12 \mathrm{~h}$ light/dark cycles and ad libitum access to fresh water and food pellets. All animals were cared for according to the University's guidelines, the German convention for the protection of animals and NIH guidelines.

In rats APR was induced in ether-anesthetized rats by intramuscular administration of 5 $\mathrm{ml} / \mathrm{kg}$ TO in both right and left hind limbs $(\mathrm{n}=5)$. Control animals did not receive any administration $(\mathrm{n}=4)$. Injected and non-injected control rats were euthanized $1 \mathrm{~h}, 2 \mathrm{~h}, 4 \mathrm{~h}, 6 \mathrm{~h}, 12 \mathrm{~h}$, 24h, 36h and 48h after TO administration under pentobarbital anesthesia. Liver, brain, spleen and the injured muscle were excised and minced, rinsed with physiological sodium saline, snap frozen in liquid nitrogen and stored at $-80^{\circ} \mathrm{C}$ till further use. Blood samples were collected from the inferior vena cava of the control and treated animals, allowed to clot overnight at $4{ }^{\circ} \mathrm{C}$ and centrifuged for $20 \mathrm{~min}$ at $2000 \mathrm{~g}$. Serum was removed and stored at $-80^{\circ} \mathrm{C}$.

For the mice experiments, a group of animals $(n=3)$ for each strain, control $(\mathrm{C} 57 \mathrm{BL} / 6 \mathrm{~J})$ and IL6-knockout, was injected intramuscularly with $0.1 \mathrm{ml}$ TO in both right and left hind limbs to induce an aseptic acute phase response. Animals were euthanized 2h, 4h, 6h, $12 \mathrm{~h}$ and $24 \mathrm{~h}$ after the treatments under pentobarbital anesthesia. Liver tissues were excised and minced, rinsed with physiological sodium saline, snap frozen in liquid nitrogen and stored at $-80^{\circ} \mathrm{C}$ till further use. 


\section{METHODS}

\subsection{Methods of cell biology}

\section{1a. Isolation of rat liver cells}

\section{1a1 Isolation of rat hepatocytes}

Hepatocytes were isolated from male Wistar rats by circulating perfusion with collagenase essentially as described previously (Seglen 1972).

\section{1a1.I. Liver perfusion}

After laparotomy, the vena portae was canulated, vena cava inferior was ligated above the diaphragm to prevent flow of the perfusion media into a whole body circulation. Finally, the vena cava inferior was cut beneath the liver and canulated. The liver was perfused in nonrecirculative mode through the portal vein with $150-200 \mathrm{ml} \mathrm{CO}_{2}$-enriched preperfusion medium at a flow rate of $30 \mathrm{ml} / \mathrm{min}$ until the liver was free from blood. To break down components of extracellular matrix, the liver was perfused in recirculative mode with collagenase perfusion medium until it started to feel soft (about 7-11 min).

\subsection{1aII. Preparation of the hepatocyte suspension}

After perfusion, the liver was excised and transferred into a sterile glass beaker filled with culture medium M 199 with additives. Glisson's capsule, i.e. collagen tissue around the liver, was carefully removed and discarded. To obtain a cell suspension, the tissue was disrupted mechanically using sterile forceps. Connective tissue and remainder of the liver capsule as well as big cell aggregates were removed by filtration of the primary cell suspension through a nylon mesh (pore-size $79 \mu \mathrm{m}$ ). Non-parenchymal cells and cell debris were removed by numerous selective sedimentations $\left(20 \mathrm{~g}, 2 \mathrm{~min}, 4^{\circ} \mathrm{C}\right)$ in wash medium. After the last centrifugation, 
hepatocytes were suspended in medium M 199 with additives. $50 \mathrm{ml}$ of M 199 was added per $1 \mathrm{~g}$ of wet weight of the sedimented cells; the cell suspension typically had a density of about $106 / 2.5 \mathrm{ml}$.

\subsection{1aIII Isolation of rat liver myofibroblasts (liver non-parenchymal cells)}

Rat liver myofibroblasts were isolated according to the method previously described (Dudas et al. 2007) with slight modifications.

\subsection{1aIV. Liver perfusion and preparation of cell suspension}

The laparotomy and canulation were performed essentially as described above (see 3.1a1). The liver was perfused with preperfusion medium containing Gey's Balanced Salt Solution (GBSS) and sodium hydrocarbonate, followed by perfusion with enzyme solution 1 containing pronase with subsequent change to enzyme solution 2 containing pronase and collagenase. After perfusion, the liver was excised and placed into the sterile Petri dish filled with enzyme solution 3 containing pronase, collagenase and DNase I and was mechanically disruptured with sterile forceps. The cell suspension obtained was stirred in the same perfusion solution for 30 min with simultaneous control of $\mathrm{pH}$ (7.5) and finally filtered through the sterile sieve and collected in $50 \mathrm{ml}$ polypropylene tubes. To separate big cell aggregates and major part of the parenchymal liver cells, the suspension was centrifuged for 4 min at $35 \mathrm{~g}\left(4^{\circ} \mathrm{C}\right)$. The supernatant was recentrifuged for $5 \mathrm{~min}$ at $640 \mathrm{~g}\left(4^{\circ} \mathrm{C}\right)$, the pellet was resuspended in $50 \mathrm{ml}$ of GBSS containing $100 \mu \mathrm{l}$ DNase I. 


\subsection{1aV Separation of non-parenchymal liver cells}

Non-parenchymal liver cells were separated using Nycodenz ${ }^{\circledR}$ density gradient as follows: the cell suspension was transferred into four sterile $50 \mathrm{ml}$ polypropylene tubes and centrifuged for $5 \mathrm{~min}$ at $640 \mathrm{~g}\left(4^{\circ} \mathrm{C}\right)$. The supernatant was discarded and the pellets were resuspended in small volume (5-6 ml) of GBSS with $100 \mu \mathrm{l}$ DNase I and pooled together in one sterile $50 \mathrm{ml}$ polypropylene tube. $14 \mathrm{ml}$ of $30 \%$ Nycodenz was added and the volume was adjusted to $24 \mathrm{ml}$ with GBSS. This mixture was divided between four sterile $15 \mathrm{ml}$ polypropylene tubes and GBSS (1.5 $\mathrm{ml}$ per tube) was carefully layered over the content of the tubes. The gradient was centrifuged for $15 \mathrm{~min}$ at $1,800 \mathrm{~g}\left(4^{\circ} \mathrm{C}\right)$. Afterwards, the interphase brown layer between Nycodenz and GBSS containing nonparenchymal liver cells was carefully transferred into sterile $50 \mathrm{ml}$ polypropylene tube and centrifuged for $5 \mathrm{~min}$ at $640 \mathrm{~g}\left(4^{\circ} \mathrm{C}\right)$.

\subsection{1aVI. Purification of myofibroblasts by counterflow elutriation}

To obtain pure of myofibroblasts, nonparenchymal liver cells were fractionated by centrifugal counterflow elutriation according to (Knook and Sleyster 1976). The nonparenchymal liver cell pellet obtained in previous step was resuspended in 5-6 $\mathrm{ml}$ of $0.4 \%$ BSA/GBSS, collected in a sterile $10 \mathrm{ml}$ syringe and injected in the elutriation system. Using JE$6 \mathrm{~B}$ elutriation rotor assembled according to the manufacturer's instructions and spun at 2,500 rpm in a J2-21 centrifuge (Beckman Instruments), fractions enriched with sinusoidal endothelial cells, myofibroblasts and Kupffer cells were collected at flow rates of $19 \mathrm{ml} / \mathrm{min}, 23 \mathrm{ml} / \mathrm{min}$ and $55 \mathrm{ml} / \mathrm{min}$, respectively. The myofibroblasts fractions were sedimented by centrifugation ( $5 \mathrm{~min}$ at $640 \mathrm{~g}, 4^{\circ} \mathrm{C}$ ), counted in a Neubauer chamber and, after assessment of cell viability by Trypan blue staining, taken up in a culture medium. 


\subsection{1aVII Non-parenchymal cells isolation from rat liver}

Rat liver macrophages (Kupffer cells) were isolated according to the method of Knook and Sleyster as previously described with slight modifications. The liver was perfused with preperfusion medium containing Gey's Balanced Salt Solution (GBSS) and sodium hydrocarbonate, followed by perfusion with enzyme solution 1 containing pronase with subsequent change to enzyme solution 2 containing pronase and collagenase. Nonparenchymal liver cells were separated using Nycodenz®(Axis-Shield PoC, Norway) density gradient as ollows: the cell suspension was transferred into four sterile $50 \mathrm{ml}$ polypropylene tubes and centrifuged for $5 \mathrm{~min}$ at $640 \mathrm{~g}$ at $4^{\circ} \mathrm{C}$. The supernatant was discarded and the pellets were resuspended in small volume $(5-6 \mathrm{ml})$ of GBSS with $100 \mu \mathrm{l}$ DNase I and pooled together in one sterile $50 \mathrm{ml}$ polypropylene tube. $14 \mathrm{ml}$ of $30 \%$ Nycodenz was added and the volume was adjusted to $24 \mathrm{ml}$ with GBSS. This mixture was divided between four sterile $15 \mathrm{ml}$ polypropylene tubes and GBSS (1.5 $\mathrm{ml}$ per tube) was carefully layered over the content of the tubes. the interphase brown layer between Nycodenz and GBSS containing nonparenchymal liver cells was transferred into sterile $50 \mathrm{ml}$ polypropylene tube and washed for $5 \mathrm{~min}$ at $640 \mathrm{~g}$. The nonparenchymal liver cell pellet obtained in previous step was resuspended in 5-6 ml of $0.4 \% \mathrm{BSA} / \mathrm{GBSS}$, collected in a sterile $10 \mathrm{ml}$ syringe and injected in the elutriation system. Using JE-6B elutriation rotor assembled according to the manufacturer's instructions and spun at 2,500 rpm in a J2-21 centrifuge (Beckman Instruments), fractions enriched with sinusoidal endothelial cells, myofibroblasts and Kupffer cells were collected at flow rates of $19 \mathrm{ml} / \mathrm{min}, 23$ $\mathrm{ml} / \mathrm{min}$ and $55 \mathrm{ml} / \mathrm{min}$, respectively. A particularly pure fraction (95\%) of Kupffer cells was sedimented by centrifugation and cells were counted by Trypan blue staining. 


\subsection{1aVIII Primary culture treatment and harvesting of rat liver cells}

The cultures of rat hepatocytes, myofibroblasts and kupffer cells were performed on $60 \mathrm{~mm}$ polystyrol dishes and maintained at $37^{\circ} \mathrm{C}$ in a $95 \%$ air/ $5 \% \mathrm{CO}_{2}$ atmosphere and saturated humidity. Rat hepatocytes were processed further for cytokine stimulation while, myofibroblasts, hepatocytes and kupffer cells were lysed in protein lysis buffer.

\subsection{1 aIX Primary culture of rat hepatocytes}

Immediately after preparation, fetal calf serum ( $4 \mathrm{ml} / 100 \mathrm{ml}$ suspension) was added to the hepatocytes suspension in order to make the efficient cell adhesion to the polystyrol dishes. Furthermore, the antibiotics ( $1 \mathrm{ml}$ of pen/strep stock solution per $100 \mathrm{ml}$ cell suspension) together with 10-7 M dexamethasone and 10-9 $\mathrm{M}$ insulin as permissive hormones were added. Rat hepatocytes were plated onto 60-mm plastic dishes at a density of $2 \times 106$ cells per dish. After the initial $4 \mathrm{~h}$ of attachment phase, the medium was changed, and the hepatocytes were further incubated in medium M 199 with the same concentrations of hormones and antibiotics used previously but without fetal calf serum. A volume of $2.5 \mathrm{ml}$ medium per $60 \mathrm{~mm}$ culture dish was added.

\subsection{1aX Stimulation of hepatocytes with acute phase cytokines}

Primary rat hepatocytes were usually stimulated with pro-inflammatory cytokines (IL6 , IL-1 $\beta$ and TNF- $\alpha$ ) at $100 \mathrm{ng} / \mathrm{ml}$ concentrations on the next day of plating. The medium was changed 6 hours prior to stimulation; the stimuli were diluted to the required concentrations in the culture medium and added directly to the culture dishes by pipetting. An equal volume of the normal culture medium was added to the dishes with cells which later served as experimental controls. After addition of the stimuli, cells were incubated for in the incubator prior to RNA and 
protein isolation. The cells were harvested at different time points, washed with phosphate buffered saline, $\mathrm{pH} 7.4$ and frozen at $-80^{\circ} \mathrm{C}$ for subsequent RNA and protein isolation.

\subsection{Human and rat cell lines}

Human hepatoma cell line (HepG2 cells) was purchased from the American Tissue Culture Collection (ATCC, Manassas, VA, USA). HepG2 cells were cultured in RPMI supplemented with $10 \%$ FCS, $2 \%$ glutamine and $1 \%$ sodium pyruvate. The glioblastoma cell lines (U373MG) were obtained from the Tumor Bank of the German Cancer Research Centre in Heidelberg, cultured in Dulbecco's modified Eagle's medium (MEM) and supplemented with $10 \%$ fetal calf serum (FCS), glutamine (1\%) and penicillin/streptomycin $1 \%$. All cells were maintained at $37^{\circ} \mathrm{C}$ in a $5 \% \mathrm{CO}_{2}$ atmosphere at $100 \%$ humidity.

\subsection{Methods in molecular biology}

\subsubsection{RNA isolation}

During the whole study, total RNA was isolated from liver, brain, spleen and injured muscle tissue samples with TRIzol reagent according to the manufacturer's instructions. Briefly, tissue samples were homogenized in $1 \mathrm{ml}$ TRIzol reagent per $100 \mathrm{mg}$ of tissue using a power homogenizer. After 5 minutes incubation at room temperature, $0.2 \mathrm{ml}$ chloroform per sample was added and samples were vigorously shaked and incubated at room temperature for 3 minutes. Samples were then centrifuged at $12,000 \mathrm{~g}$ for 30 minutes and the acqueous phase so obtained in the supernatants was carefully collected. A volume of $0.5 \mathrm{ml}$ of isopropyl alcohol was succevssively added to the collected phase and samples were incubated at room temperature for 10 minutes. The RNA precipitation was favoured centrifuging again at 12,000 $\mathrm{g}$ for 10 minutes. After a short washing step in ethanol 75\%, RNA was shortly air-dried and resuspended 
in a volume of approximately $50 \mu \mathrm{l}$ of RNase and Dnase free water. The RNA was then quantified by measuring the absorbance at $260 \mathrm{~nm} / 280 \mathrm{~nm}$.

\subsubsection{Reverse transcription (RT)}

The cDNA was generated by reverse transcription of $3.0 \mu \mathrm{g}$ of total RNA with $100 \mathrm{nM}$ of dNTPs, 50pM of primer oligo(dT)15, $200 \mathrm{U}$ of moloney murine leukemia virus reverse transcriptase (M-MLV RT), 16U of protector RNase inhibitor, 1X RT buffer and $2.5 \mathrm{ml}$ of $0.1 \mathrm{M}$ DTT for $1 \mathrm{~h}$ at $40^{\circ} \mathrm{C}$.

\subsubsection{Real time quantitative Polymerase chain reaction}

The cDNA samples are analyzed by the Real Time PCR using the following ingredients for each PCR reaction:

"X" primer-forward (5mM) $\underline{\text { Volume per reaction }}$

"X" primer-reverse $(5 \mathrm{mM})$ $1.5 \mu 1$

$\mathrm{H}_{2} \mathrm{O}$

$1.5 \mu 1$

SYBR Green Master Mix Taq Polymerase

$6.5 \mu 1$

$13.0 \mu 1$

$2.5 \mu 1$ of the cDNA sample or $2.5 \mu 1$ of $\mathrm{H} 2 \mathrm{O}$ for the negative control was added to each PCR reaction.

\subsection{3.a Thermal cycler amplification program}

The amplification was performed at $50{ }^{\circ} \mathrm{C}$ for $2 \mathrm{~min}, 95^{\circ} \mathrm{C}$ for $2 \mathrm{~min} ., 95^{\circ} \mathrm{C}$ for $15^{\prime \prime}$ to $60^{\circ} \mathrm{C}$ for $30^{\prime \prime}$ for 45 cycles (Figure 2) in an ABI prism 7000 sequence detection system. All samples were assayed in duplicate. Expression of different genes was analyzed using Platinum SYBR Green qPCR mix UDG. The PCR amplification program was followed by dissociation curve protocol for controlling the specificity of the PCR products. Specific temperature of dissociation of the PCR product was calculated by the Primer Express software. Curves of 
amplification were analyzed to measure the $\mathrm{Ct}$ value in the linear range of the amplification. The results were normalized to the house keeping gene and fold change expression was calculated using Ct values by Prism Graph Pad 4 software.

\subsection{3.b Standard Curve}

Serially diluted PCR products, of the gene of interest are amplified by Real Time PCR and $\mathrm{Ct}$ values are calculated. The standard curves were obtained graphically by using the following parameters: Ct values and the logarithm of the number of copies. Standard curve were calculated for the gene of interest and the housekeeping genes. Number of copies of gene in the sample was obtained by extrapolation of the measured $\mathrm{Ct}$ value to the relative standard curve. Normalization of gene expression in each sample was performed by calculating the ratio of number of copies of the gene of interest with respect to the number of copies of the housekeeping gene.

\subsection{3.c Primers designing}

Primers for different genes were designed using the program "Primer Express" (ABI System) and the gene bank data (http://www.ncbi.nlm.nih.gov). All the primer sets used for realtime PCR are listed in the Table $1 \mathrm{a}$ and $\mathrm{b}$.

\subsubsection{Southern blot analysis of PCR products.}

Hepcidin gene expression was also analyzed in the liver and the brain by conventional PCR according to the following cycles: $94^{\circ} \mathrm{C}$ for 2 minutes, $94^{\circ} \mathrm{C}$ for 30 seconds, $60^{\circ} \mathrm{C}$ for 1 minute (40 cycles) and finally at $72^{\circ} \mathrm{C}$ for 2 minutes. The PCR reaction products in a volume of $10 \mu 1$ for hepcidin and $6 \mu \mathrm{l}$ for $\beta$-actin were separated electrophoretically in a $1.2 \%$ agarose gel and blotted onto a nylon membrane by capillary transfer and successively crosslinked by UV. 
The blot was hybridized with a probe synthesized by PCR reaction with cDNA obtained from rat kidney and radiolabelled with $\gamma$-CTP through Nick translation kit. The hybridization was performed at $62^{\circ} \mathrm{C}$ for 2 hours, followed by washing steps with $2 \mathrm{X} \mathrm{SSC}+0.1 \% \mathrm{SDS}$. $\beta$-actin cDNA was used as an internal standard.

Table 1a: Mice primer sequences used for real-time PCR analysis

\begin{tabular}{|l|l|l|}
\hline \multicolumn{1}{|c|}{ Primer } & \multicolumn{1}{|c|}{$\mathbf{5} \rightarrow \mathbf{3}$ Forward } & \multicolumn{1}{c|}{$\mathbf{5} \rightarrow \mathbf{3}$ Reverse } \\
\hline Mice GAPDH & AGAACATCATCCCTGCATCC & CACATTGGGGGTAGGAACAC \\
\hline Mice $\beta$-actin & ATTGTTACCAACTGGGACGACATG & CGAAGTCTAGAGCAACATAGCACA \\
\hline Mice hepcidin & AGAGCTGCAGCCTTTGCAC & ACACTGGGAATTACAGCATTTA \\
\hline Mice Fpn-1 & CCATGATGAAATGCAGAAGG & CTGCTGTTTGCAGGAGTAAT \\
\hline Mice Fpn-1a & AAAGAAGACCCCGTGACAGC & AAAGAAGACCCCGTGACAGC \\
\hline Mice Fpn-1b & GCCGGTTGCAGTTTCAATGT & TCCCCGTGTTTGTTCTGATG \\
\hline
\end{tabular}

Table 1b: Rat primer sequences used for real-time PCR analysis

\begin{tabular}{|l|l|l|}
\hline \multicolumn{1}{|c|}{ Primer } & \multicolumn{1}{|c|}{$\mathbf{5} \rightarrow \mathbf{3}$ Forward } & \multicolumn{1}{c|}{$\mathbf{5} \rightarrow \mathbf{3}$ Reverse } \\
\hline Rat UBC & CAC CAA GAA GGTCAA ACA GGAA & AAG ACA CCT CCC CAT CAA ACC \\
\hline Rat $\beta$-actin & TGTCACCAACTGGGACGATA & AACACAGCCTGGATGGCTAC \\
\hline Rat Transferrin & GGCATCAGACTCCAGCATCA & GCAGGCCCATAGGGATGTT \\
\hline Rat TfR1 & ATACGTTCCCCGTTGTTGAGG & GGCGGAAACTGAGTATGGTTGA \\
\hline Rat TfR 2 & AGCTGGGACGGAGGTGACTT & TCCAGGCTCACGTACACAACAG \\
\hline Rat DMT-1 & GCT GAG CGA AGA TAC CAG CG & TGT GCA ACG GCA CAT ACT TG \\
\hline Rat Fpn-1 & TTC CGC ACT TTT CGA GAT GG & TACAGTCGAAGCCCAGGACTG \\
\hline Rat Fpn-1a & AAAGAAGACCCCGGTGGCAGC & GGCCAAGGTAGAGGAGGAATTT \\
\hline
\end{tabular}


Methods

\begin{tabular}{|l|l|l|}
\hline Rat Fpn-1b & GTTGGTTGGAGTTTCAATGTTG & GGCCAAGGTAGAGGAGGAATTT \\
\hline Rat HJV & ATG CCG TGT CCA AGG AGC TT & TCC ACC TCA GCC TGG TAG AC \\
\hline Rat Hepcidin & GAA GGC AAG ATG GCA CTA AGC A & TCT CGT CTG TTG CCG GAG ATA G \\
\hline Rat HFE & ATC AGC CTC TCA CTG CCA CT & CAA GTG TGT CCC CTC CAA GT \\
\hline Rat Hephastin & CAC ATT TTT CCA GCC ACC TT & TGA CGA ACT TTG CCT GTG AG \\
\hline Rat IL-6 & GTCAAC TCC ATC TGC CCT TCA G & GGC AGT GGC TGT CAA CAA CAT \\
\hline Rat IL-1 $\beta$ & TAC CTA TGT CTTGCC CGT GGA G & ATCATCCCA CGA GTCACAGAGG \\
\hline Rat TNF- $\alpha$ & ACA AGG CTG CCC CGA CTAT & CTCCTGGTATGAAGTGGCAAATC \\
\hline Rat Cyclin E & GTTCCATTCGCCATGGTTAT & GTGTGGGTCTGGATGTTGTG \\
\hline Rat RNR & ACTAAGCCCAGCATTGAGGA & AAAGGAGGCCTCAGCTTTCT \\
\hline
\end{tabular}

\subsection{Methods of biochemistry}

\subsubsection{Protein extraction from liver tissue and cultured hepatocytes}

\subsection{1a Preparation of tissue homogenates}

All steps were performed at $4{ }^{\circ} \mathrm{C}$ to prevent proteolytic degradation of the proteins. About $100 \mathrm{mg}$ of frozen tissue was homogenized with Ultra-Turrax TP 18/10 model homogenizer 3

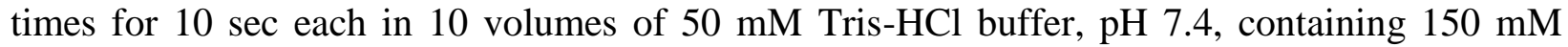
$\mathrm{NaCl}, 1 \mathrm{mM}$ EDTA, $1 \%$ Triton X-100, 1mM PMSF, $1 \mathrm{mM}$ benzamidine, $1 \mu \mathrm{g} / \mathrm{ml}$ leupeptin, $10 \mu \mathrm{M}$ chymostatin, $1 \mu \mathrm{g} / \mathrm{ml}$ antipain, $1 \mu \mathrm{g} / \mathrm{ml}$ pepstatin A. Crude homogenates were passed 5 times through a $22 \mathrm{G}$ administration canula connected to a syringe. To pellet the nuclei and particular matter, crude homogenates were centrifuged for $5 \mathrm{~min}$ at $10,000 \mathrm{~g}\left(4^{\circ} \mathrm{C}\right)$. Nuclear protein and cytoplasmic fractions were isolated as described before (Budick-Harmelin et al. 2008). For membrane and cytosolic extract 2x105 HepG2 cells per dish were homogenized in 
membrane buffer containing $5 \mathrm{M} \mathrm{NaCl}, 1 \mathrm{M}$ Tris- $\mathrm{HCl} \mathrm{pH} 7.5,0.5 \mathrm{M}$ EDTA, 10mg/ml of PMSF, aprotinin and leupeptin. After homogenizing, cell lysate was centrifuged at $1000 \mathrm{rpm}$ for 10 minutes. Supernatant was collected as cytosolic extract and the pellet (membrane extract) was resuspended in lysis buffer (prepared as mentioned above in whole lysate) and stored at -20 0C for further use. Protein concentration of supernatants was determined by the bicinchoninic acid (BCA) method (Smith et al. 1985) using the BCA protein assay reagent kit (Pierce, Bonn, Germany). Prepared homogenates were dispensed in aliquots and stored at $-20^{\circ} \mathrm{C}$ until use.

\subsection{1b Preparation of cell lysate}

All steps of the procedure were performed at $4{ }^{\circ} \mathrm{C}$ to prevent proteolytical degradation of the proteins. The cells frozen on the culture dishes were thawed on ice. $1 \mathrm{X}$ ice-cold lysis buffer, comprised of $150 \mathrm{mM} \mathrm{NaCl}, 1 \mathrm{mM}$ EDTA, 1\% Triton X-100, $50 \mathrm{mM}$ Tris-HCl, $\mathrm{pH} 7.4$ and supplemented with protease inhibitors, was added to the cells $(500 \mu 1$ per $6 \mathrm{~cm} \mathrm{dish})$ followed by incubation on ice for $10 \mathrm{~min}$. Afterwards, the cells were scraped with a disposable scraper, transferred to new tubes and passed 5 times through a $22 \mathrm{G}$ administration canula connected to a syringe. To pellet the nuclei and particular matter, prepared lysates were centrifuged for 5 min at $10,000 \mathrm{~g}\left(4^{\circ} \mathrm{C}\right)$ and the protein concentration of supernatants was determined by BCA method using the kit from Pierce. Prepared lysates were aliquoted and stored at $-20^{\circ} \mathrm{C}$ until use.

\subsubsection{Proteins isolation and Western Blot}

Fifty micrograms from the total protein lysate were loaded in a 4-12\% Nu-PAGE BisTris (Invitrogen) gel and separated after $2 \mathrm{hrs}$ electrophoresis at $80 \mathrm{~V}$. After the transfer in a semidry apparatus at $26 \mathrm{~V}$ for $1.5 \mathrm{~h}$, the membranes were blocked in $5 \%$ milk, and blotted with primary antibodies overnight at $4^{0} \mathrm{C}$. The secondary antibodies were horse reddish peroxidase 
conjugated goat anti-rabbit and goat anti-mouse immunoglobulins (DAKO) diluted at 1:1000. Membranes were developed with ECL chemiluminescence Kit (Amersham).

\subsubsection{Immunohistochemistry and immunocytology}

Immunohistochemical analysis was performed on $4 \mu \mathrm{m}$-thin cryostat sections fixed in methanol/acetone to localize the antigens on the tissues. Immunocytology was performed on LabTek slides (8 wells slides) containing rat hepatocytes, Kupffer cells, Human HepG2 cell line, Rat glioblastomas cell line, and U373 cell line were washed twice with cold PBS and incubated in methanol (10 minutes)/acetone (20 seconds) for fixation.

After blocking non-specific binding with a solution of PBS containing $1 \%$ bovine serum albumin (Serva, Heidelberg, Germany) and 10\% goat serum (Dako) for $1 \mathrm{~h}$ at room temperature, the primary antibodies were incubated overnight at $4{ }^{\circ} \mathrm{C}$ on the sections. The rabbit polyclonal antibodies were detected with an Alexa-555-conjugated goat-anti-rabbit and mouse monoclonal antibodies were detected with Alexa-488 conjugated goat-anti-mouse secondary antibodies from Invitrogen (Darmstadt, Germany). For double-staining, each of the mentioned primary antibodies was incubated with mouse anti ED-1 (Serotec) (diluted 1:100) overnight at $4^{\circ} \mathrm{C}$. A mix of Alexa555-conjugated goat-anti-rabbit and FITC-conjugated goat anti-mouse Igs from (Invitrogen Darmstadt, Germany) was successively incubated for $1 \mathrm{~h}$ at room temperature in dark. Sections/ labTeks were counter-stained with DAPI (Molecular Probes, Invitrogen) and observed with an epifluorescence microscope (Axiovert 200M, Zeiss, Germany). Negative control immunostainings were performed by omission of the primary antibody, by usage of isotypematching control immunoglobulins.

Antigens were blocked to determine the antibody specificity using the blocking peptide provided by manufacturer. Blocking was performed according to standard protocol provided by 
manufacturer. Briefly, after determining the optimal concentration of antibody that consistently gives a positive result in immunohistochemical protocol the concentration of blocking peptide to be used was determined. For example, if the primary antibody is being used successfully in at a concentration of $0.5 \mu \mathrm{g} / \mathrm{ml}$ the blocking peptide was used at a concentration of $1 \mu \mathrm{g} / \mathrm{ml}$. The antibody was diluted in blocking buffer to the final volume needed for the two experiments. Then this antibody dilution was divided equally into two tubes. In the first tube, labeled "Blocked", add the blocking peptide to a final concentration of $1 \mu \mathrm{g} / \mathrm{ml}$. In the second tube, labeled "Control", add an equivalent amount of buffer. Both tubes were incubated overnight at $4^{\circ} \mathrm{C}$ with agitation. The staining protocol was performed on the two identical samples, using the blocked antibody for one and the control for the other. Antigens were evaluated similarly as for immunohistochemical experiments.

\subsubsection{Prussian blue iron staining in liver and spleen}

Cryostat sections, 4- $\mu$ m thick (Reichert Jung, Wetzlar, Germany), were air dried and used for iron detection by Prussian blue method after fixation for $1 \mathrm{~min}$. in ice cold acetone and $9 \mathrm{~min}$. in ice cold methanol at room-temperature. Slides were stained with Accustains Iron stain from Sigma-Aldrich using the protocol provided by the manufacturer. Briefly, the tissue sections were hydrated to deionized water. Slides were placed in working iron stain solution for $10 \mathrm{~min}$ followed by rinsing in deionized water. Slides were subsequently stained with working pararosaniline solution for $3-5 \mathrm{~min}$ and rinsed in deionized water followed by a rapid dehydration through alcohol and xylene. 


\subsection{Methods in clinical chemistry}

\subsubsection{Iron measurement}

\subsection{1a Principle}

Iron bound to transferrin is released in an acidic medium as ferric iron and is then reduced to ferrous iron in the presence o ascorbic acid. Ferrous iron forms a blue complex with ferene. The absorbance at $595 \mathrm{~nm}$ is directly proportional to the iron concentration.

$$
\begin{gathered}
\text { Transferrin }\left(\mathrm{Fe}^{3+}\right)_{2} \rightarrow 2 \mathrm{Fe}^{2+}+\text { transferrin } \\
\mathrm{Fe}^{+}+3 \text { Ferene } \rightarrow \text { Ferrous Ferene (blue complex) }
\end{gathered}
$$

\subsection{1b Reagents}

Final concentration

R1: Acetate buffer

Thiourea

R2: Ascorbic acid

$\mathrm{pH} 4.5$

$800 \mathrm{mM} / 1$

$90 \mathrm{mM} / 1$

Ferene

Thiourea

Standard
$45 \mathrm{mM} / 1$

$0.6 \mathrm{mM} / \mathrm{l}$

$20 \mathrm{mM} / 1$

$100 \mu \mathrm{g} / \mathrm{dl}(17.9 \mu \mathrm{M} / \mathrm{l})$

Should be protected from light, reagents are stable at $2-25^{\circ} \mathrm{C}$ until the expiry date.

\subsection{1c Assay Procedure}

To determine the serum iron level, $100 \mu \mathrm{l}$ of the serum sample along with $1000 \mu \mathrm{l}$ of the reagent 1 was taken in the reaction tube. For blank $100 \mu \mathrm{l}$ of dd $\mathrm{H} 2 \mathrm{O}$ was used. The sample and reagent 1 was mixed thoroughly, incubated for 5 minutes and read the absorbance (A1). After 
that $250 \mu \mathrm{l}$ of the Reagent 2 was added, mixed thoroughly and the absorbance (A2) was read after 10 minutes of incubation.

\subsection{1d Calculations}

$$
\Delta \mathrm{A}=[(\mathrm{A} 2-0.82 \mathrm{~A} 1) \text { sample/Std. }]-[(\mathrm{A} 2-0.82 \mathrm{~A} 1) \text { blank }]
$$

The factor 0.82 compensates the decrease of the absorbance by addition of reagent 2 . The factor is calculated as follows:

$$
(\text { Sample }+\mathrm{R} 1) / \text { Total volume. }
$$

This compensation is necessary as a high sample volume is used.

$$
\begin{gathered}
\text { Iron }[\mu \mathrm{g} / \mathrm{dl}]=\Delta \mathrm{A} \text { Sample } / \Delta \mathrm{A} \mathrm{Std} / \mathrm{Cal} \times \text { Conc. Std. } / \mathrm{Cal}[\mu \mathrm{g} / \mathrm{dl}] \\
\text { Conversion factor Iron }[\mu \mathrm{g} / \mathrm{dl}] \times 0.1791[\mu \mathrm{M} / 1]
\end{gathered}
$$

\subsection{1e Measuring range}

The test has been developed to determine iron concentrations within a measuring range from 5-1000 $\mu \mathrm{g} / \mathrm{dl}(0.9-179 \mu \mathrm{M} / \mathrm{l})$. When values exceed this value samples should be diluted $1+$ 2 with $\mathrm{NaCl}$ solution $(9 \mathrm{~g} / \mathrm{l})$ and the results multiplied by 3 .

\subsection{1f Specificity and sensitivity}

The test was specific and no interference was observed by conjugated and free bilirubin up to $60 \mathrm{mg} / \mathrm{dl}$, hemoglobin up to $100 \mathrm{mg} / \mathrm{dl}$, lipemia up to $2000 \mathrm{mg} / \mathrm{dl}$ triglycerides, and copper up to $200 \mu \mathrm{g} / \mathrm{dl}$. The lower limit of detection for the test is $2 \mu \mathrm{g} / \mathrm{dl}(0.4 \mu \mathrm{M} / \mathrm{l})$.

\subsection{Statistical analysis}

The data were analyzed using Prism Graph pad 5 software (San Diego, USA). All experimental errors are shown as SEM. Statistical significance was calculated by Student's t test and one way ANOVA with Dunnett post hoc test. Significance was accepted at $\mathrm{P}<0.05$. 


\subsection{Safety measures}

All operations with genetically modified organisms and plasmid DNA were performed in accordance to the "Gentechnikgesetz" of 1990 and to the rules prescribed by the "GentechnikSicherheitsverordnung" of 1990. Ethidium bromide, formaldehyde, DEPC and other chemicals deleterious for the environment, when used in the course of the work, were carefully managed and disposed properly in accordance with institutional guidelines. All the operations with radioactive chemicals were performed in a radioactivity class II laboratory and the radioactive waste was disposed off according to the institutional instructions. 


\section{RESULTS}

\subsection{Changes in mRNA expression of acute-phase cytokines in injured muscle, liver and brain}

The gene expression of major acute phase cytokines (IL-6, IL-1 $\beta$ and TNF- $\alpha$ ) was analyzed by RT-PCR analysis at the site of injury (the muscle) and in the distant organs of study (liver and brain). In injured muscle, acute phase cytokine gene-expression demonstrated highly significant increase of IL-6 with a maximum expression by 6h (1982 \pm 777 fold). An early (2h) and constant (until 6h) significant up-regulation (425 \pm 95 fold) of IL-1 $\beta$ was detected. Although the order of magnitude was lower than for IL-1 $\beta$ and IL-6, TNF- $\alpha$ was also significantly induced with a maximum of ( $3.6 \pm 3$ fold) by $48 \mathrm{~h}$, (Figure 6 ; $\mathrm{P}<0.01)$.

In rat liver, the mRNA expression of IL- $1 \beta$ and TNF- $\alpha$ genes was significantly $(\mathrm{P}<0.01)$ upregulated with a maximum expression by $6 \mathrm{~h}(4.5 \pm 0.6$ fold $)$ and $(4 \pm 1.1$ fold $)$ respectively. In contrast, a slight upregulation of IL-6 gene expression was also observed nevertheless, the results for IL-6 gene expression were non-significant in the liver after onset of acute-phase reaction (Figure 6). In brain tissue, a mild change in gene-expression of acute-phase cytokines (IL-6, IL$1 \beta$ and TNF- $\alpha$ ) was observed during acute-phase reaction. IL- 6 and TNF- $\alpha$ gene-expression was upregulated $(2.3 \pm 0.4$-fold $)$ by $6 \mathrm{~h}$ and $(2.31 \pm 0.11$-fold $)$ by $12 \mathrm{~h}$ respectively. In contrast, IL- $1 \beta$ gene expression was significantly downregulated (Figure 6; $\mathrm{P}<0.05$ ) 


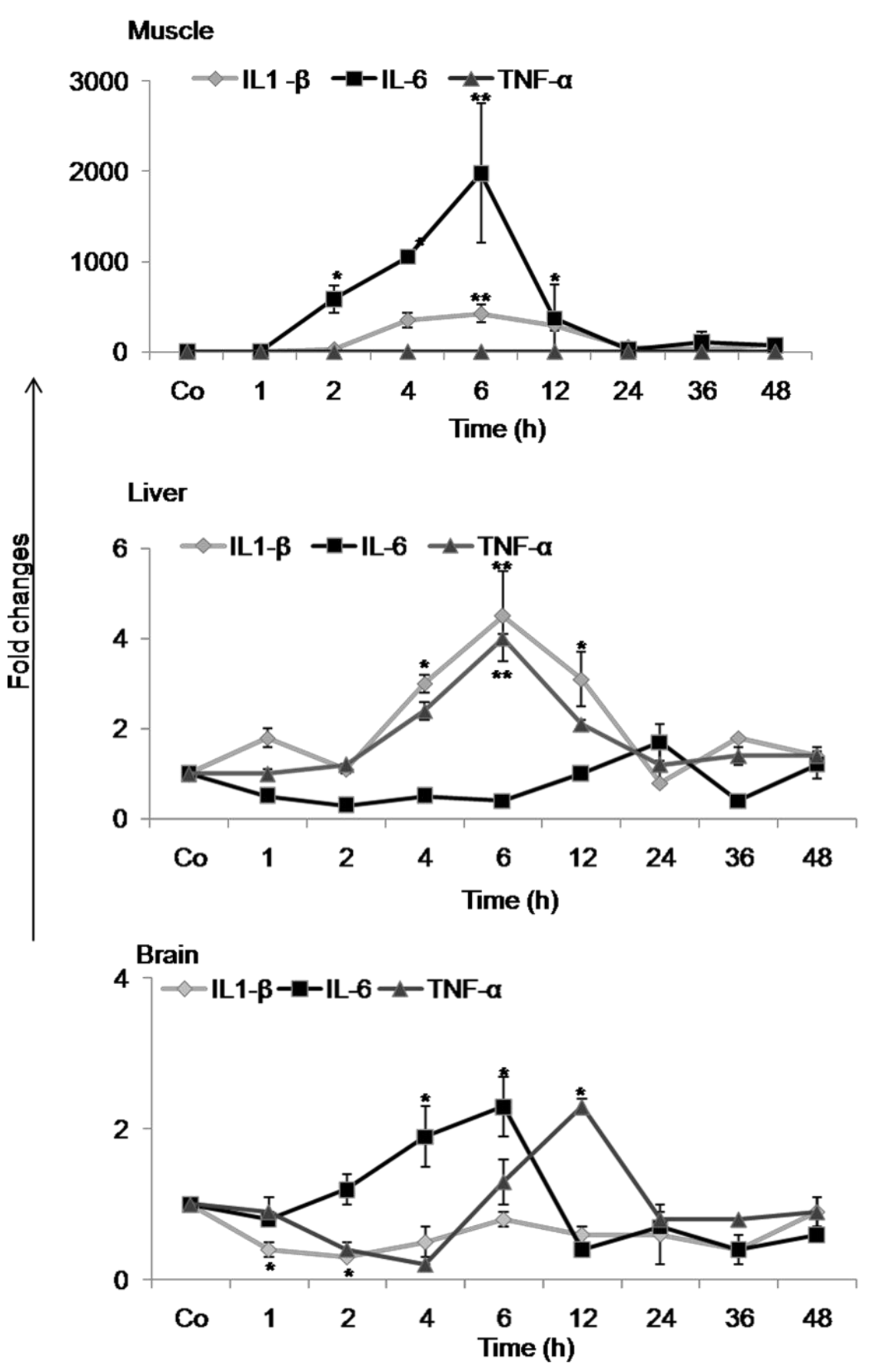

Figure 6: mRNA expression of acute-phase cytokines (IL-6, IL1- $\beta$ and TNF- $\alpha$ ) in rat muscle, liver and brain after TO-administration. RT-PCR analysis of total RNA from muscle, liver and brain tissue shows gene expression of acute phase cytokines. $\mathrm{Ct}$ values were normalized with UBC as a housekeeping gene. The results represent the fold changes of mRNA expression where control values are normalized to one. Results represent mean value \pm S.E.M. $\left({ }^{*} \mathrm{P} \leq 0.05, * * \mathrm{P} \leq 0.01\right.$ analyzed by one way ANOVA, n=4). 


\subsection{Expressional change in hemeoxygenase-1 (positive acute phase protein) in liver and} brain

In rat liver and brain, APR was confirmed by the expressional changes in hemeoxygenase-1 (HO-1) gene and protein expression. Gene expression of HO-1 was analyzed by RT-PCR and further confirmed by means of western blot analysis. In the liver, RT-PCR showed an increase in HO-1 gene expression early (1h) after the TO administration, this increase was statically significant with a strong upregulation by $6 \mathrm{~h}(54.59 \pm 2.97$-fold; Figure $7 ; \mathrm{P}<0.0001$ vs. Control).

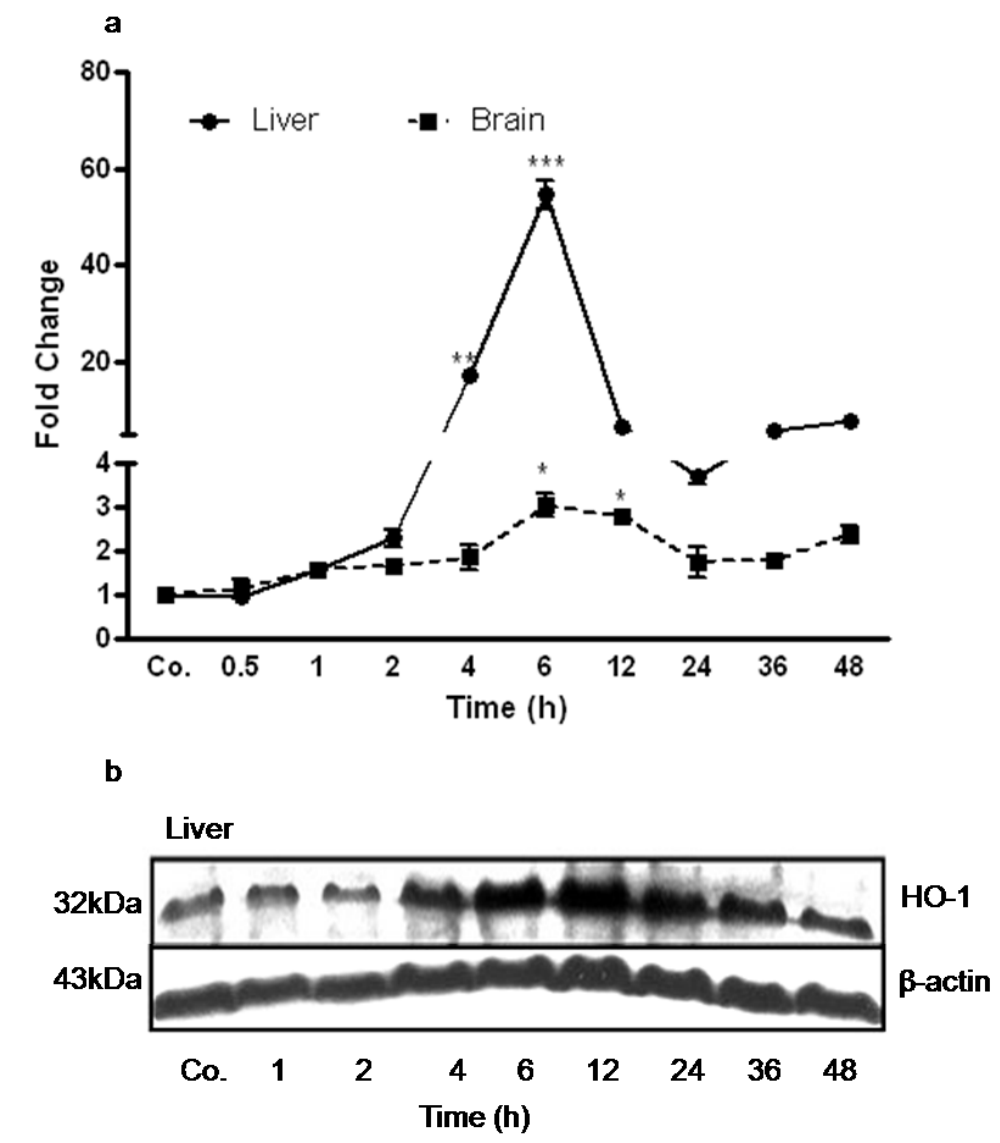

Figure 7: Changes of heme oxygenase-1-(HO-1) transcript amount in the liver and brain tissue during APR. a) RT-PCR analysis of total RNA from rat liver and brain during APR. RT-PCR was normalized by using UBC as housekeeping gene Results show the fold changes in the mRNA expression of HO-1 where control values are normalized to one. Results represent mean 
value \pm S.E.M. ( $* * * P<0.0001$, analyzed by one way ANOVA; $n=3)$. b) Western blot analysis of total protein lysates $(50 \mu \mathrm{g})$ from rat liver during APR at various time-points with antibodies specific for HO-1 and $\beta$-actin. Published: (Malik et al. 2010).

In the brain, the kinetics of HO-1 gene expression were similar to that observed in liver anyhow, the order of magnitude of the increase in mRNA expression was much lower than that of liver tissue. Nevertheless, upregulation started slightly later and reached its maximum (3.03 \pm 0.25 -fold) by $6 \mathrm{~h}$ ( $P<0.05$ vs. Control; Figure 7$)$. The changes in mRNA expression of HO-1 gene observed by RT-PCR were further confirmed by western blot analysis of total lysates from liver tissues. Western blot analysis for HO-1 protein detected a band at 32kDa. Compared to controls, HO-1 protein expression was upregulated during APR; this increase was at its maximum by 6-24h of acute-phase reaction (Figure 7).

\subsection{Changes in serum and tissue iron levels}

Serum and tissue iron level was measured by ferrozine based assay. Changes in the iron concentration were studied in serum, liver, brain and spleen of control rats and at different time points during APR. Control values were normalized to 100-percent. The serum iron concentration significantly decreased during APR. This decrease reached a minimum $(41 \pm 1.5$ percent; $\mathrm{P} \leq 0.01$ vs control) at $24 \mathrm{~h}$. At the same time, liver iron concentration increased gradually during APR and remained elevated throughout the course of study. Increase reached its maximum (141 \pm 3.2 percent; $\mathrm{P} \leq 0.05$ vs control) at $12 \mathrm{~h}$. However, spleen iron concentrations did not increase during the study. Infact, though non-significant, there was a decrease (75 \pm 13 percent) in spleen tissue iron concentration. The brain iron concentration increased slightly (110 \pm 5 percent) with a maximum at $2 \mathrm{~h}$ and remained above control concentration until 12h after TO administration but changes were statistically non-significant. Moreover, nuclear 
and cytoplasmic iron concentration from liver lysates was measured. A significant increase of iron concentration in liver cytoplasmic $(141 \pm 5.4$ percent; $\mathrm{P} \leq 0.05$ vs control $)$ at $24 \mathrm{~h}$ and nuclear fraction (160 \pm 3 percent; $\mathrm{P} \leq 0.001$ vs control) at $24 \mathrm{~h}$ was observed (Figure 8 ).
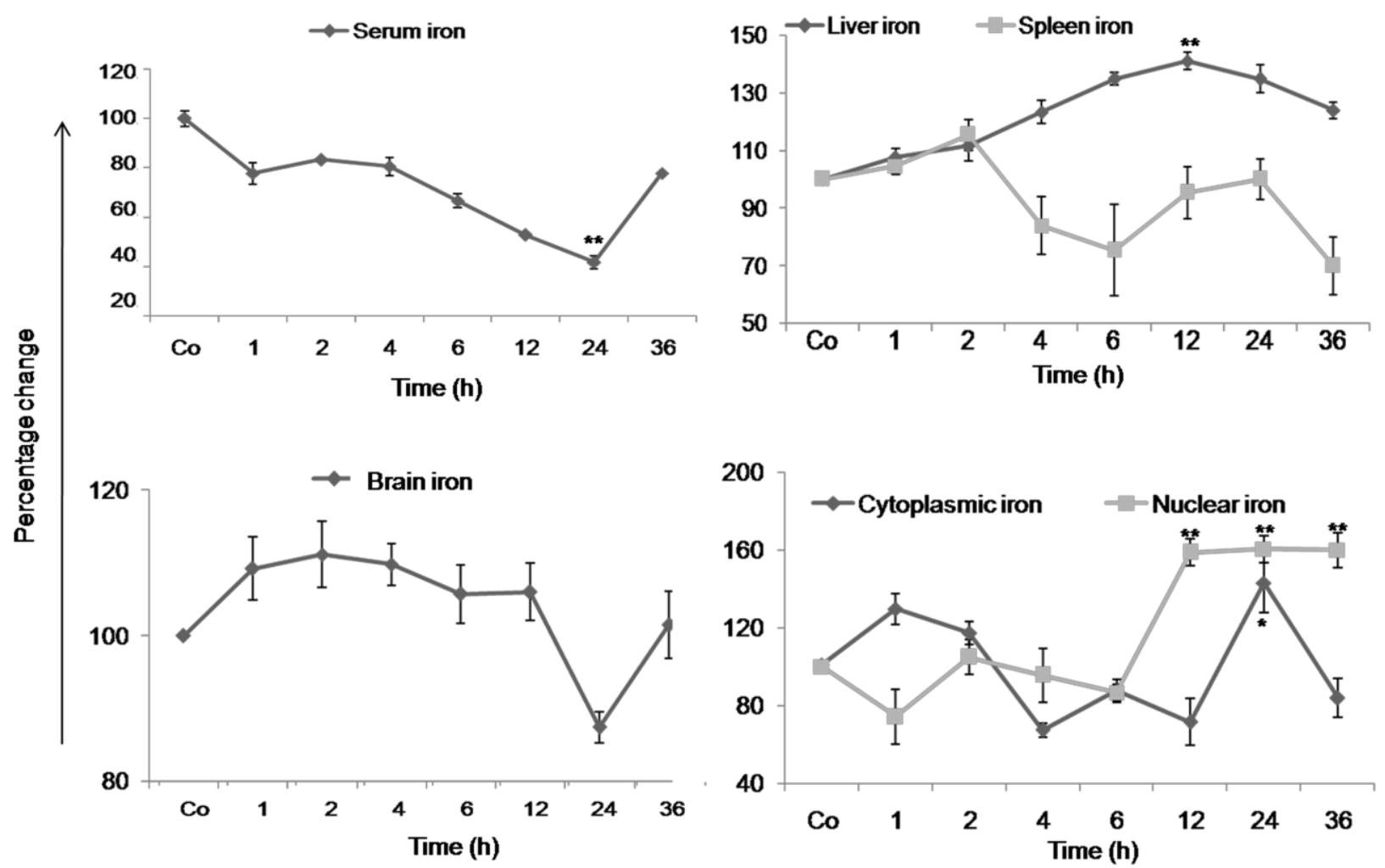

Figure 8: Changes of serum and tissue iron concentration during APR. Iron concentrations of serum, liver, spleen, brain tissue lysates and liver tissue fractions were determined by ferrozine based assay as described in materials and methods. Control values were normalized to 100 percent. Results represent mean value \pm S.E.M. $(* * \mathrm{P}<0.01 * \mathrm{P}<0.05$ analyzed by one way ANOVA; $n=3)$.

\section{3b Prussian blue staining of liver and spleen tissues}

Regardless of spleen iron concentration, the decrease of serum iron and the increase of liver iron concentrations were statistically significant; even though, we were not able to show the increase of iron deposition in liver cells by Prussian blue iron staining (data not shown). It is 
likely that to detect an increase of iron concentration in the tissue by staining, the levels would have to increase to even higher levels.

\subsection{Changes in mRNA expressions of hepcidin, Hjv, HFE, hephastin Fpn-1 in rat liver, brain and spleen}

In rat liver, hepcidin gene expression started increasing (2h) after onset of APR which was significantly maximum by $6 \mathrm{~h}(7.4 \pm 0.01$ fold). Whereas, a quick, abrupt (1h) and significant decrease in Fpn-1, Fpn-1a, Fpn-1b, hephastin, HFE and HJV gene expression was observed, which kept on decreasing through-out the course of study. This decrease was at its minimum for Fpn-1 (0.4 \pm 0.1 fold) by $24 \mathrm{~h}$, for Fpn-1a $(0.5 \pm 0.1$ fold $)$, for Fpn-1b $(0.3 \pm 0.07$ fold $)$, for hephastin $(0.4 \pm 0.1$ fold $)$ by $36 \mathrm{~h}$, for HFE $(0.3 \pm 0.1$ fold $)$ and for HJV $(0.2 \pm 0.01$ fold $)$ by $24 \mathrm{~h}(\mathrm{P}<0.001 v s$. Control; Figure 9).

Similarly, in brain, RT-PCR indicate a steep increase (starting $2 \mathrm{~h}$ after TOadministration) in the hepcidin gene expression with a maximum by 4-6h (approx. 3-fold) which remained significantly above the control concentrations until $48 \mathrm{~h}(\mathrm{P}<0.05$ vs. Control). Fpn1-, Fpn-1a, Fpn-1b, Hjv- and HFE-genes-expression was downregulated early (1h) after TOadministration. Fpn-1 and Fpn-1a showed the minimum expression by $1 \mathrm{~h}(0.5 \pm 0.01$ fold $)$ and ( $0.43 \pm 0.03$ fold) respectively and Fpn-1b was decreased $(0.27 \pm 0.03$ fold) by $12 \mathrm{~h}$ of APR. Hjvgene-expression was significantly downregulated $(0.2 \pm 0.014$ fold $)$ with a minimum concentration by $6 \mathrm{~h}$, when the hepcidin gene-expression was at its maximum. While, hephastin gene expression was significantly upregulated $(4.8 \pm 0.41$-fold) in the brain at $24 \mathrm{~h}$ after $\mathrm{TO}$ administration $(P<0.0001$ vs. Control $)$. Furthermore, Southern blot analysis was performed to confirm the RT-PCR results it indicated a gradual increase of hepcidin DNA amount in brain tissue with a maximum expression by $48 \mathrm{~h}$ after APR (Figure 10). 
In spleen, the mRNA expression of hepcidin was significantly increased with a maximum $(2.5 \pm 0.5$ fold $)$ at $12 \mathrm{~h}$ after $\mathrm{TO}$-administration. A significant $(\mathrm{P}<0.0001$ vs. Control $)$ decrease in the mRNA expression of Fpn-1, Fpn-1a and Fpn-1b was observed early (1h) after APR which was at its minimum for Fpn-1 ( $0.3 \pm 0.02$ fold) by $6 \mathrm{~h}$, Fpn-1a $(0.6 \pm 0.08$ fold $)$ by $24 \mathrm{~h}$, and Fpn- $1 \mathrm{~b}$ $(0.2 \pm 0.03$ fold $)$ by $24 \mathrm{~h}$ of $\mathrm{TO}$-administration. However, the changes in gene expression of hephastin, HFE, HJV were less evident and statistically non-significant (Figure 11).

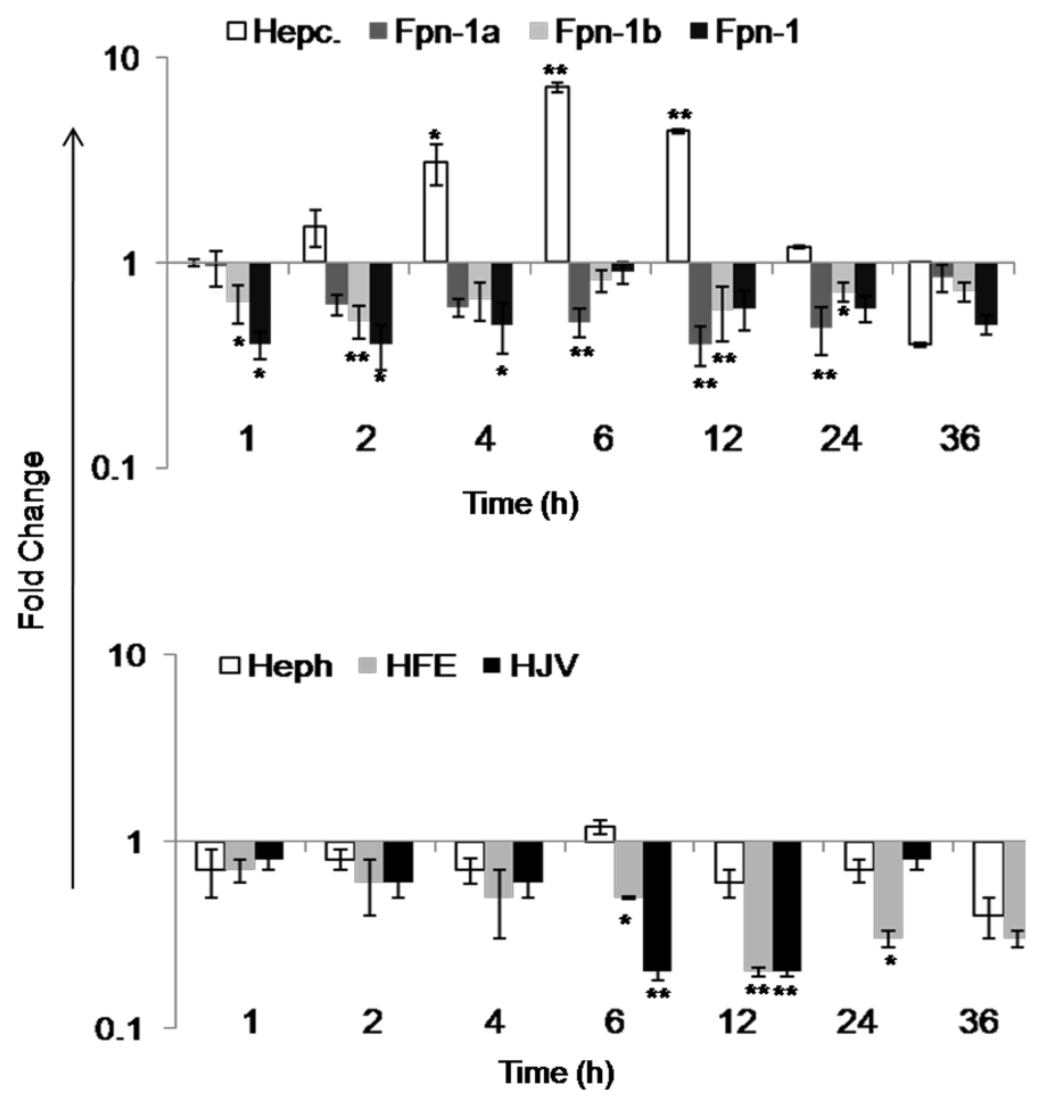

Figure 9: RT-PCR analysis of total liver RNA to demonstrate the changes of hepcidin-, Fpn1-, Fpn-1a-, Fpn-1b-, hephastin-, HFE- and Hjv-transcript amount in the liver tissue during APR. The mRNA expression of each gene was analyzed by real-time PCR and normalized using UBC as housekeeping gene. Result shows the fold changes where control values are normalized to 
one. Results represent mean value \pm S.E.M. $(* P<0.05$, $* * \mathrm{P}<0.01$ analyzed by one way ANOVA; $\mathrm{n}=3)$.
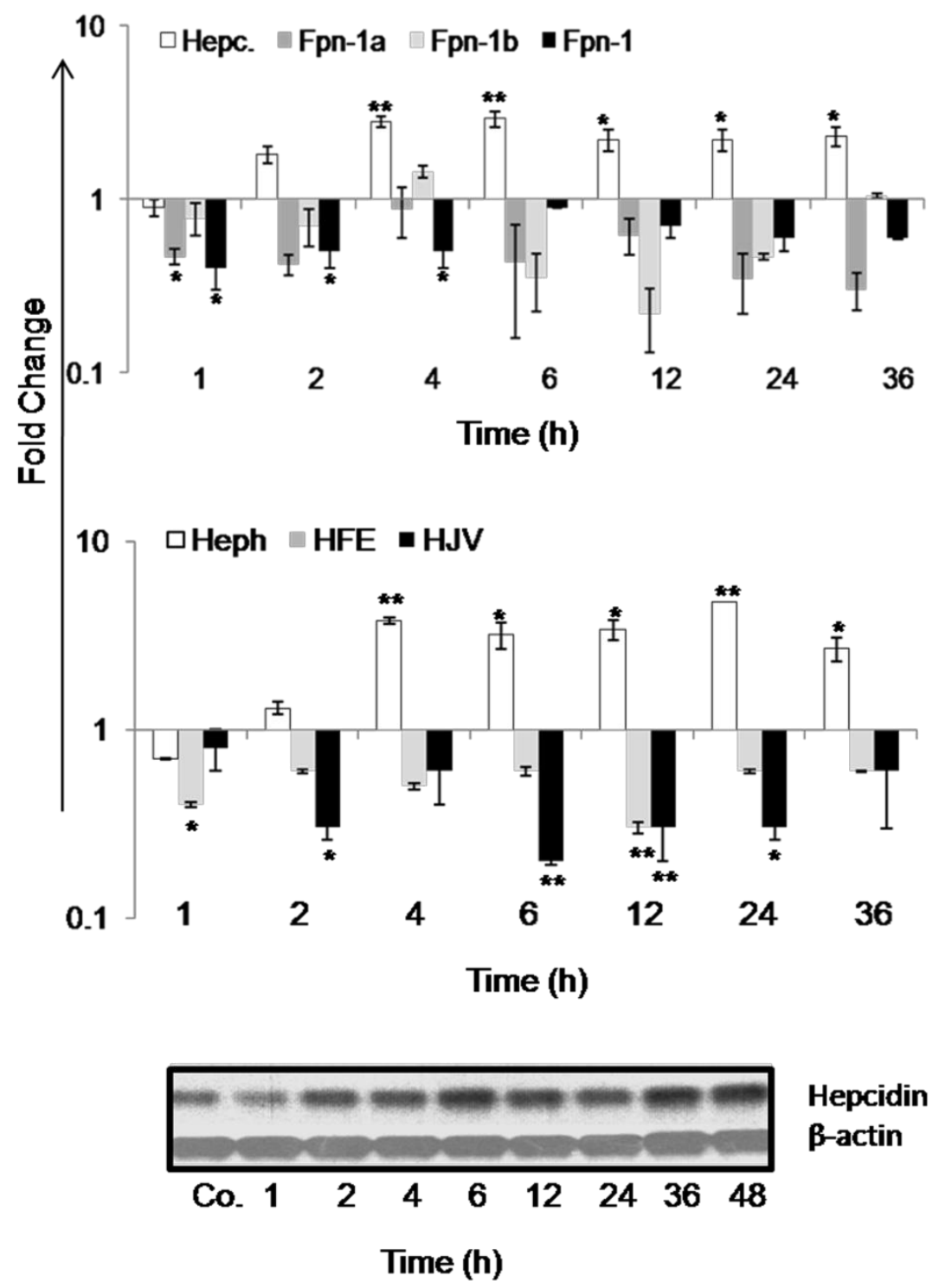

Hepcidin

B-actin

Figure 10: RT-PCR of total RNA from brain to demonstrate the changes of hepcidin-, Fpn-1-, Fpn-1a, Fpn-1b, hephastin-, HFE- and Hjv-transcript amount in the brain tissue during APR (upper panel). The mRNA expression was analyzed by RT-PCR and normalized using UBC as housekeeping gene. Data show the fold changes in comparison to controls where the control values are normalized to one. Results represent mean value \pm S.E.M. $(* P<0.05, * * \mathrm{P}<0.01$, 
analyzed by one way ANOVA; $n=3$ ). The lower panel: Change in gene expression of hepcidin at transcriptional concentration showed by Southern blot analysis using $\beta$-actin as loading control.

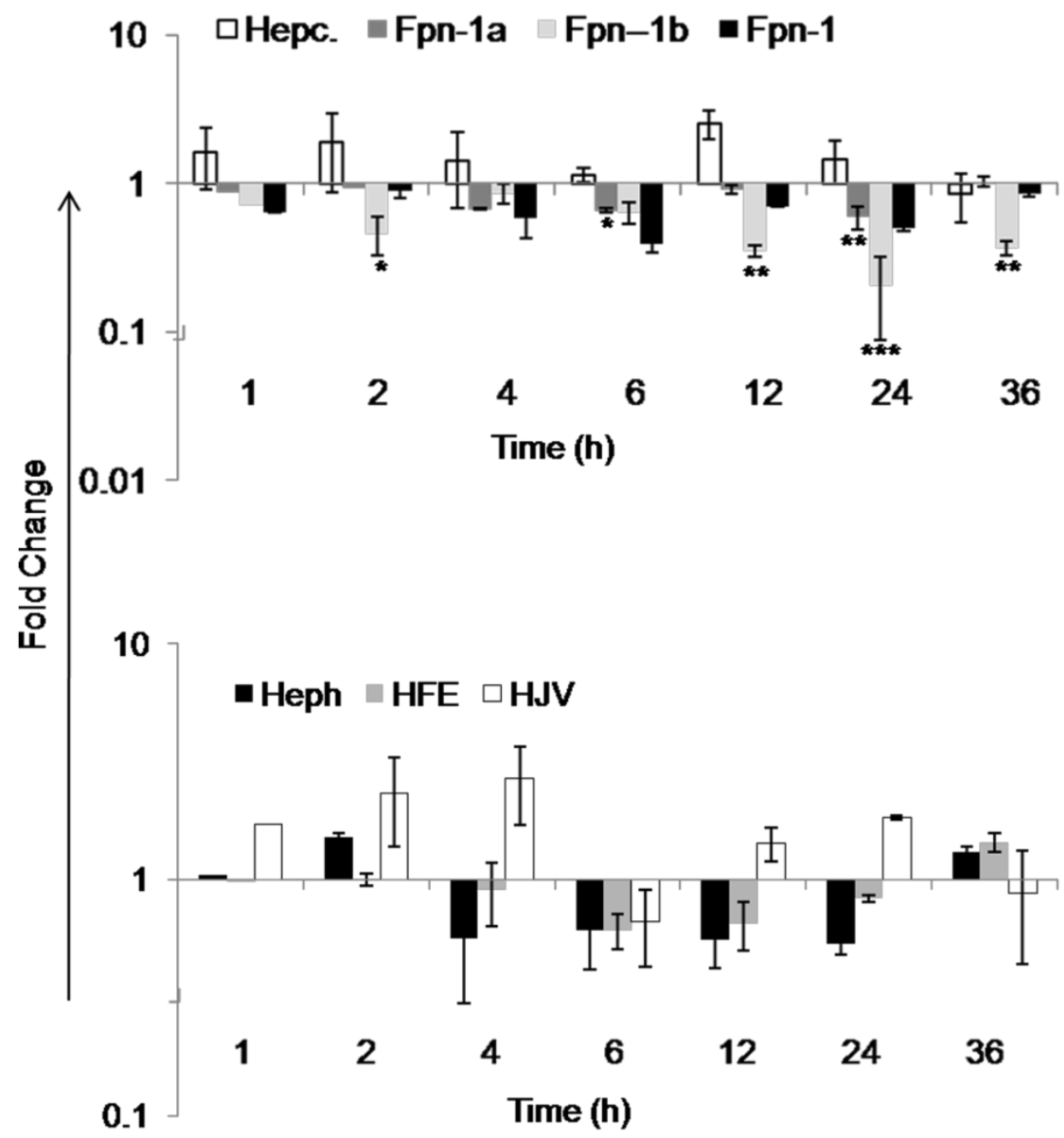

Figure 11: RT-PCR analysis of total RNA from spleen to demonstrate the changes of hepcidin-, Fpn1-, Fpn-1a-, Fpn-1b-, hephastin-, HFE- and Hjv-transcript amount during APR. The mRNA expression was analyzed by RT-PCR and normalized using UBC as housekeeping gene. Data shows fold changes of gene expression where the control values were normalized to one. Results represent mean value \pm S.E.M. $(* P<0.05$, $* * \mathrm{P}<0.01$, $* * * \mathrm{P}<0.001$ analyzed by one way ANOVA; $\mathrm{n}=3)$. 
4.5 Changes in mRNA expressions of iron import proteins (Tf, TfR1, TfR2 and DMT-1) in rat liver, brain and spleen

The mRNA expression of iron import proteins (Tf, TfR1, TfR2 and DMT-1) was analyzed by RT-PCR in rat liver, brain and spleen. In the liver compared to controls, an increase $(1.3 \pm 0.1)$ of transferrin-gene-expression was observed with by 6 followed by a downregulation in late time points of APR. An early and significant increase of TfR1 gene expression was observed which was found to reach the maximum at $6 \mathrm{~h}(1.5 \pm 0.4$ fold $)$ after the onset of APR. Changes in TfR2 gene expression were maximum (1.8 \pm 0.03 fold $)$ by $6 \mathrm{~h}$. A quick and significant increase in DMT-1 gene expression was observed during acute-phase reaction with a maximum by $12 \mathrm{~h}(2.9 \pm 0.3$ fold; $\mathrm{P}<0.05$ vs. Control; Figure 12$)$.

In brain tissue Tf gene expression was upregulated in the brain (two fold) after the onset of acute-phase reaction. TfR1-mRNA started increasing $1 \mathrm{~h}$ after the onset of APR with a maximum $(3.7 \pm 0.13$-fold $)$ at $6 \mathrm{~h}$ time point $(\mathrm{P}<0.001$ vs. Control). On the other hand, changes of TfR2-mRNA were mild but significant. In contrast, DMT1 gene expression was downregulated with a minimum expression $(0.4 \pm 0.1$ fold) by $24 \mathrm{~h}$ after the onset of APR (Figure 13$)$.

However, in spleen, Tf, TfR1, TfR2 gene expression was downregulated throughout the course of study with a minimum expression for Tf $(0.7 \pm 0.01$ fold $)$ by $6 \mathrm{~h}$, for TfR $1(0.18 \pm 0.09$ fold) by $24 \mathrm{~h}$, for TfR2 $(0.16 \pm 0.01$ fold $)$ by $24 \mathrm{~h}$. The DMT-1 gene expression was significantly downregulated $(0.1 \pm 0.02$ fold) by $24 \mathrm{~h}(\mathrm{P}<0.0001$ vs. Control; Figure 14$)$. 


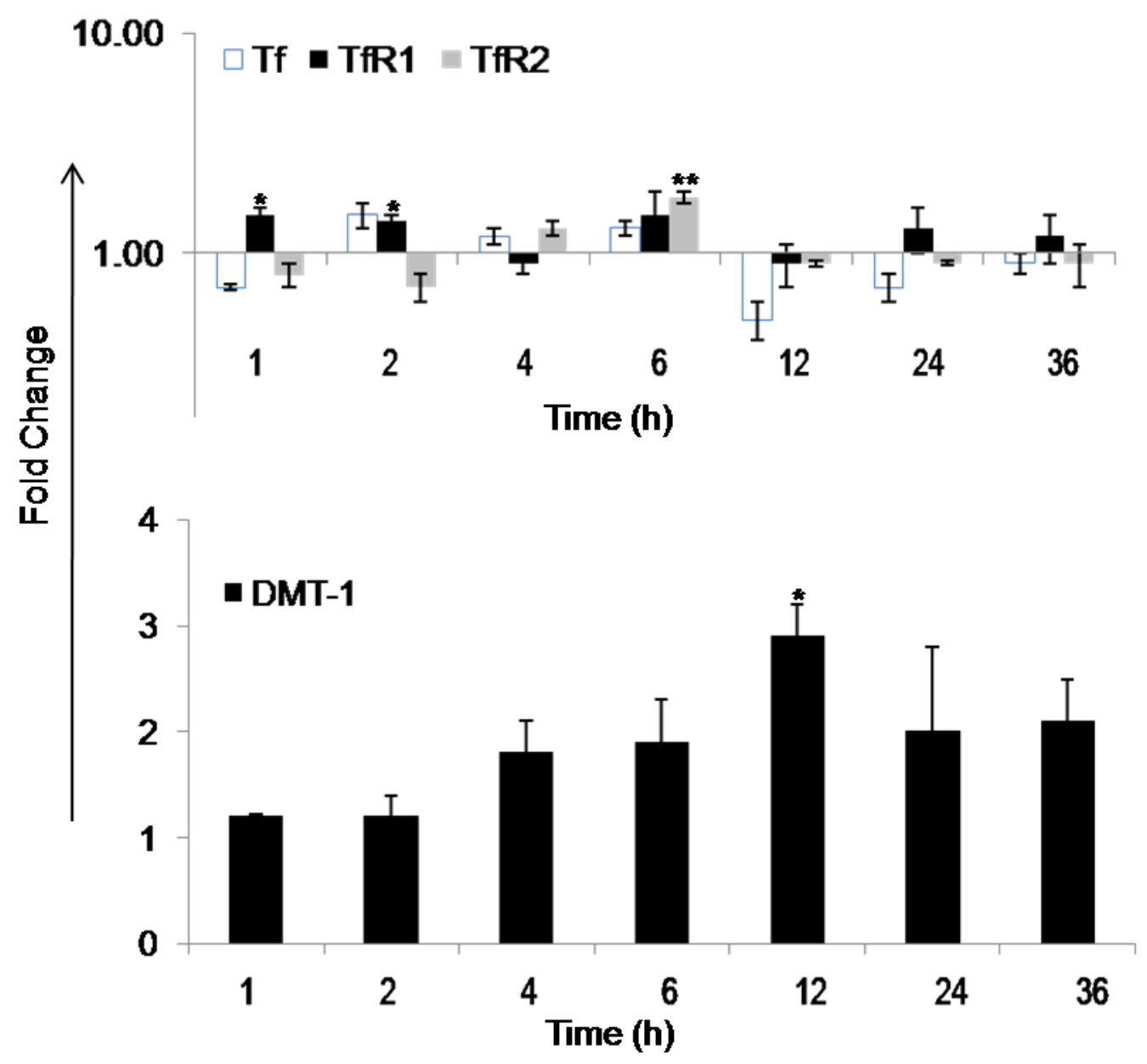

Figure 12: RT-PCR analysis of total RNA from rat liver to show the changes of TfR1, TfR2, Tfand DMT-1 (the iron import proteins) transcript amount during APR. The mRNA expression of transferrin (Tf), transferrin receptor1 (TfR1) and transferrin receptor2 (TfR2) was analyzed by real time PCR and normalized with ubiquitin $\mathrm{C}$ as housekeeping gene. Data shows the fold changes of respective gene compared to controls where the control values are normalized to one. Results represent mean value \pm S.E.M. ( $* P<0.05$, analyzed by one way ANOVA; $n=3)$. 


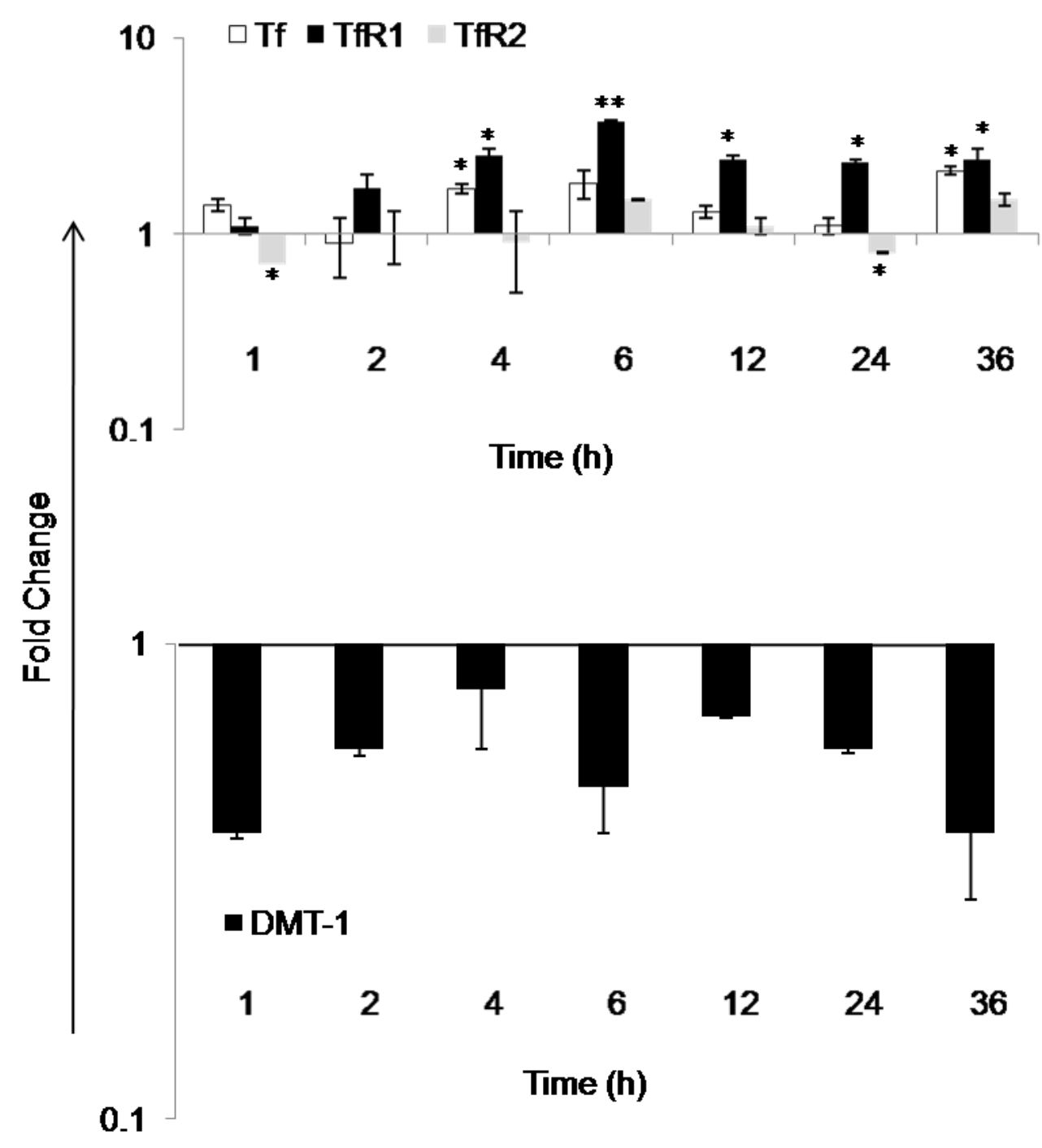

Figure 13: RT-PCR analysis of total RNA from brain to demonstrate the changes of Tf-, TfR1, TfR2, and DMT-1 (the iron import proteins) transcript amount in the brain tissue during APR. The mRNA expression of transferrin (Tf), transferrin receptor1 (TfR1) and transferrin receptor2 (TfR2) was analyzed by real time PCR and normalized with UBC as housekeeping. Data represents the fold changes in comparison to controls where the control values are normalized to one. Results represent mean value \pm S.E.M. $(* * P<0.001$, analyzed by one way ANOVA; $n=3)$. 


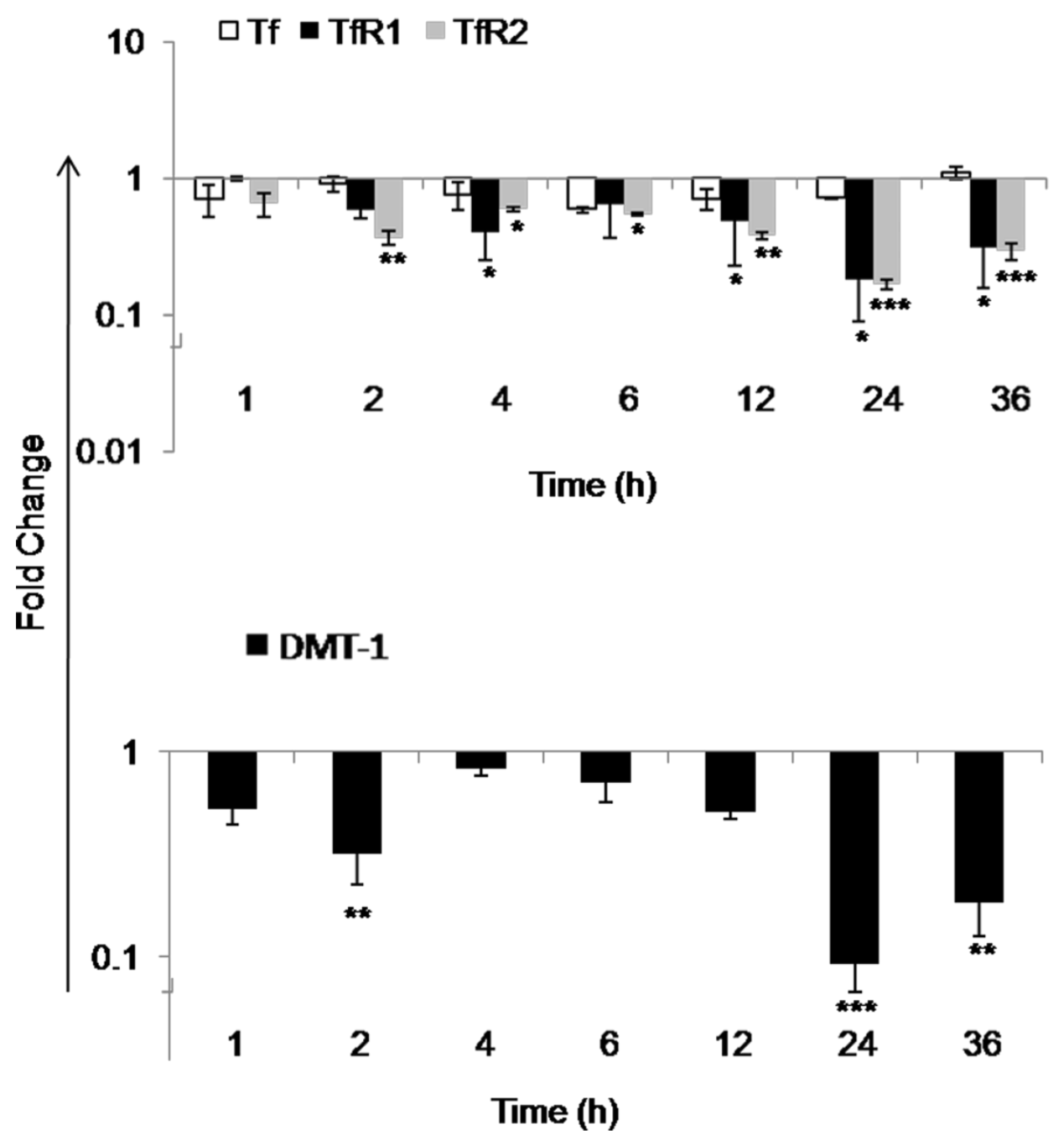

Figure 14: RT-PCR analysis of total RNA from spleen to demonstrate the changes of Tf, TfR1, TfR2 and DMT-1 (the iron import proteins) transcript amount in the spleen tissue during APR. The mRNA expression of transferrin (Tf), transferrin receptor 1 (TfR1) and transferrin receptor 2 (TfR2) was analyzed by real time PCR and normalized with UBC as housekeeping. Data represents the fold changes of respective gene where the control values were normalized to one. Results represent mean value \pm S.E.M. $(* \mathrm{P}<0.05$, $* * P<0.001, * * * \mathrm{P}<0.001$ analyzed by one way ANOVA; $n=3)$. 


\subsection{Changes in mRNA expressions of iron storage proteins (Ferritin $\mathrm{H}$ and $\mathrm{L}$ ) in rat liver,}

\section{brain and spleen}

In addition to the measurement of mRNA expressional changes of the iron import (Tf, TfR1, TfR2, DMT-1) and export proteins (Fpn-1, hephastin), the expressional analysis of 'iron storage protein' ferritin was also analyzed by RT-PCR. The gene expression of ferritin isoforms

(Heavy chain; $\mathrm{H}$ and light chain; L) was analyzed. In liver, gene expression of ferritin- $\mathrm{H}$ and ferritin L was significantly $(\mathrm{P} \leq 0.05)$ increased after APR and remained elevated throughout the course of study. This increase was at its maximum for ferritin- $\mathrm{H}(2.5 \pm 0.1$ fold $)$ by $24 \mathrm{~h}$ and for ferritin-L ( $2.4 \pm 0.1$ fold) by $12 \mathrm{~h}$ of APR when the maximum increase in liver iron concentration was also observed. Similarly, in brain, the gene expression of ferritin- $\mathrm{H}$ and ferritin- $\mathrm{L}$ was slightly upregulated early after APR and remained elevated throughout the course of study. The maximum expression of ferritin- $\mathrm{H}$ ( $1.9 \pm 0.002$ fold $)$ and ferritin-L ( $1.7 \pm 0.3$ fold $)$ was detected by $2 \mathrm{~h}$ when an increase in brain iron concentration was at its maximum. In spleen, a non-significant and a slight increase in ferritin-L mRNA was observed however, the expression of ferritin $\mathrm{H}$ remained stable around the control values (1.1 \pm 0.3 fold; Figure 15).

\section{7 mRNA expression of other iron regulatory proteins in the rat liver, brain and spleen}

In rat liver, the mRNA expression of IRP1 was slightly upregulated during the study with a maximum expression ( $1.7 \pm 0.1$ fold) by $6 \mathrm{~h}$ of acute phase response. The mRNA expression of IRP2 gene was downregulated $(0.4 \pm 0.3$ fold) early (1h) after APR which went to baseline concentration during $2-12 \mathrm{~h}$ followed by a downregulation $(0.3 \pm 0.3$ fold) by $24-36 \mathrm{~h}$ of acute phase response. In brain, the gene expression of IRP1 was downregulated ( $0.5 \pm 0.1$ fold) early (1h) after APR followed by an increase ( $2.9 \pm 0.5$ fold; $\mathrm{P} \leq 0.001$ vs controls) at $4 \mathrm{~h}$. However, during the rest of the time points, the mRNA amount of IRP 1 remained near to the baseline 
concentration as was observed for IRP2. In spleen, the mRNA expression changes of IRP1 and IRP2 were less pronounced with a slight increase in IRP 1 (Figure 16).

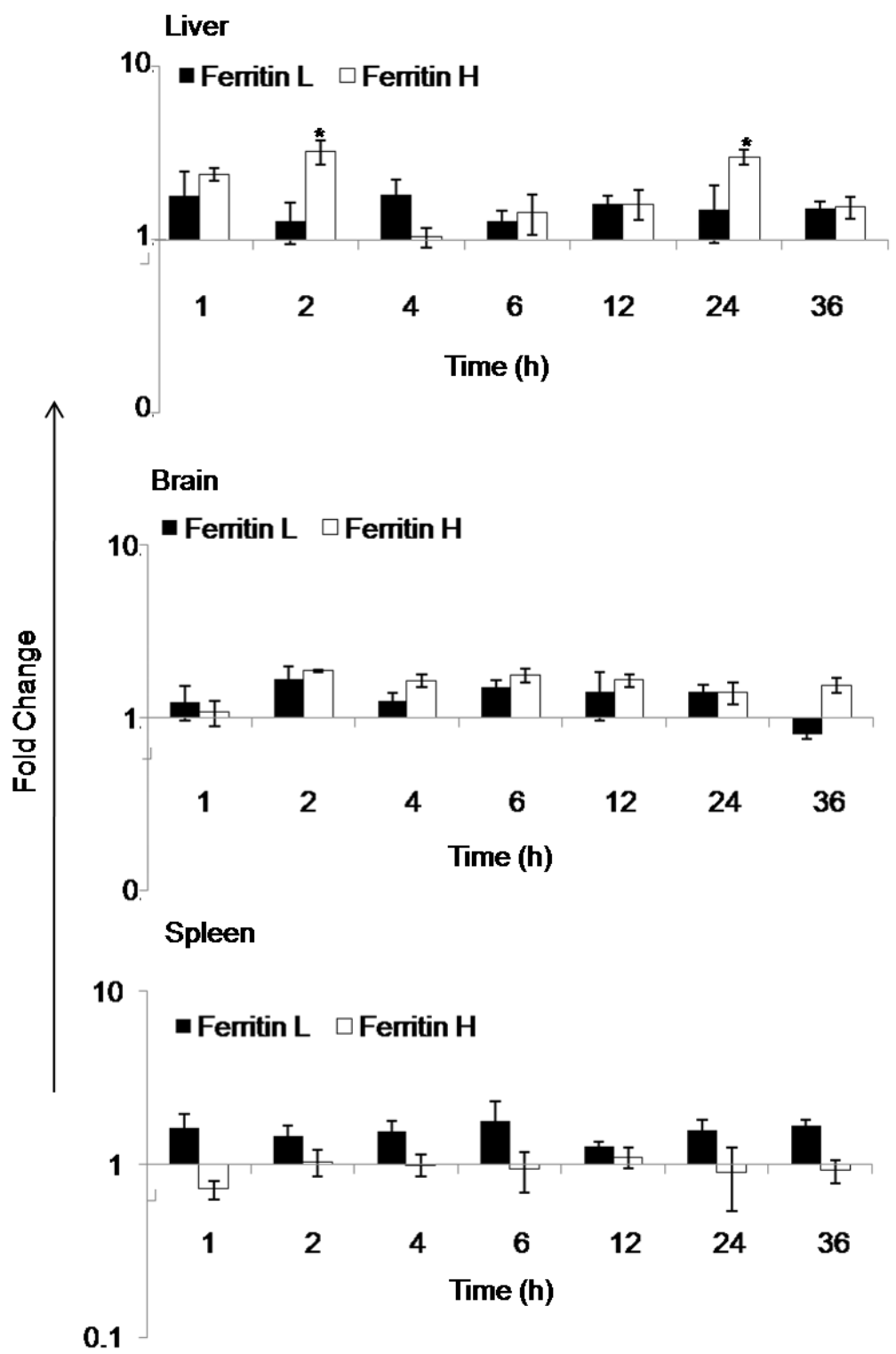

Figure 15: RT-PCR of total RNA from liver, brain and spleen to demonstrate the changes of ferritin-H and ferritin-L (the iron storage proteins) transcript amount during acute-phase response. Fold change in mRNA expression was normalized with UBC as housekeeping gene as revealed by real-time PCR. The data shows fold changes in comparison to controls where control values are normalized to one. Results represent mean value \pm S.E.M. $(* \mathrm{P}<0.05$ analyzed by one way ANOVA; $n=3)$. 

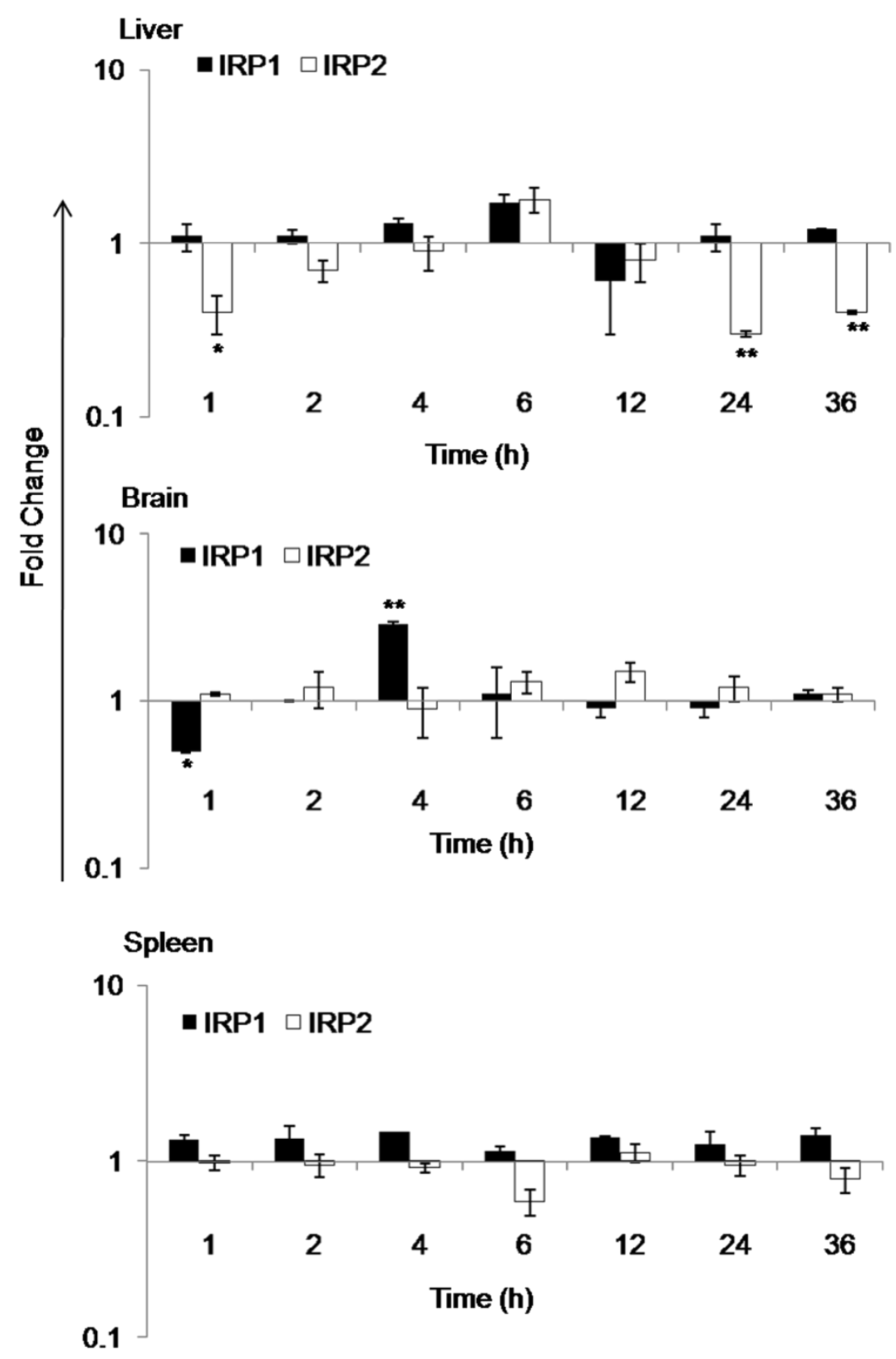

Figure 16: RT-PCR of total RNA from liver, brain and spleen to demonstrate the changes of IRP-1 and IRP-2 (the iron regulatory proteins) transcript amount in the liver, brain and spleen during APR. Fold change in mRNA expression was normalized with UBC as housekeeping gene as revealed by real-time PCR. The data shows fold changes in comparison to controls where control values are normalized to one. Results represent mean value \pm S.E.M. $(* * P<0.001$ analyzed by one way ANOVA; $\mathrm{n}=3)$. 


\subsection{Changes in protein expression of iron transport proteins during APR}

\section{8a Western blot analysis of iron transport proteins in rat liver during APR}

For rat liver, Western blot analysis was performed to confirm the changes occurring at mRNA concentration and to quantify the protein expression of iron transport proteins in rat liver. As observed at mRNA concentration, the Western blot analysis showed a decrease in the iron export proteins; Fpn-1 early (1h) after APR with almost fully diminished expression at 24h. Hephastin protein expression was also decreased early (1h) after APR this decrease was at its minimum at $36 \mathrm{~h}$ (Figure 17).

Similar to what was observed at mRNA level, the Western blot analysis of iron import proteins (DMT-1, Tf, TfR1 and TfR2). Western blot analysis of DMT-1 revealed two immunoreactive bands for the protein $(65 \mathrm{kDa}$ and $34 \mathrm{kDa})$. Similar to what was observed at mRNA level, the protein expression of DMT-1 was gradually upregulated with a maximum expression by $6 \mathrm{~h}$ of acute phase response. Similarly, a steep increase in Tf (the iron binding and transport protein) was observed with a maximum by 36h. Similarly, a quick (1h) and intense increase of TfR1 protein was observed after APR which showed a slight decrease (still upregulated in comparison to controls) followed by an increase by $6-36 \mathrm{~h}$ of acute phase response. Likewise, a gradual increase in TfR2 protein was also observed in rat liver during acute phase response. Though the magnitude of increase was less than that of observed for TfR1 protein, TfR2 was at its maximum by 6 and 36h. The expression of Beta actin was used as a house keeping protein to control equal loading (Figure 17). 


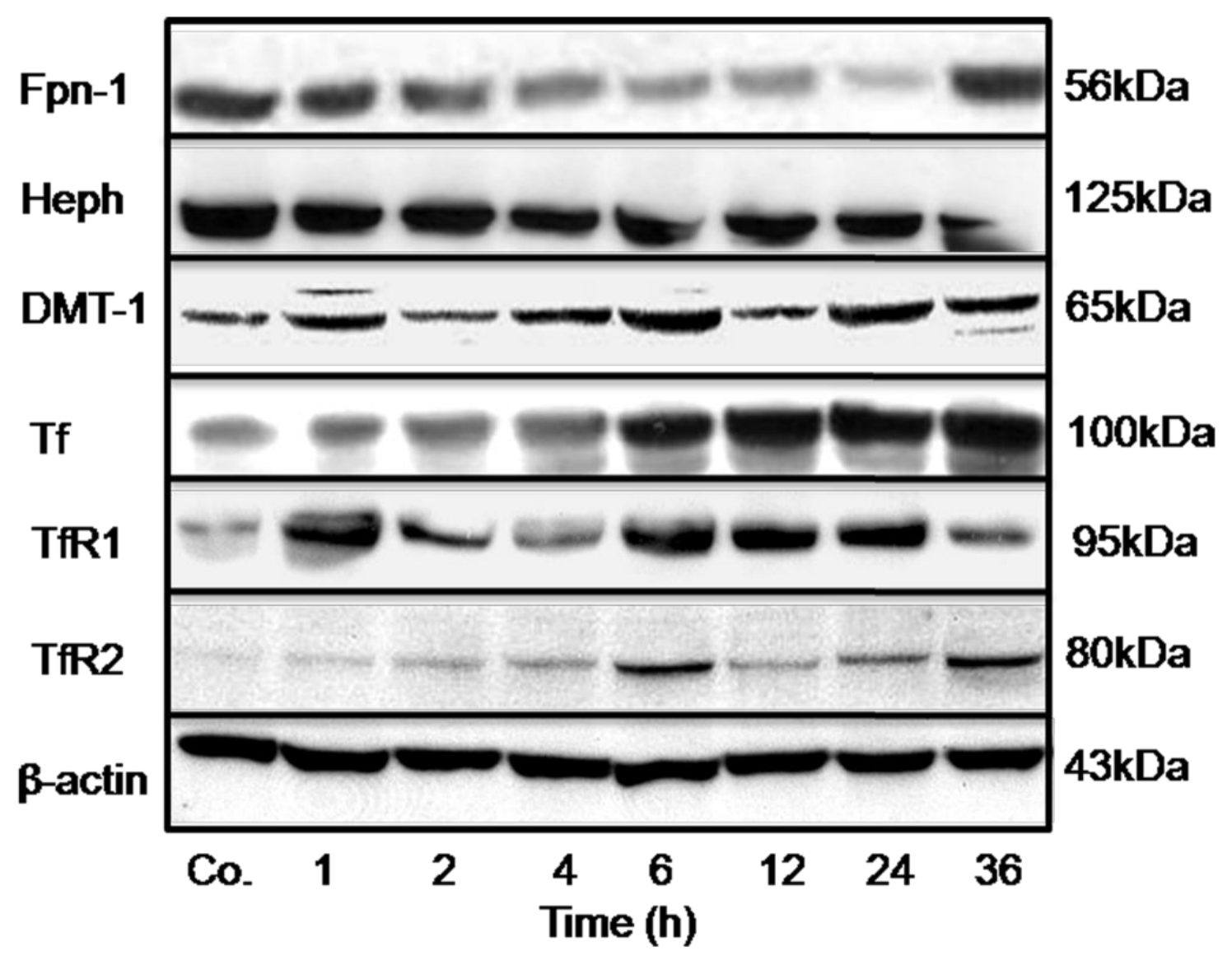

Figure 17: Western blot analysis of total rat liver lysates $(50 \mu \mathrm{g})$ for iron transport proteins. Western blot analysis of iron export proteins (Fpn-1 and hephastin) and iron import proteins (DMT-1, Tf, TfR1, TfR2) in rat liver during APR. The results show representative figure from three technical replicates.

\section{8b Densitometry analysis of changes in protein expression in rat liver APR}

The results of Western blot analysis were confirmed in three technical replicates and densitometry analysis was performed to quantify the expressional changes at protein concentration and significance was determined by statistical analysis using one way ANOVA. In all experiments the expression of control rats was normalized to $100 \%$. In comparison to controls rats $(100 \%)$, the densitometry analysis of Fpn-1 protein expression decreased (down to $63 \pm 14$ percent) by $1 \mathrm{~h}$ after acute phase response. Fpn-1 protein expression was almost diminished (down to $1.2 \pm 0.5$ percent) by $24 \mathrm{~h}(\mathrm{P} \leq 0.001)$. The protein expression of hephastin also showed a 
decrease during acute phase response. Compared to controls, the densitometry analysis demonstrated a highly significant decrease $(\mathrm{P} \leq 0.0001)$ of hephastin protein expression with a minimum expression (down to $15 \pm 5$ percent) by $36 \mathrm{~h}$ (Figure 18 ).
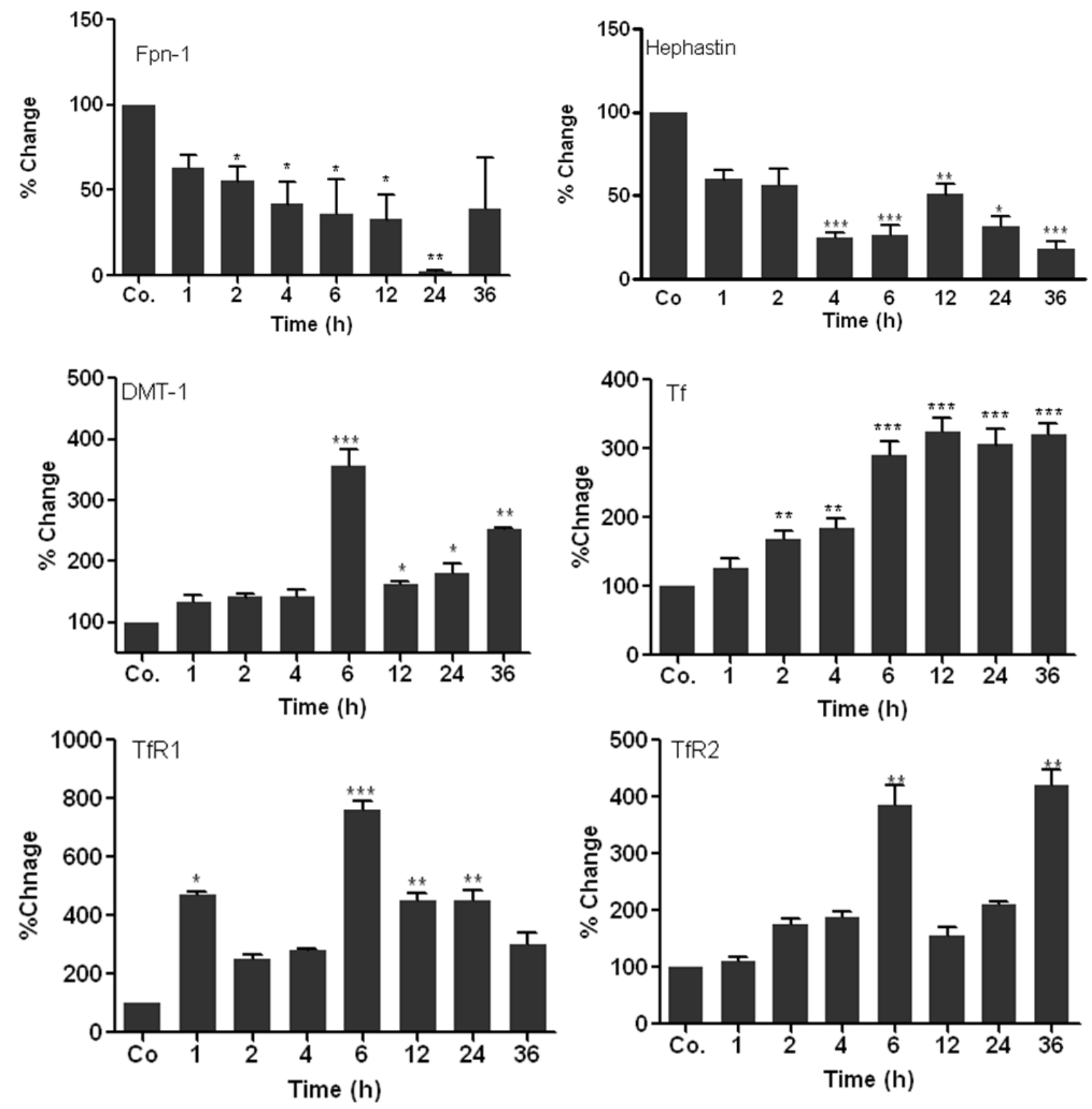

Figure 18: Densitometry analysis of western blots performed for rat liver during APR. The result shows the percentage changes of protein amount in comparison to controls where the control values were normalized to 100 percent. Densitometry was performed using Image J software. Results represent mean values \pm SEM $(* * * \mathrm{P}<0.0001$ analyzed by one-way ANOVA; $\mathrm{n}=3)$. 
The quantification of DMT-1 protein expression indicated an increase in DMT-1 protein during acute phase response. This increase was more pronounced (370 \pm 10 percent) and statistically significant ( $\mathrm{P} \leq 0.0001 v s$ Controls) by $6 \mathrm{~h}$ of APR. Similarly, a, gradual and significant increase $(\mathrm{P} \leq 0.0001$ vs Controls) in Tf protein expression was analyzed during the study. This increase was at its maximum by $36 \mathrm{~h}$ of acute phase response. Compared to controls, an abrupt (1h) and highly significant $(\mathrm{P} \leq 0.0001$ vs Controls) increase in TfR1 protein expression was found which was upregulated throughout the study with a maximum expression remained by $6 \mathrm{~h}$ (780 \pm 30 percent). Similarly, TfR2 protein was also upregulated during the study with a different of magnitude. This increase was statistically significant $(\mathrm{P} \leq 0.001$ vs Controls $)$ and maximum by

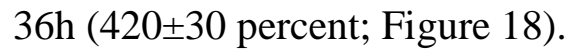

\section{8c Comparative analysis of TfR1 protein expression in rat liver and brain}

The protein expression pattern of TfR1 in rat liver, brain and serum was compared by means of Western blot analysis. Western blot analysis for TfR1 detected a protein of the same molecular weight in brain tissue and in serum as was observed in liver tissue. As was observed in rat liver (Figure 19a), an early (1h) increase in protein expression of TfR1 was observed in brain tissue which remained upregulated throughout the study with a significantly maximum expression from 2-12h of APR (approx. 300 percent; $\mathrm{P} \leq 0.001$; Figure 19b). Similarly in the serum, TfR1 protein expression was significantly upregulated early (1h) after APR reaching at its maximum ( $420 \pm 5$ percent) by $2 \mathrm{~h}$ and remained upregulated until the last time points $(\mathrm{P} \leq 0.0001$; Figure 19c). 


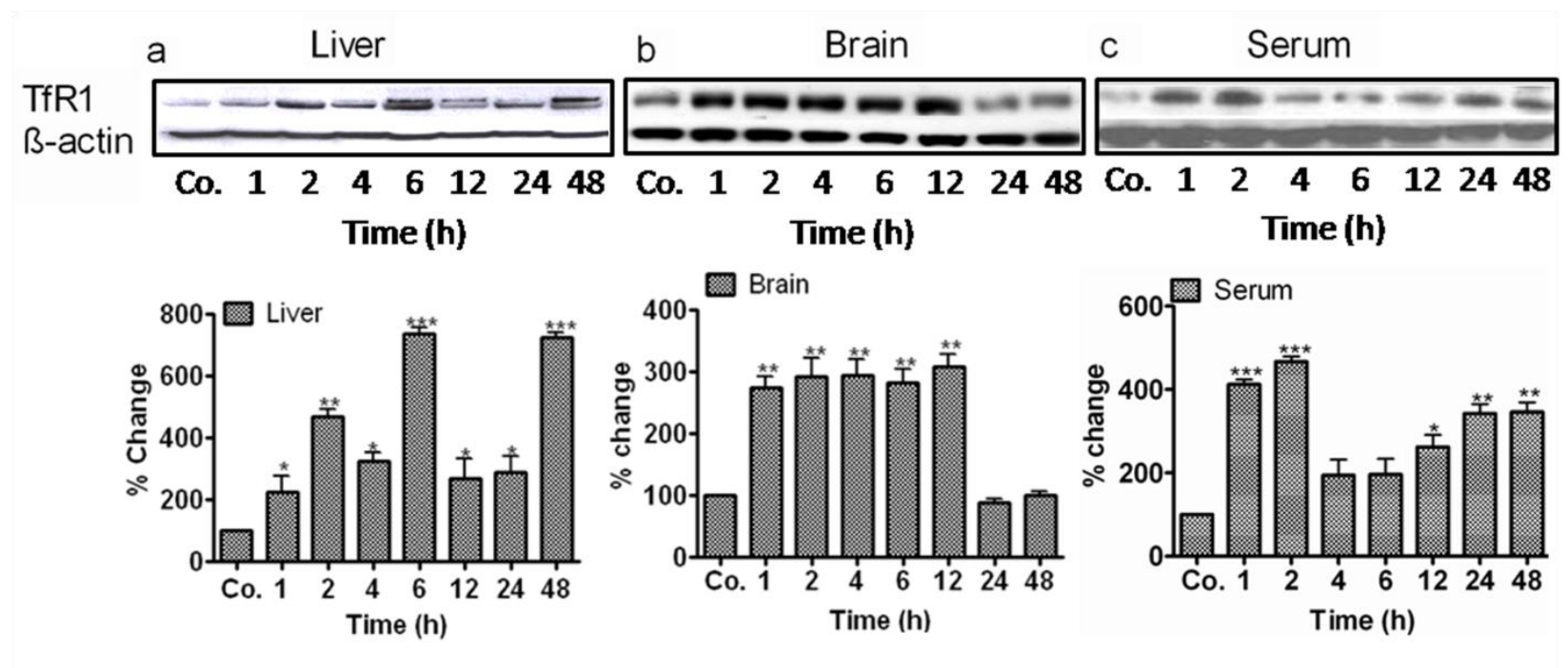

Figure 19: Identification and comparison of TfR1 protein in rat liver, brain and serum at different time points during acute phase response. Western blot analysis of TfR1 (95-kDa) from total protein lysates $(50 \mu \mathrm{g})$ of rat liver, brain and serum. $\beta$-actin $(43 \mathrm{kDa})$ was used as equal loading control. Densitometry analysis of western blots was also performed to show the changes in the protein expression of TfR1. Results represent mean value \pm S.E.M. $(* * * P<0.0001$ analyzed by one way ANOVA; n=3). Published: (Malik et al. 2011)

\subsection{Immunohistochemical identification of iron transport proteins in rat liver, brain and spleen during APR}

\section{9a Immunohistochemical detection of TfR1 protein localization in rat liver, brain and spleen}

In addition to quantification of TfR1 protein in rat liver and brain, the localization of TfR1 protein in rat liver, brain and spleen was investigated during acute phase response. By using same monoclonal antibody against TfR1, immune-reactivity of TfR1 was detected by indirect immunofluorescent staining in liver, brain and spleen of control and TO-administrated rat. In the liver tissue, a strong membranous expression of TfR 1 protein was observed in control and TO-administrated rat. The TfR1 protein expression increased during APR (Figure 20a, b). Moreover, for the liver tissue, sequential section staining for TfR1 and ED-1 (macrophage 
marker) was performed to identify the cell type expressing TfR1 protein. The sequential sections staining revealed a strong membranous and cytoplasmic expression of TfR 1 in hepatocytes and in sinusoidal cells (Figure 20c, d).
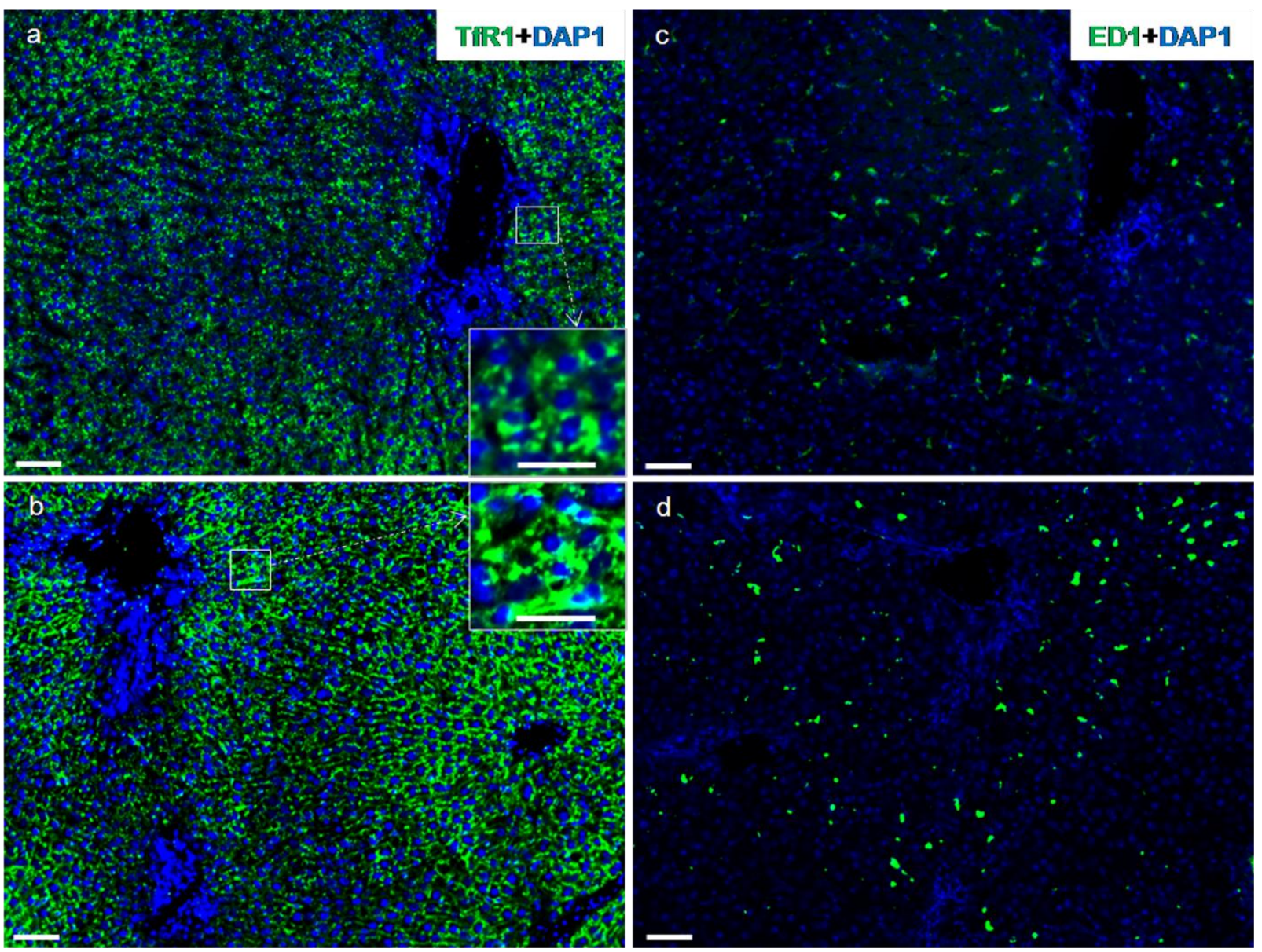

Figure 20: Immunofluorescence detection of TfR1 and ED-1 in the rat liver. TfR1 and ED-1 positive cells in sequential sections of rat liver tissue at different time points during acute phase response. Right panel: ED-1+DAPI, the left panel TfR1+ DAPI. a) and c) are control rat liver b) and d) 6 hours after TO administration. Insets show the higher magnification of TfR1 positive cells in the liver tissue. Results are representative of 3 animals (original magnification x100, scale bar $100 \mu \mathrm{m})$.

Likewise, TfR1 protein localization was investigated in rat brain by means of indirect immunofloresence staining. Interestingly in the brain, by using the same monoclonal antibody, 
the immunodetection of TfR1 protein, revealed nuclear expression in brain tissue. The TfR1protein expression was more intense in the brain tissue during acute phase response(Figure 21a-d). Furthermore, TfR1 immunoexpression was detected in rat spleen. As was observed for liver tissue, immunodetection of TfR1 in spleen tissue sections revealed the membrane positivity of TfR1 protein in white and red pulp cell population. TfR1 expression was more intense in membranes of cells in marginal zone and of red pulp area (Figure 22a-d).
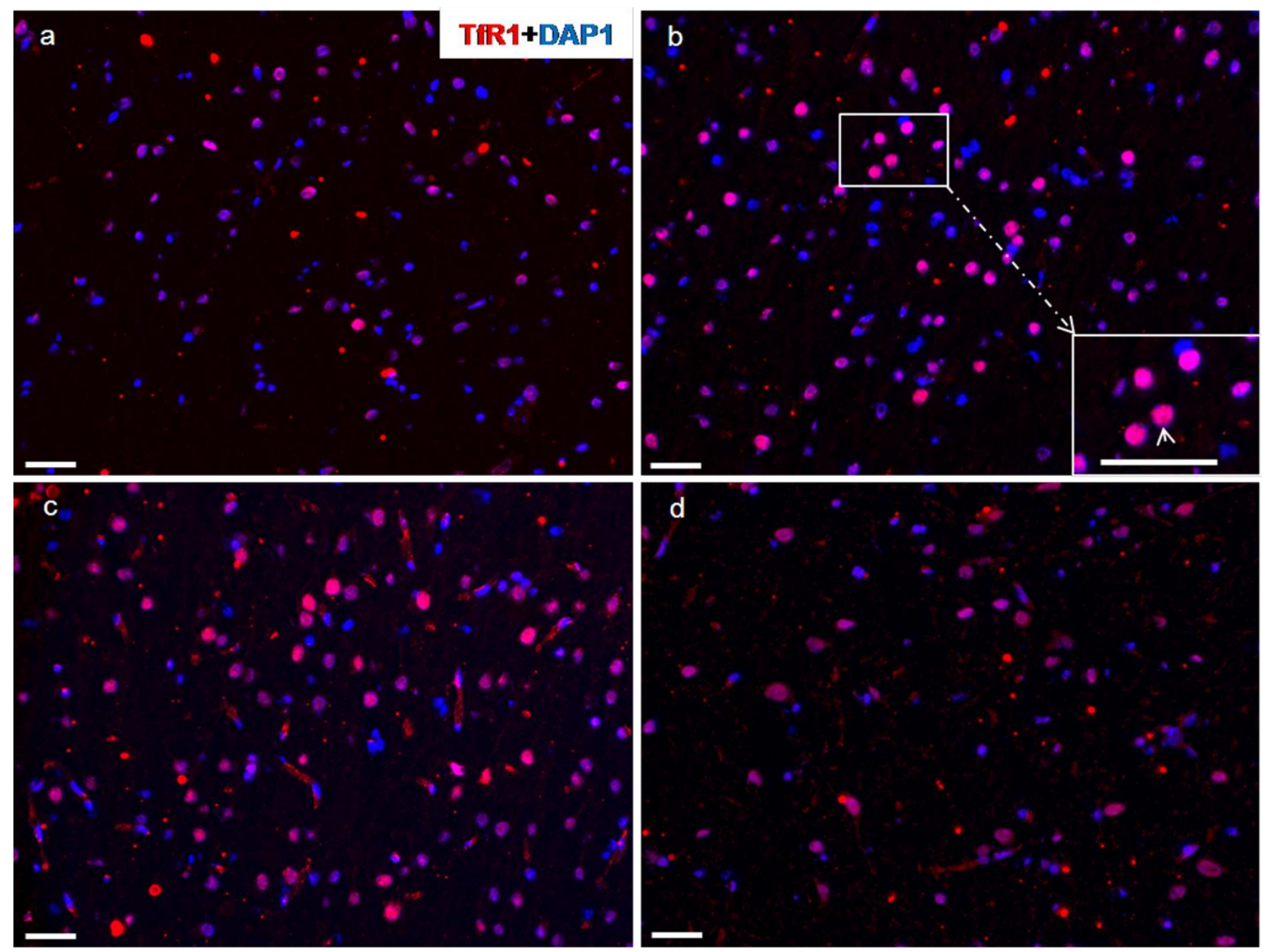

Figure 21: Microscopic demonstration of immunofluorescence detection of TfR1 on cryostat sections of rat brain. TfR1 positive cells in rat brain during acute phase response. a) TfR1 immunoexpression in control brain (b) 4 hours, white arrow in insets, lower right indicates the TfR1-positive cells in the brain (c) 6 hours and (d) 24 hours after TO treatment. Results are 


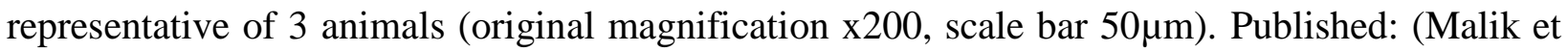
al. 2011)
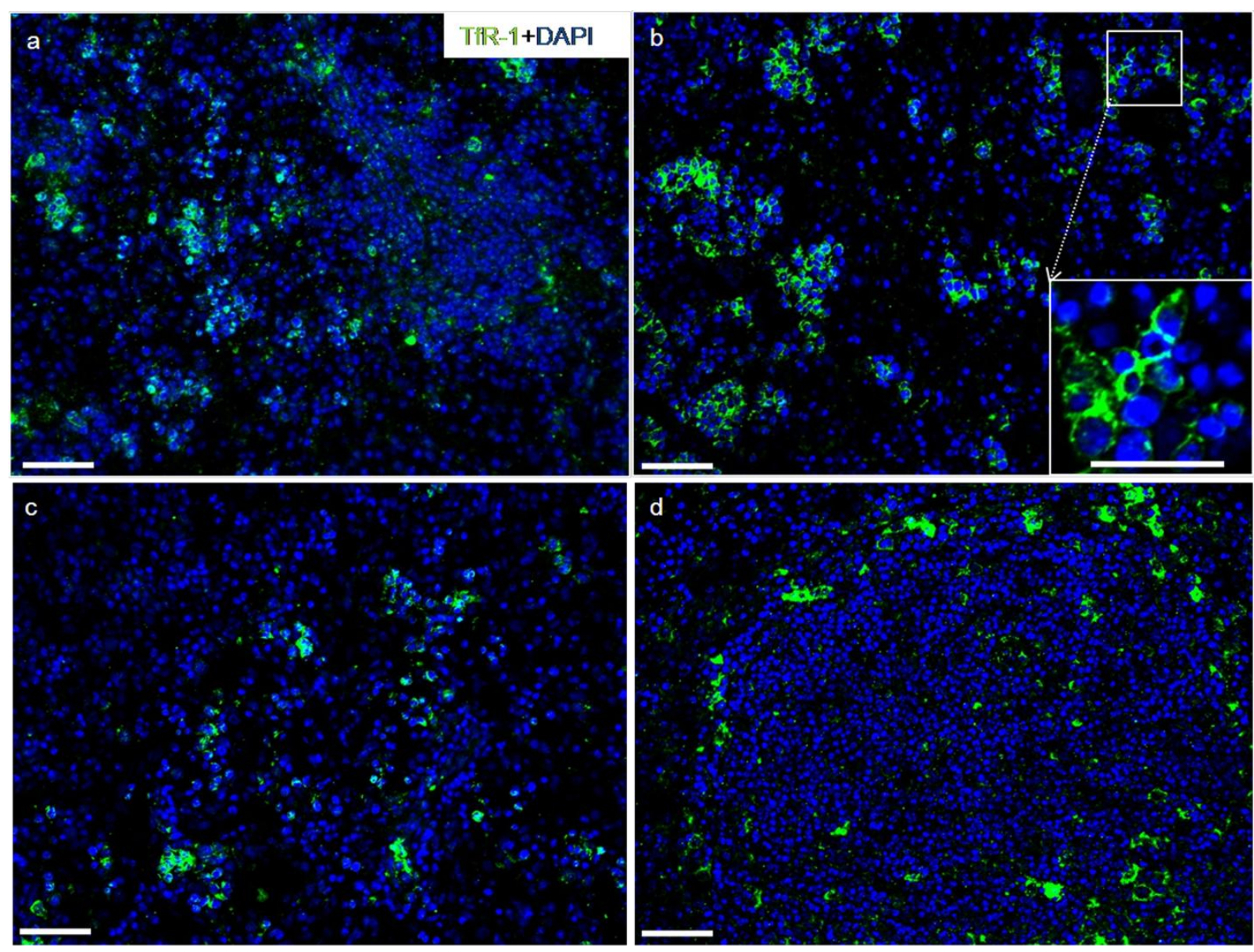

Figure 22: Microscopic demonstration of immunofluorescence detection of TfR1 on cryostat sections of rat spleen. TfR1 positive cells in rat spleen during acute phase response. a) TfR1 immunoexpression in spleen of control rats (b) 6 hours, the inset demonstrates the higher magnification (c) 12 hours and (d) 24 hours white pulp area in spleen. Results are representative of 3 animals (original magnification x200, scale bar $100 \mu \mathrm{m}$ ).

\section{$4.9 b$ Detection of TfR1 localization in liver cells (confirmation of TfR1 membranous expression in liver)}

In addition to the immunohistochemical analysis of liver tissue, the membrane localization of TfR1 was confirmed by immunocytology using isolated liver cells and cell lines. Liver cells were isolated from control rats, cultured and immunocytology was performed as 
described in materials and methods section. The immunocytology of liver cells confirmed the immunohistological observations in the rat liver tissue sections. TfR1 was observed in the membrane and cytoplasm of primary cultured rat hepatocytes (Figure 23a) and Kupffer cells (Figure 23b) as well as in HepG2 cells (human hepatoma cell line) (Figure 23c).

By using the same monoclonal antibody against TfR1 for western blot analysis positivity of TfR1 (molecular weight=95kDa) in isolated liver cells lysate was demonstrateable (Figure 24a). The protein intensity of TfR1 was the strongest in the Kupffer cells followed by hepatocytes. Liver-myofibroblasts (LMF) and hepatic stellate cells (HSC) cells showed the weakest detection at protein concentration. In human hepatoma cell line (HepG2), only membrane and cytoplasmic detection of TfR1 was observed (Figure 24b).
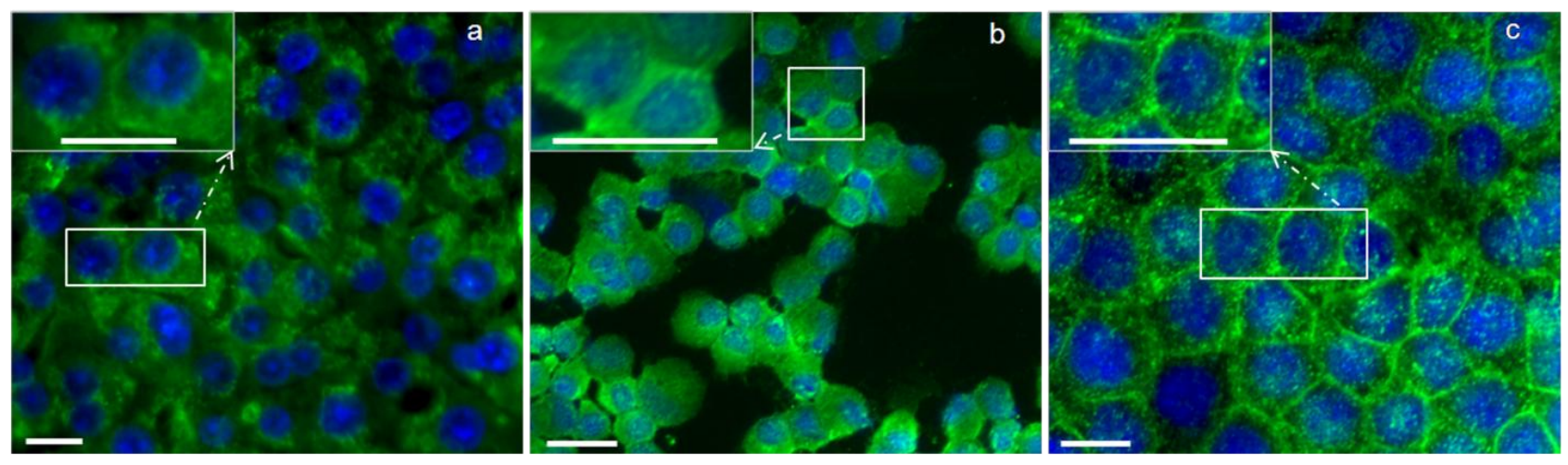

Figure 23: Microscopic demonstration of immunofluorescence detection of TfR1 in isolated rat (a) hepatocytes, (b) Kupffer cells and (c) human hepatoma cell line (HepG2). Results are representative of three experiments for each cell type (original magnification $\mathrm{x} 400$, scale bar 20 $\mu$ m). Published: (Malik et al. 2011). 
a Rat liver isolated cells

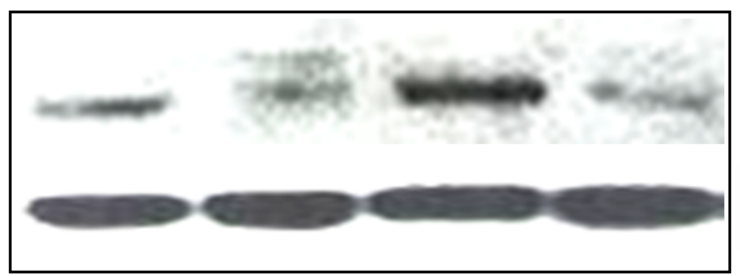

Hep. LMF Kup. HSC
Hep $=$ Hepatocytes

TfR1 LMF= Liver

(myo)fibroblasts

Kup.= Kupffer cells

ß-actin

$\mathrm{HSC}=$ Hepatic

stellate cells

b Hep G2-cells

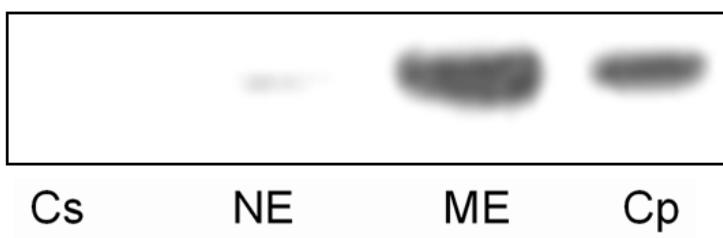

$\mathrm{Cs}=$ Cytosolic extract

$\mathrm{NE}=$ Nuclear extract

$\mathrm{ME}=$ Membrane extract

$\mathrm{Cp}=$ Cytoplasmic extract

Figure 24: (a) Western blot analysis of TfR1 ( $95 \mathrm{kDa}$ ) in rat liver isolated cells using $\beta$-actin (43 $\mathrm{kDa}$ ) as loading control. (b) Western blot analysis of TfR1 in protein $(50 \mu \mathrm{g})$ extracted from different fractions of hepatoma cell line (Hep G2). Results represent one of three experiments. Published: (Malik et al. 2011).

\section{9c Immunohistochemical detection of TfR1 expression in brain cell lines (confirmation of TfRInuclear expression)}

Similarly, rat neuronal and glioblastoma cell lines were used to confirm immunohistochemical detection of nuclear expression of TfR1. In contrast to liver cells and in agreement with the immunohistochemistry findings for the brain tissue, the same monoclonal antibody showed strong nuclear positivity in brain neural stem cells; however a weak cytoplasmic and membranous expression was also detected (Figure 25a). A human glioblastoma cell line (U373MG) also showed a strong nuclear positivity for TfR1 (Figure 25b). 

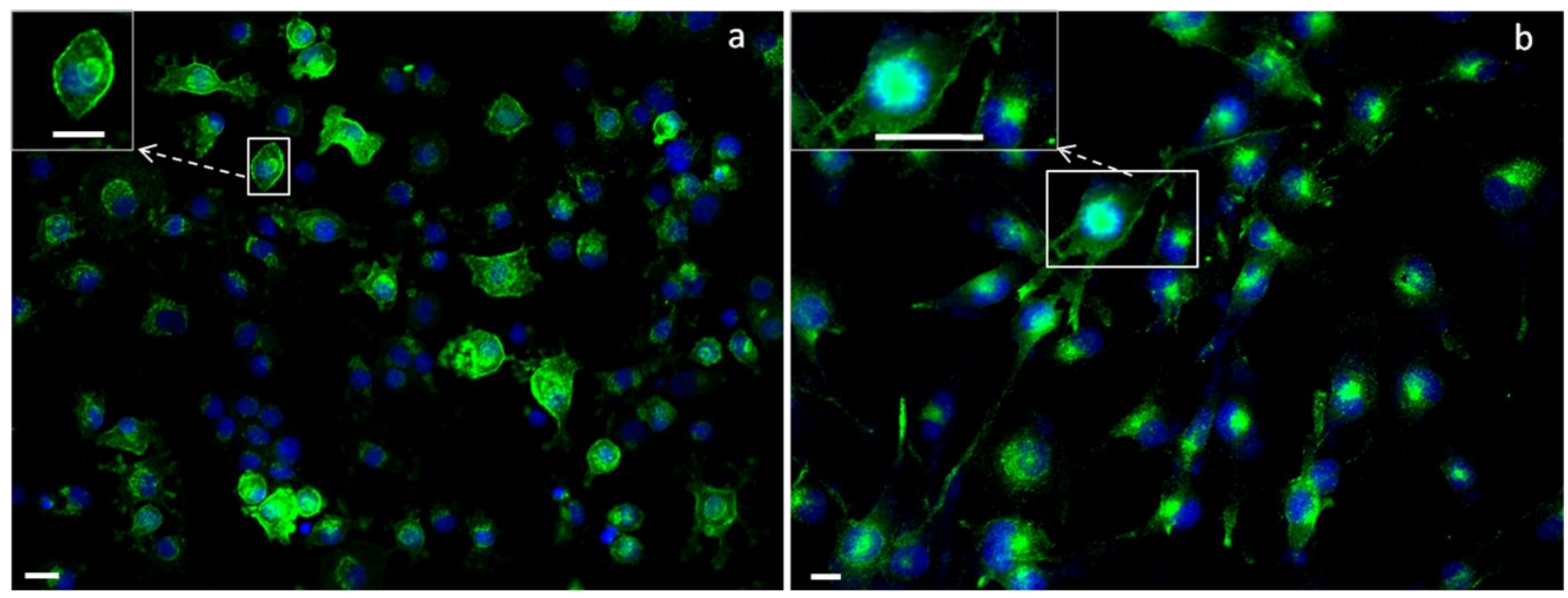

Figure 25: Microscopic demonstration of immunofluorescence detection of TfR1 in (a) rat neural stem cells (NSC) and (b) human glioblastoma cell line (U373MG). Results are representative of three experiments for each cell type (original magnification x200, scale bar

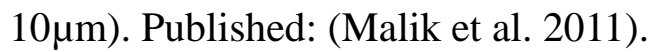

\section{9d Immunohistochemical detection of TfR2 localization in rat liver, brain and spleen}

Indirect immunofloresence staining was performed to detect the protein localization of TfR2 in rat liver, brain and spleen. Surprisingly, in the control and TO-administrated rat liver tissue, a strong nuclear expression of TfR2 protein was observed in control and TOadministrated rat liver tissue. TfR2 protein was expressed in the large nuclei of hepatocytes (distinguished on visual morphology). Moreover, it was also expressed in the small nuclei of sinusoidal area (expected to be liver macrophages). To identify this cell type, double immunofloresence staining for TfR2 and ED-1 (macrophage marker) was performed to identify the cell type expressing TfR2 protein. The double immunofloresence staining revealed coexpression of TfR2 in liver macrophages (Figure 26).

Similarly, TfR2 protein localization was investigated in rat brain. As observed for the liver, TfR2 was detected in the nuclei of brain tissue. The TfR2 protein was expressed in dot forms in the nuclei of brain tissue. Furthermore, TfR2 immunoexpression was detected in rat 
spleen. As was observed in the liver, and brain tissue, immunodetection of TfR2 in spleen revealed the nuclear expression of TfR 2 protein in white and red pulp cell population. However, TfR2 protein expression was more intense in nuclei of white pulp area (Figure 26).

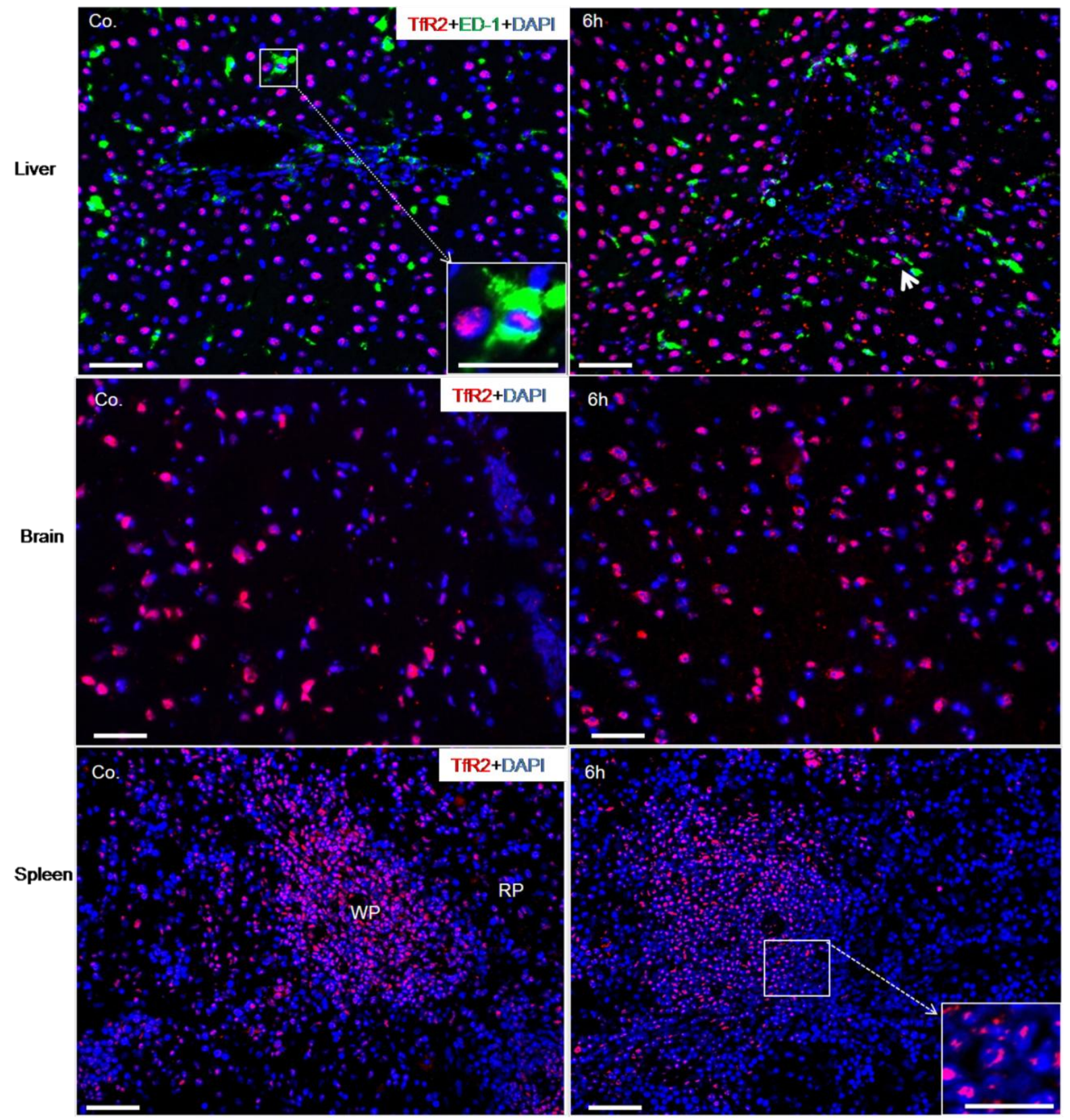

Figure 26: Microscopic demonstration of immunofluorescence detection of TfR2 on cryostat sections of rat liver, brain and spleen. The upper most panel: Double immunofloresence staining of TfR2 (red) and ED-1(green) in rat liver. The white arrow and insets indicate the co-expression 
of both proteins. The middle panel: immunofloresence detection of TfR2 in rat brain. The lower panel: immunolocalization of TfR2 in rat spleen. The inset indicates the higher magnification. Co (control), WP (white pulp), RP (red pulp). Results are representative of 3 animals (original magnification x200, scale bar $100 \mu \mathrm{m})$.

\section{9e Immunofloresence detection of DMT-1 localization in rat liver, brain and spleen}

Indirect immunofloresence staining was performed to detect the protein localization of DMT-1 in rat liver, brain and spleen. Likewise TfR2, DMT-1 was also detected in the nuclei of liver, brain and spleen tissue. In the liver tissue, a strong nuclear expression of DMT-1 protein was observed in control and TO-injected rat liver tissue. DMT-1 protein expression was more intense in TO-injected rat liver tissue. It was organized in well-defined spots in hepatocytes (distinguished on the basis of visual morphology) and the intensity of these dots increased during APR. Moreover, it was also expressed in the small nuclei of sinusoidal area (expected liver macrophages). To identify this cell type, double immunofloresence staining for DMT-1 and ED1 (macrophage marker) was performed to identify the cell type expressing DMT-1 protein. The double immunofloresence staining revealed co-expression of DMT-1 in liver macrophages (Figure 27). Similarly, DMT-1 was detected in the nuclei of brain tissue. It was detected in large and small nuclei of the brain cells where some cells have a more intense expression of DMT-1 than others. In the brain tissue, the immunoexpression of DMT-1 was reduced during APR. Likewise, in spleen, DMT-1 was localized in the nuclei of red pulp and white pulp area with a more intense expression in the nuclei of white pulp area. During APR, the immunoexpression of DMT-1 in spleen was also reduced (Figure 27). 


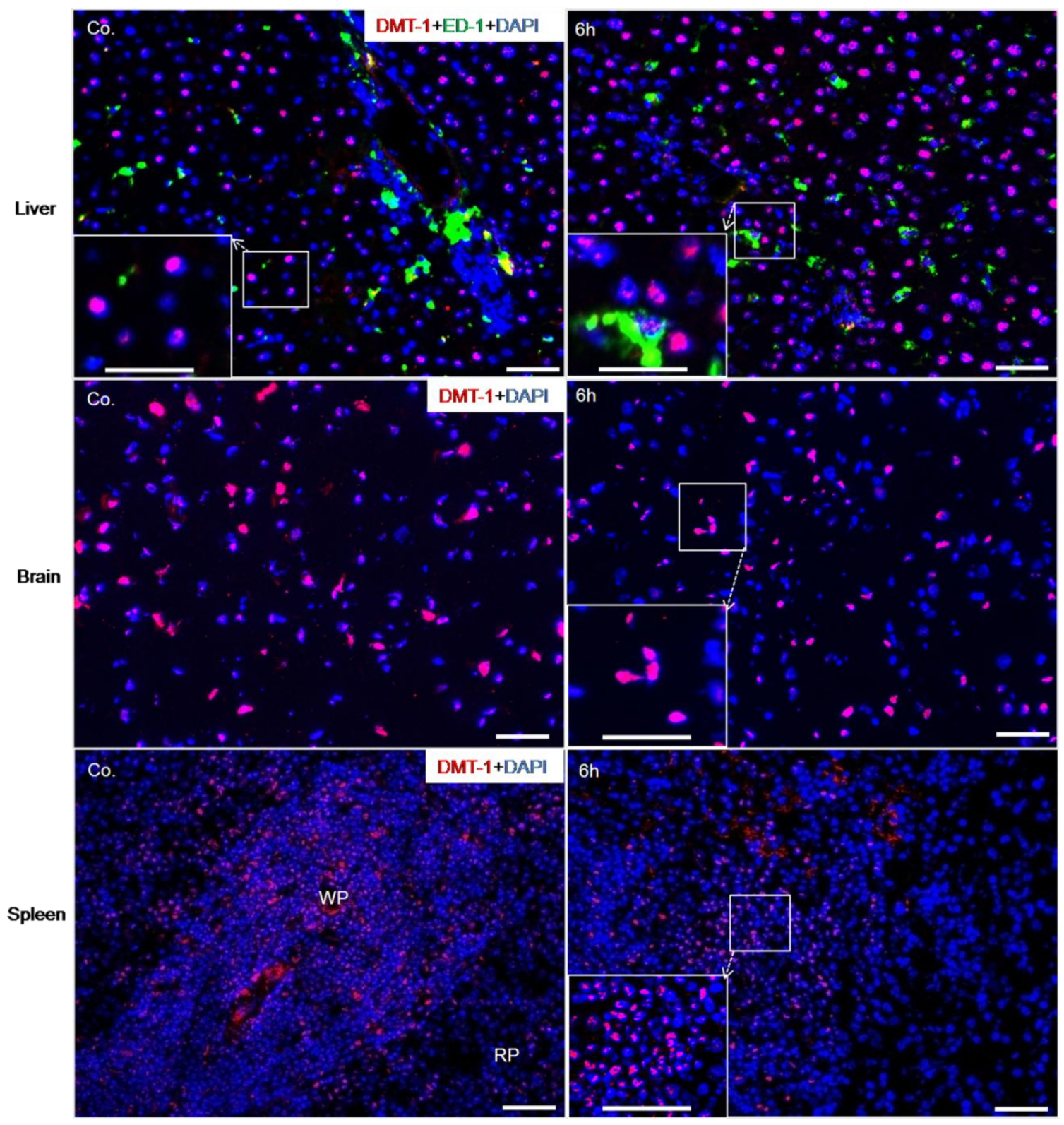

Figure 27: Microscopic demonstration of immunofluorescence detection of DMT-1 on cryostat sections of rat liver, brain and spleen. The upper most panel: Double immunofloresence staining of DMT-1 (red) and ED-1(green) in rat liver. DMT-1 is localized in the nuclei of liver hepatocytes and Kupffer cells. The middle panel: Immunofloresence detection of DMT-1 in rat brain indicates nuclear localization of DMT-1. The lower panel: immunolocalization of DMT-1 in control rat spleen and at $6 \mathrm{~h}$ of acute phase response. DMT-1 is more intense in the cell population of white pulp area. Insets indicate the higher magnification. Co (control), WP (white pulp), RP (red pulp). Results are representative of 3 animals (original magnification x200, scale bar $100 \mu \mathrm{m})$. 


\section{9f Detection of Fpn-1 protein localization in rat liver, brain and spleen}

The immunohistochemical analysis of Fpn-1 protein revealed quite surprising results. Likewise TfR2 and DMT-1, Fpn-1 was detected in the nuclei of control and TO administrated rat liver and brain tissue. In liver Fpn-1 was organized in well-defined spots in hepatocytes (distinguished on the basis of visual morphology). Moreover, it was also expressed in the small nuclei of sinusoidal area (expected liver macrophages). To identify this cell type, double immunofloresence staining for Fpn-1 and ED-1 (macrophage marker) was performed to identify the cell type expressing Fpn-1 protein. The double immunofloresence staining revealed coexpression of Fpn-1 in liver macrophages (Figure 28). The immunoexpression of Fpn-1 protein decreased during acute phase response. Similarly, Fpn-1 protein was located in the nuclei of brain tissue. The Fpn-1 protein was expressed in dot forms in large and small nuclei of brain tissue. Furthermore, Fpn-1 immunoexpression was detected in rat spleen. Contrary to what was observed for rat liver and brain, immunodetection of Fpn-1 revealed a strong membrane expression in spleen tissue. Fpn-1 protein was expressed in the cell membrane of white and red pulp cell population (Figure 28). The nuclear localization of Fpn-1 in rat liver and brain was confirmed by using two different antibodies. Similar pattern of expression was observed using both antibodies. The one Rabbit-anti-Fpn-1 corresponding to N-terminus (abnova Heidelberg, Germany) having $100 \%$ identity with rat Fpn-1 protein sequence, and the other is rabbit anti-Fp1 having 95\% with rat Fpn-1 protein sequence. 


\section{Results}

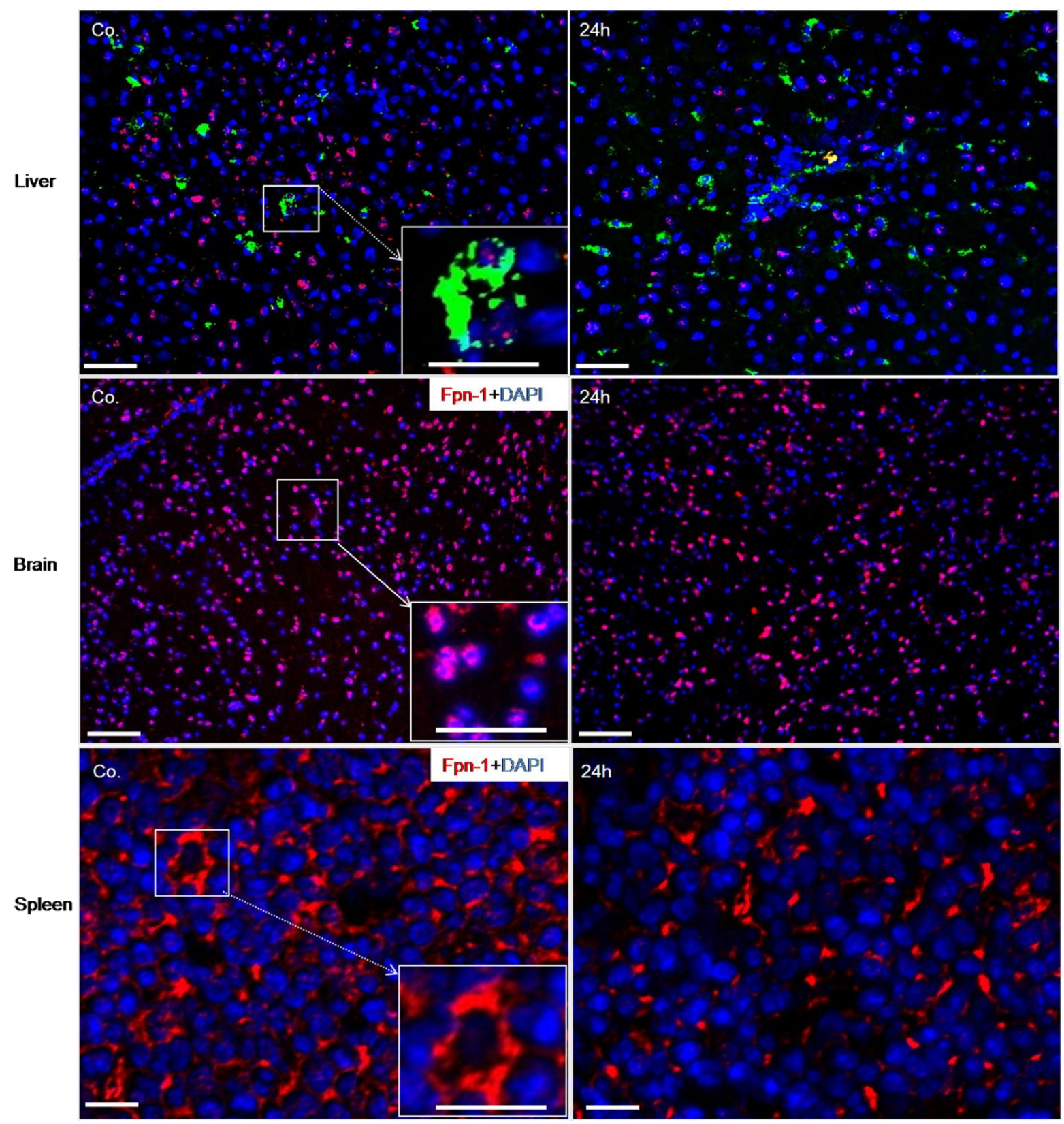

Figure 28: Microscopic demonstration of immunofluorescence detection of Fpn-1 on cryostat sections of rat liver, brain and spleen. The upper most panel: Double immunofloresence staining of Fpn-1 (red) and ED-1(green) in rat liver (original magnification x200, scale bar $100 \mu \mathrm{m}$ ). The middle panel: Immunofloresence detection of Fpn-1 in rat brain (Original magnification x100, scale bar $200 \mu \mathrm{m})$. The lower panel: immunolocalization of Fpn-1 in control rat spleen and at $24 \mathrm{~h}$ of acute phase response (original magnification $\mathrm{x} 400$, scale bar $50 \mu \mathrm{m}$ ). Co (control, WP (white pulp), RP (red pulp). The insets indicate the higher magnification. Results are representative of 3 animals. 


\section{9g Blocking of Fpn-1, DMT-1 and TfR2 immunoexpression using blocking peptide}

The immunoexpression of Fpn-1, DMT-1 and TfR2 was blocked using the antiserum provided by the manufacturer against specific antibody. The blocking of primary antibody was carried in parallel with the immunostaining (in presence of primary antibody) used as positive controls. In the blocking experiment the sections get the mixture of primary antibody and the antiserum. Negative controls were performed with the omission of primary antibody. Antigen development with Rhodamine conjugated secondary antibody blocked the nuclear expression of Fpn-1, DMT-1 and TfR2 confirming the specificity of respective antibody (Figure 29).

Moreover, the differential cellular localization of TfR1, TfR2, DMT-1 and Fpn-1 was further demonstrated by means of indirect immunostaining of respective antibody followed by antigen development using horse-reddish-peroxidase conjugated secondary antibody. Immunodetection of TfR 1 in rat liver, confirmed membrane positivity (brown colour) while the nuclei were clearly blue (stained with hematoxylin). In contrast, TfR2, DMT-1 and Fpn-1 were located in the nuclei of liver tissue giving the nucleus a dark brown colour (Figure 30).

\section{9g Immunohistochemical detection of iron transport proteins in isolated rat liver cells}

The nuclear localization of iron transport proteins was further confirmed in isolated control rat liver cells. Hepatocytes and Kupffer cells of control rats were cultured and immunocytology was performed as was done for TfR1. In agreement to the immunohistochemical identification for liver tissue, immunocytology of liver cells demonstrated the nuclear expression of TfR2, DMT-1 and Fpn-1 in the nuclei of rat hepatocytes and kupffer cells (Figure 31). 


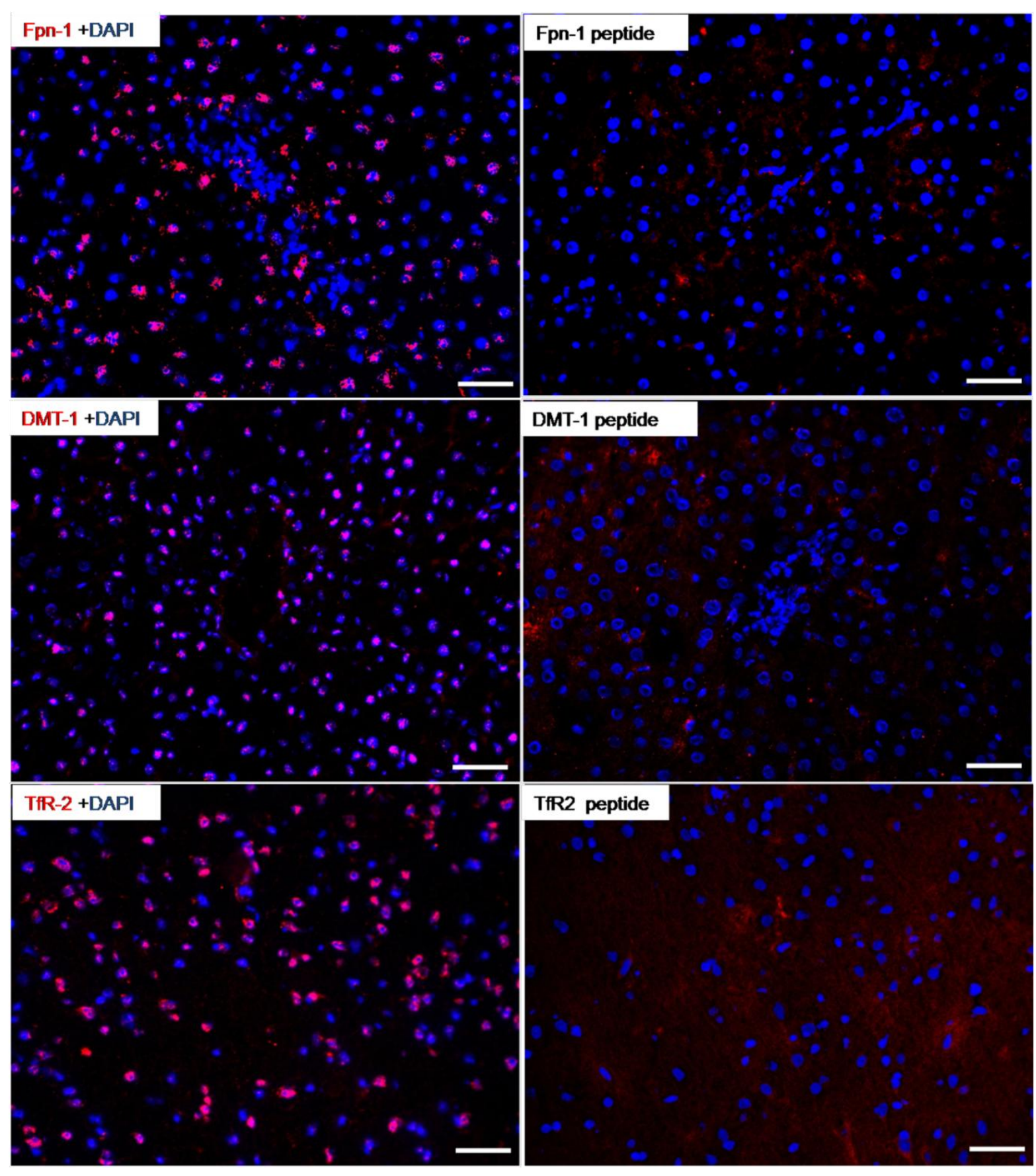

Figure 29: Microscopic demonstration of blocking of immunohistochemical expression of Fpn1, DMT-1 and TfR2 protein. The immunoreactivity of primary antibodies was blocked using antisera against specific antibody provided by the manufacturer. The experiment was performed parallel in the presence of antibody alone and with the mixture of antibody and blocking peptide (antisera). The antigens were visualized using rhodamine conjugated secondary antibody. Results are representative of 3 animals (original magnification x200, scale bar $100 \mu \mathrm{m}$ ). 


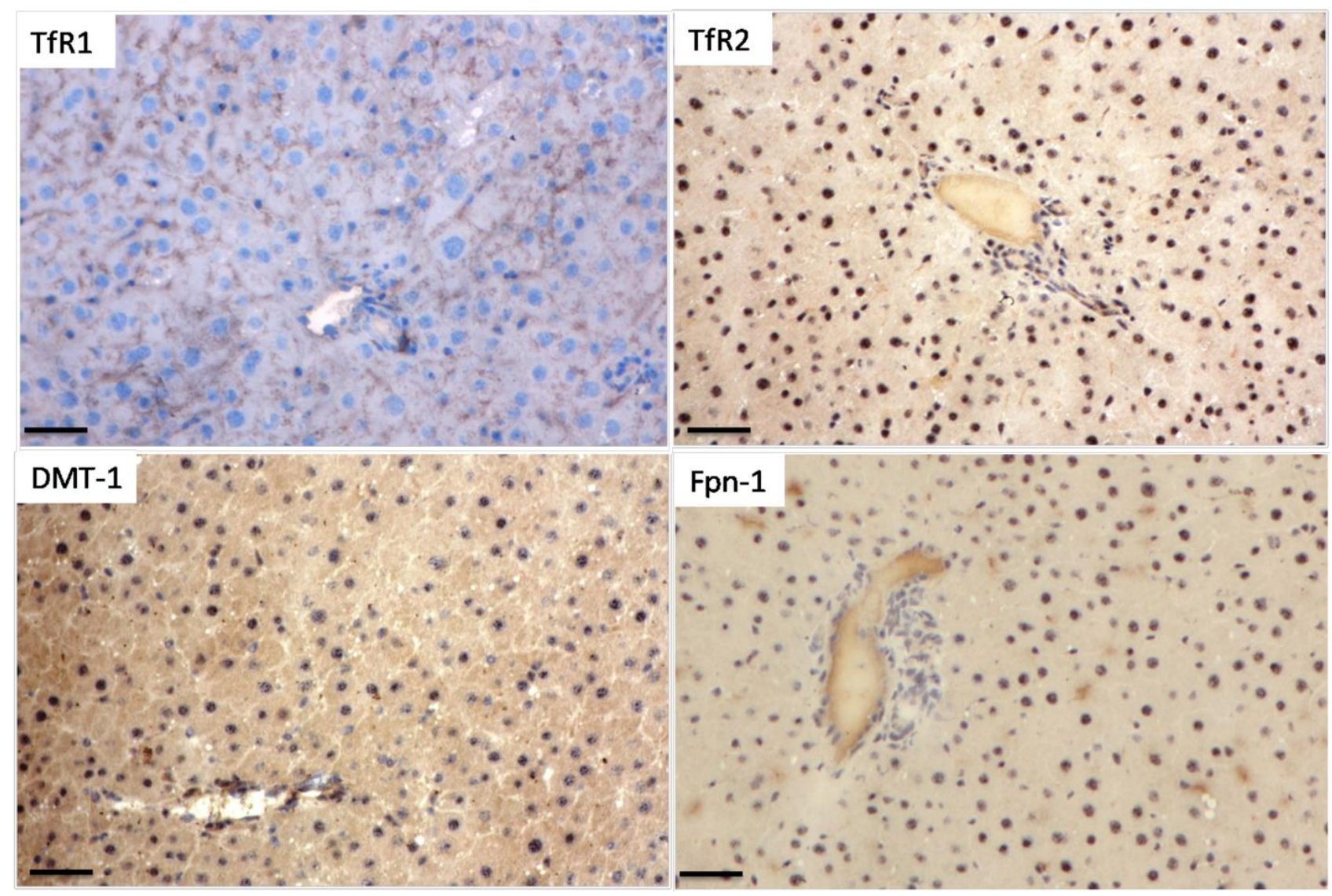

Figure 30: Microscopic demonstration of immunodetection of TfR1, TfR2, DMT-1, and Fpn-1 on cryostat sections of rat liver. Indirect immunostaining was performed using peroxidase conjugated secondary antibodies. The antigens were developed with a horse-reddish- peroxidase conjugated secondary antibody with a counterstaining of nuclei by hematoxylin. Results are representative of 3 animals (original magnification x200, scale bar $100 \mu \mathrm{m}$ ).

\section{9h Detection of iron transport proteins in isolated liver cells and tissue fraction by means of western blot analysis}

The results of immunohistochemical analysis and immucytology from liver were further confirmed by means of Western blot analysis of isolated protein fractions from liver tissues and total proteins harvested from cultured liver cells (hepatocytes, Kupffer cells and myofibroblasts). Western blot analysis confirmed the nuclear expression of Fpn-1, DMT-1 and TfR2 in the 
protein fractions of control liver. However, a very weak expression was also observed in the cytoplasmic extract (Figure 32a) whereas; Tf and TfR1 protein was detected only in the membrane and cytoplasmic fractions of control liver tissue. Among major liver cell types (hepatocytes, Kupffer cells and myofibroblasts), with a difference of expressional intensity Fpn1, DMT-1, Tf, TfR1 and TfR2 protein was expressed in isolated rat hepatocytes and kupffer cells but not in myofibroblasts (Figure 32b).

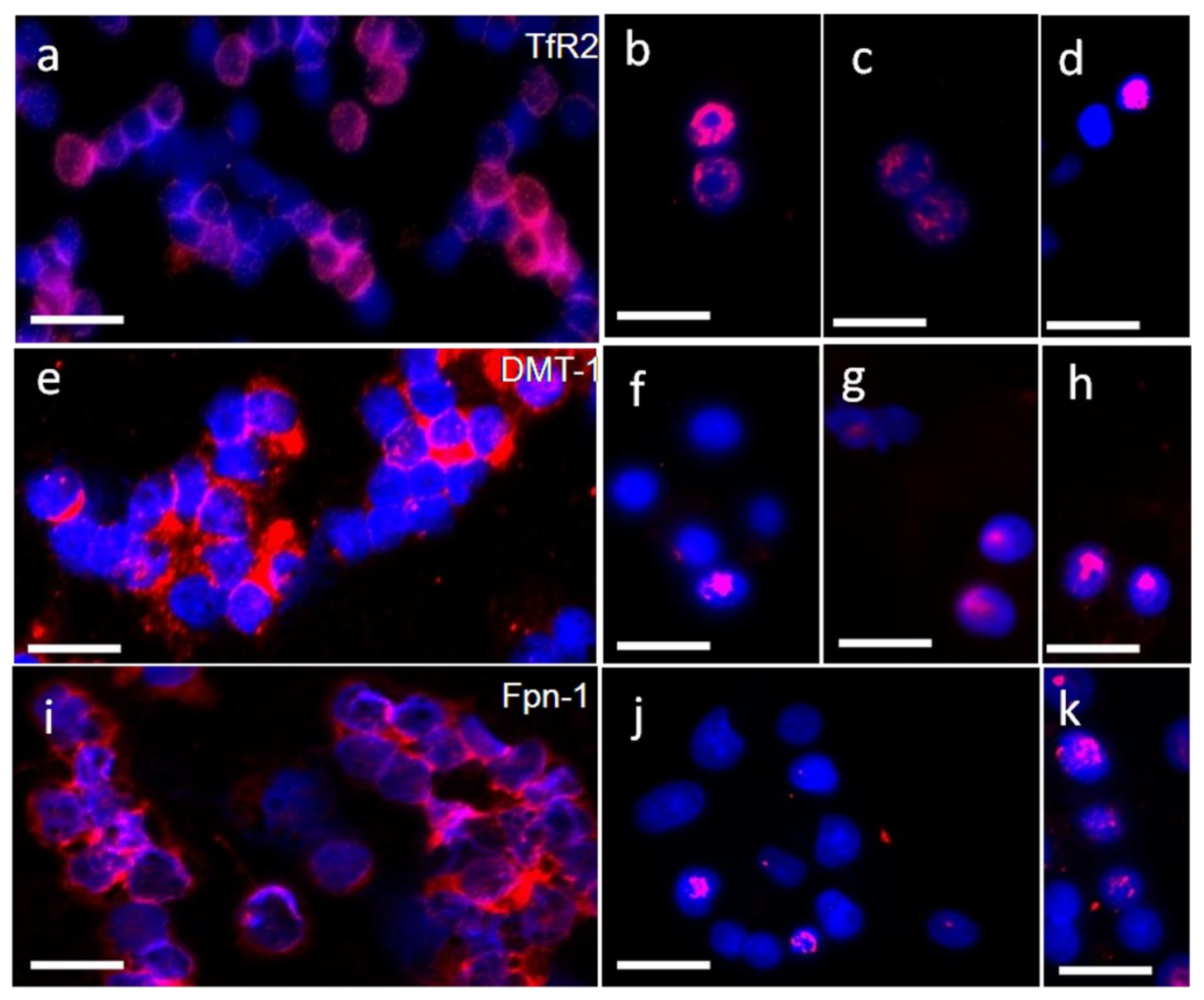

Figure 31: Microscopic demonstration of immunohistochemical detection of TfR2, DMT-1, and Fpn-1 in cultured rat liver cells. Rat hepatocytes and Kupffer cells isolated and cultured under normal conditions and immunocytology was performed as described in methods. The left panel; detection of TfR2 (a), DMT-1 (e) and Fpn-1 (i) in isolated rat Kupffer cells. The right panel; detection of TfR2 (b-d), DMT-1 (f-h) and Fpn-1 (j,k) in isolated hepatocytes. The small insets in 
right panel are taken from different areas of cultured cells in lab-tecs. Results are representative of 3 experiments (original magnification $\mathrm{x} 400$, scale bar $50 \mu \mathrm{m}$ ).

\subsection{Changes in mRNA expression of ribonuclease reductase (RNR) and Cyclin $E$ in rat liver during acute phase response}

Ribonucleotide reductase (RNR) is an iron dependent (Hogbom et al. 2001), cytoplasmic enzyme that catalyzes the formation of deoxyribonucleotides from ribonucleotides (Elledge et al. 1992). Deoxyribonucleotides in turn are used in the synthesis of DNA during $S$ phase of the cell cycle (Herrick and Sclavi 2007). Cyclin E, a member of cyclins super-family, is commonly known as an S-phase cyclin play a key role during DNA replication complex assembly and activation (Coverley et al. 2002).

To justify the increased iron demand by liver cells and nuclei, the expression pattern of ribonucleotide reductase and Cyclin E was analyzed by RT-PCR. The mRNA expression of RNR gene was significantly upregulated $(\mathrm{P} \leq 0.0001)$ during APR. This increase was at its maximum ( $25 \pm 6$ fold) by $36 \mathrm{~h}$. Similarly, the mRNA expression of nuclear enzyme; Cyclin E was significantly upregulated $(\mathrm{P} \leq 0.0001)$ during the study with a maximum expression by

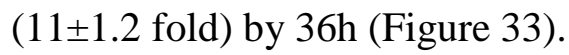

\subsection{Changes in cyclin $\mathbf{E}$ protein expression in rat liver during acute phase response}

The changes observed in cyclin E mRNA expression pattern were further confirmed by means of immunohistology and Western blot analysis of rat liver. Indirect immunofloresence staining was performed to detect cyclin E protein expression. Cyclin E was detected in the nuclei of liver cells. Compared to controls, there was an increase in Cyclin E protein expression during 
acute phase response. Western blot analysis of total liver protein indicated a gradual increase in cyclin E protein amount with a maximum at 36h of APR (Figure 34).
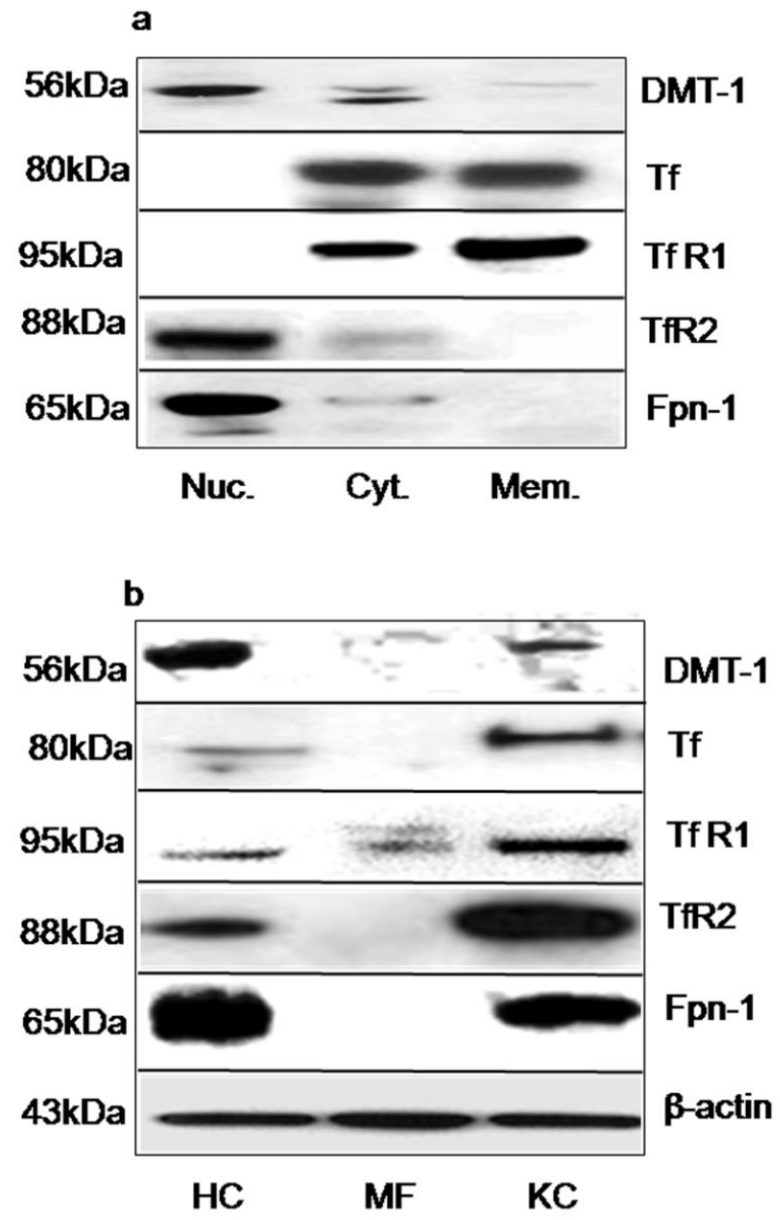

Figure 32: Western blot analysis of DMT-1,Tf, TfR1, TfR2 and Fpn-1. a) Expression of iron transport proteins in control liver tissue fractions $(50 \mu \mathrm{g})$. (Nuc.: nuclear extract, Cyto.: cytoplasmic extract, Memb.: membrane extract). b) Comparative expression of iron transport proteins in major cell population of rat liver in (HC: hepatocytes, MF: Myofibroblasts, KC: Kupffer cells). $\beta$-actin was used as a loading control. Result demonstrates the representative figure of three experiments. 

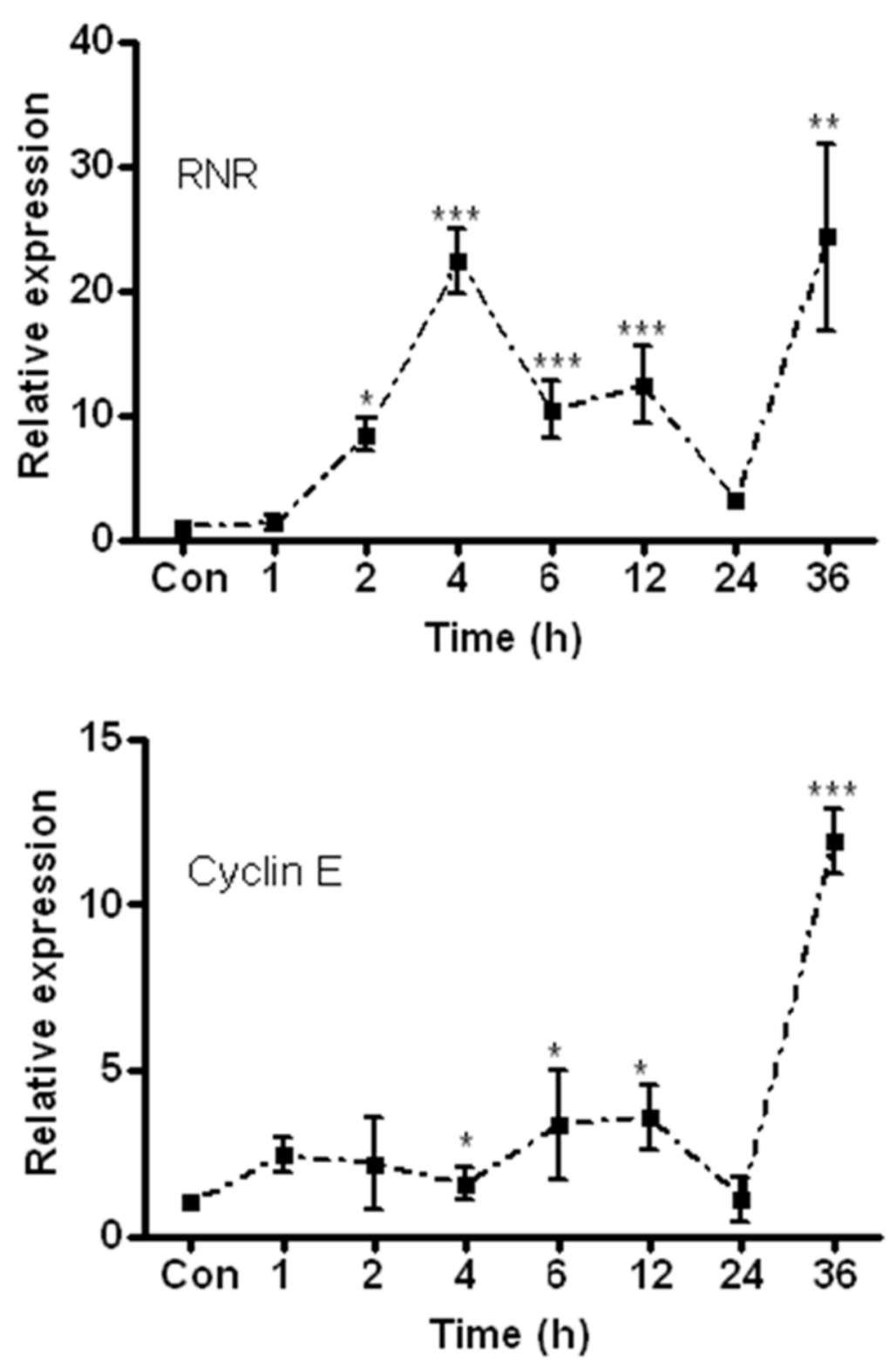

Figure 33: RT-PCR analysis of total RNA from rat liver tissue to demonstrate the changes of RNR and cyclin E mRNA amount. Changes of RNR and cyclin E transcript amount in the liver tissue during acute-phase reaction. Fold change in mRNA expression was normalized with UBC as housekeeping gene at different time points after intramuscular TO administration as revealed by real-time PCR. The data shows fold changes in comparison to controls where control values are normalized to one. Results represent mean value \pm S.E.M. $\left(* \mathrm{P}<0.05,{ }^{*} * P<0.001\right.$, $* * * \mathrm{P}<0.001$ analyzed by one way ANOVA; $\mathrm{n}=3$ ). 

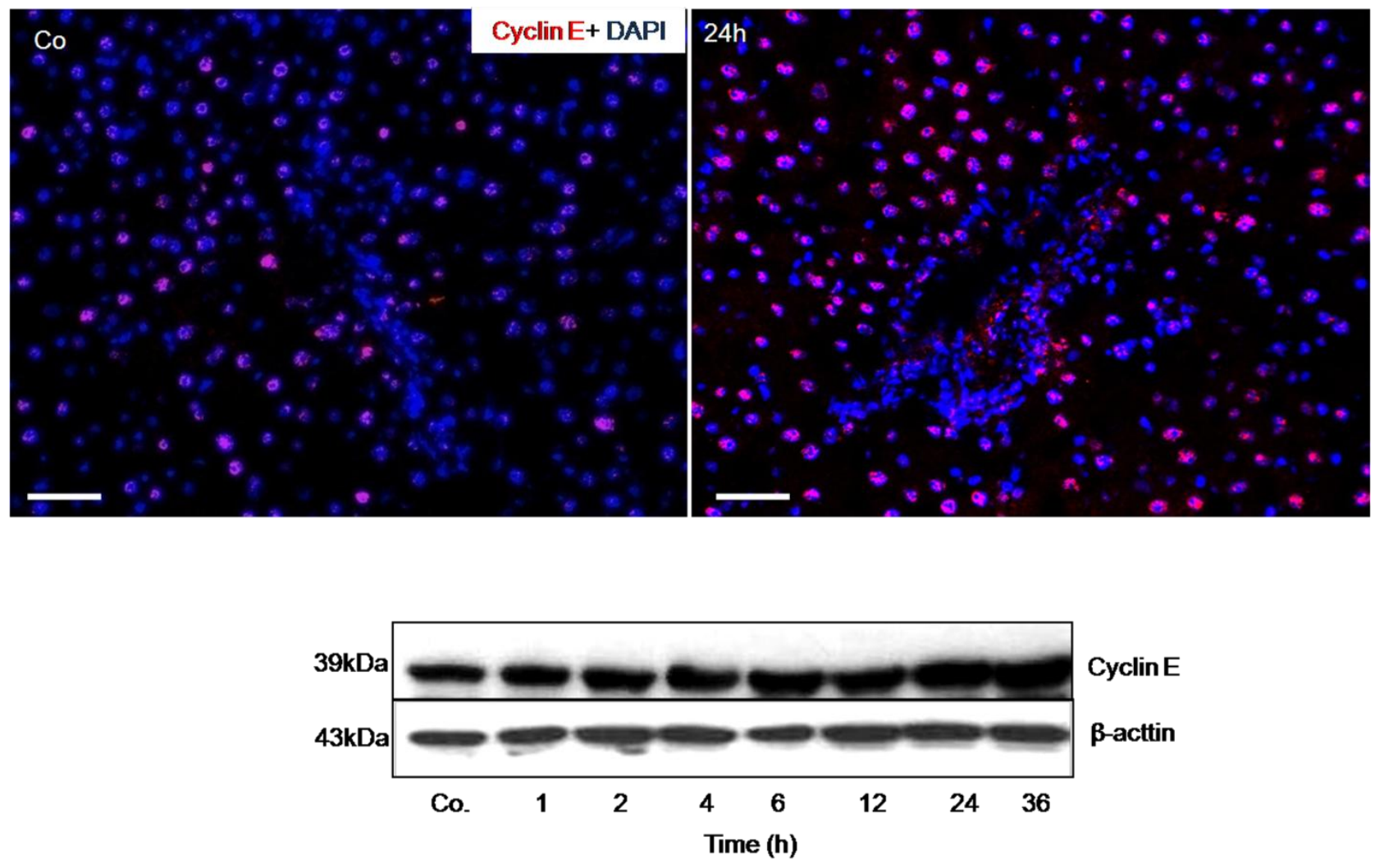

Figure 34: Changes in the protein expression of cyclin $\mathrm{E}$ in rat liver during acute phase response. Upper panel; microscopic demonstration of indirect immunofloresence of cyclin $\mathrm{E}$ in control (Co.) and TO-injected rat liver at $24 \mathrm{~h}$ (original magnification x200, scale bar $100 \mu \mathrm{m}$ ). The lower panel; Western blot analysis of total protein lysates $(50 \mu \mathrm{g})$ from rat liver for cyclin E protein during APR. Results are representative of three experiments.

\subsection{2 mRNA Expression pattern of hepcidin Fpn-1, Fpn-1a and Fpn-1b in mice liver during}

\section{APR}

In rat liver and brain, the downregulation (1h) of Fpn-1 gene expression before hepcidin goes up (2h) indicated hepcidin independent regulation of Fpn-1 gene. Moreover, Fpn-1 protein was almost diminished by $24 \mathrm{~h}$ of APR. The possible hypothesis for these downregulation was an increased level of acute phase cytokines (mainly IL-6 in the model of study). To investigate and validate the role of major acute-phase cytokine (IL-6) in the hepatic Fpn-1 gene regulation, the 
mRNA expression of Fpn-1 and its isoforms together with hepcidin was analyzed in the livers of wild type and IL-6 knock-out mice at different time points after intramuscular TOadministration. RT-PCR demonstrated an upregulation of hepcidin gene expression in wild type and IL-6 knock-out mice. However, in wild type mice, the constitutive expression of hepcidin was higher ( $3.5 \pm 0.5$ fold) than in their IL-6 knockout counterparts ( $1.5 \pm 0.1$ fold) by $12 \mathrm{~h}$ of APR. Moreover, Fpn-1, Fpn-1a and Fpn-1b gene expression was also downregulated in wild type and IL-6 knock-out mice under acute phase conditions.

However, the decrease in mRNA amount of Fpn-1 and its isoforms was higher in wild type mice than their IL-6 knock-out counterparts. In wild type mice, this decrease was at its minimum for Fpn-1 ( $0.3 \pm 0.1$ fold) by $12 \mathrm{~h}$ and in IL-6 knock-out mice $(0.6 \pm 0.1$ fold) by $4 \mathrm{~h}$ of APR. Similarly, in wild type mice, Fpn-1a was decreased to its minimum ( $0.3 \pm 0.03$ fold $)$ by $6 \mathrm{~h}$ and in IL- 6 knock-out mice this decrease was $(0.7 \pm 0.04$ fold $)$ by $4 \mathrm{~h}$ of APR. However, the decrease of Fpn-1b mRNA expression in wild type mice was ( $0.5 \pm 0.1$ fold) by $6 \mathrm{~h}$ and in IL-6 knock-out mice it was decreased $(0.4 \pm 0.06$ fold) by 4 h of APR (Figure 35). The table 2 represents the comparison of fold changes in mRNA expression of Fpn-1, Fpn-1a and Fpn-1b in wild type and IL-6 knock-out mice during APR. The lower ther value the higher is the decrease (Table 2).

\subsection{Changes in protein expression of Fpn-1 in wild type and IL-6 knock-out mice during acute phase response}

Furthermore, Western blot analysis was performed to demonstrate the changes in Fpn-1 protein expression in wild type and IL-6 knock-out mice during acute phase response. The western blot analysis of total protein from wild type mice indicated a decrease of Fpn-1protein protein expression $2 \mathrm{~h}$ after APR which became almost undetectable by $24 \mathrm{~h}$ (as observed for rat 
livers). In IL-6 knock-out mice, a very mild decrease in Fpn-1 protein expression was observed (Figure 36).
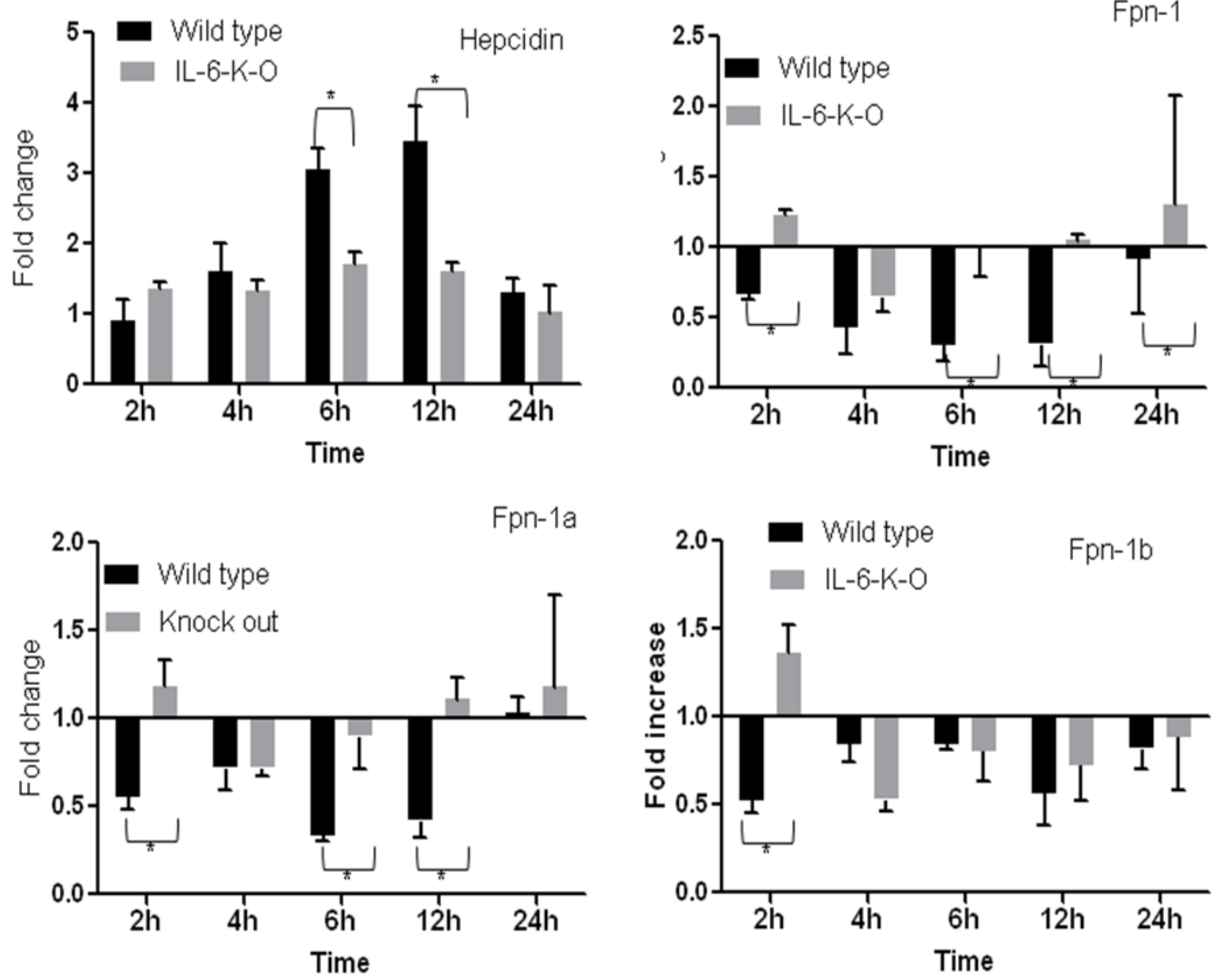

Figure 35: RT-PCR analysis of total RNA from mice liver during APR. Gene expression of hepcidin, Fpn-1, Fpn-1a and Fpn-1b in wild type (black bars) and IL-6 knock-out (gray bars) mice liver during acute phase response. RT-PCR was normalized by using GAPDH as housekeeping gene. Results represent the fold changes of mRNA expression of respective gene where, the control values were normalized to one. Data show the results of three animals (mean values \pm SEM. $*$ P<0.05 analyzed by one-way ANOVA). 
Table 2: Comparison of changes in mRNA amount of Fpn-1 and its isoforms in wild type and IL-6 knock-out mice liver during APR.

\begin{tabular}{|c|c|c|}
\hline \multirow{2}{*}{ Gene } & \multicolumn{2}{|c|}{$\begin{array}{c}\text { Changes in mRN amount of Fpn-1 and } \\
\text { isoforms }\end{array}$} \\
\cline { 2 - 3 } & Wild typ mice & $\begin{array}{c}\text { I-6 Knock-0ut- } \\
\text { mice }\end{array}$ \\
\hline Fpn-1 & $0.3 \pm 0.1$ & $0.70 \pm 0.1$ \\
\hline Fpn-1a & $0.3 \pm 0.03$ & $0.73 \pm 0.04$ \\
\hline Fpn-1b & $0.5 \pm 0.1$ & $0.4 \pm 0.06$ \\
\hline
\end{tabular}

4.14 Changes in mRNA expression of Fpn-1 and hepcidin in rat hepatocytes after cytokine treatment

To demonstrate the direct effect of IL-6 on hepatocytes Fpn-1 gene regulation, rat hepatocytes were isolated, cultured and stimulated with recombinant IL-6. RNA and proteins were extracted from cell lysates from control and IL-6 treated cells. The mRNA expression was quantified by RT-PCR. The mRNA expression of Fpn-1, Fpn-1a and Fpn-1b decreased early (1h) after stimulation with IL-6. This decrease was statistically significant $(\mathrm{P} \leq 0.001)$ for Fpn-1 $(0.11 \pm 0.07)$ at $12 \mathrm{~h}$, for Fpn-1a $(0.11 \pm 0.04)$ at $24 \mathrm{~h}$ and for Fpn-1b $(0.10 \pm 0.04$ fold $)$ at $24 \mathrm{~h}$. mRNA expression of hepcidin gene was upregulated with a maximum at $6 \mathrm{~h}$ after IL-6

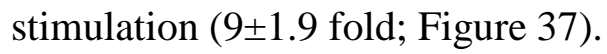



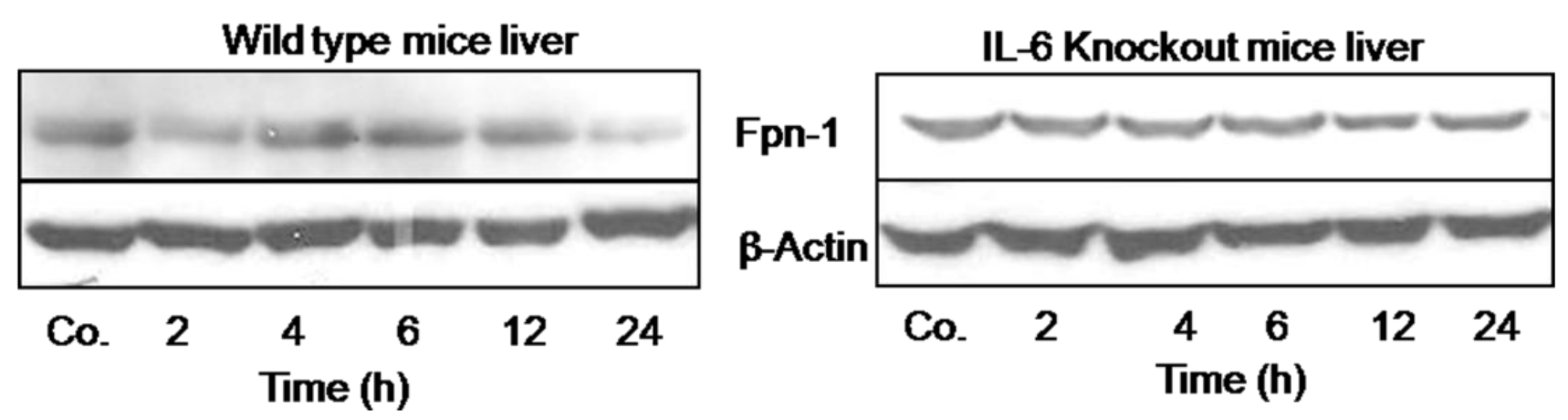

Figure 36: Fpn-1 protein expression in the livers of wild type and IL-6 knock-out mice during acute phase response. Western blot analysis of total protein lysates $(50 \mu \mathrm{g})$ for Fpn-1 protein in wild type and IL-6 knock-out during acute phase response. The result indicates representative figure of three experiments.

To address the question of Fpn-1 tendency of downregulation in IL-6 knock-out mice and the effect of other acute phase cytokines (IL-1 $\beta$ and TNF- $\alpha$ ) in Fpn-1 gene regulation, rat hepatocytes were stimulated with IL-1 $\beta$ and TNF- $\alpha$ and gene expression of Fpn-1, Fpn-1a, Fpn$1 \mathrm{~b}$ and hepcidin, was analyzed by RT-PCR. As observed for hepatocytes after IL-6 stimulation, with a difference of magnitude, the mRNA expression of Fpn-1, Fpn-1a and Fpn-1b decreased after stimulation with IL-1 $\beta$ and TNF- $\alpha$. This decrease was at its minimum for Fpn-1 $(0.31 \pm 0.15)$ at $12 \mathrm{~h}$ after IL-1 $\beta$ stimulation and $(0.24 \pm 0.16)$ at $6 \mathrm{~h}$ after TNF- $\alpha$ stimulation, for Fpn-1a $(0.33 \pm 0.07)$ at $6 \mathrm{~h}$ after IL-1 $\beta$ stimulation and $(0.6 \pm 0.23)$ after TNF- $\alpha$ stimulation and for Fpn-1b $(0.20 \pm 0.15)$ after $\mathrm{IL}-1 \beta$ stimulation and $(0.50 \pm 0.25)$ after TNF- $\alpha$ stimulation. The mRNA expression of hepcidin gene was upregulated with a maximum at $12 \mathrm{~h}$ after IL-1 $\beta$ stimulation (2.02 \pm 0.2 fold) and (2.5 \pm 0.23 fold) after TNF- $\alpha$ stimulation (Figure 38$)$. The table 3 compares the fold changes of Fpn-1, Fpn-1a and Fpn-1b in rat hepatocytes after cytokine treatment. The lower the value the higher is the decrease (Table 3). 


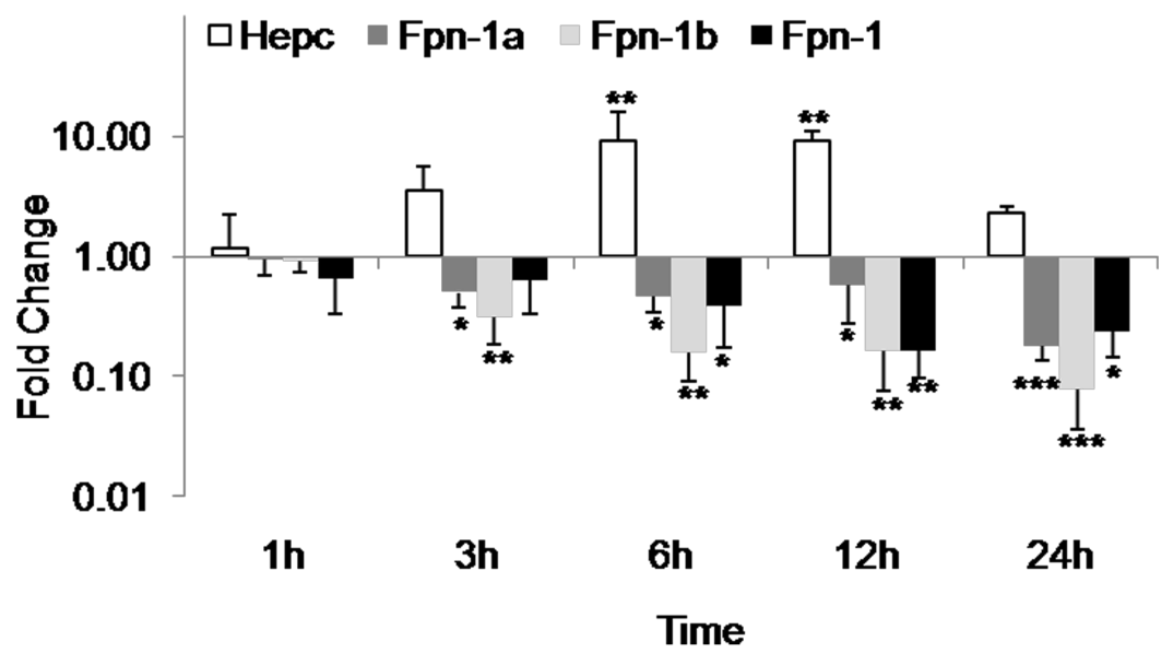

Figure 37: RT-PCR analysis of total RNA from rat hepatocytes after IL-6 stimulation. Quantification of Fpn-1, Fpn-1a, Fpn-1b and hepcidin gene expression in isolated rat hepatocytes after IL-6 treatment. The mRNA expression was analyzed by real time PCR and was normalized by using UBC as housekeeping gene. Results represent the fold changes of mRNA expression of respective gene where, the control values were normalized to one. Data show the results of three technical replicates (mean values \pm SEM. $* * * \mathrm{P}<0.0001$ analyzed by one-way ANOVA).

Table 3: Comparison of changes in mRNA amount of Fpn-1 and its isoforms in rat hepatocytes after cytokine treatment.

\begin{tabular}{|c|c|c|c|}
\hline \multirow[b]{2}{*}{ Gene } & \multicolumn{3}{|c|}{ Changes in mRNA amount } \\
\hline & IL-6 stimulation & L-1p stimulation & TNF-a stimulation \\
\hline Fpn-1 & $0.11 \pm 0.07$ & $0.31 \pm 0.15$ & $0.24 \pm 0.16$ \\
\hline Fpn-1a & $0.11 \pm 0.04$ & $0.33 \pm 0.07$ & $0.6 \pm 0.23$ \\
\hline Fpn-1b & $0.10 \pm 0.03$ & $0.2 \pm 0.15$ & $0.5 \pm 0.25$ \\
\hline
\end{tabular}




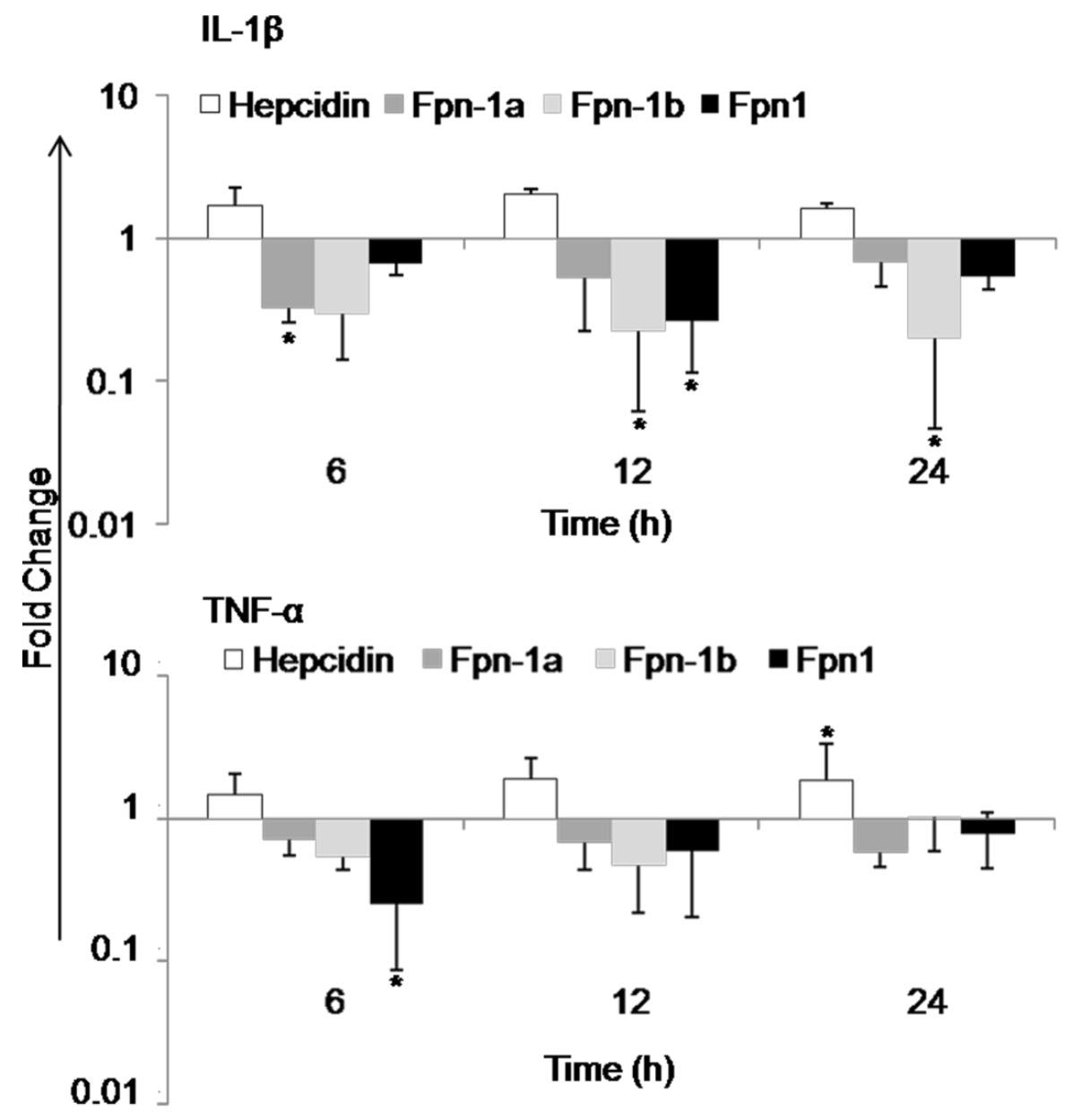

Figure 38: RT-PCR analysis of total RNA from rat hepatocytes after IL- $1 \beta$ and TNF- $\alpha$ stimulation. Quantification of Fpn-1, Fpn-1a, Fpn-1b and hepcidin gene expression in isolated rat hepatocytes after IL-1 $\beta$ and TNF- $\alpha$ treatment. The mRNA expression was analyzed by real time PCR and was normalized by using UBC as housekeeping gene. Results represent the fold changes of mRNA expression of respective gene where, the control values were normalized to one. Data show the results of three experiments (mean values $\pm \mathrm{SEM},{ }^{*} \mathrm{P}<0.05$ analyzed by oneway ANOVA).

4.15 Changes in protein expression of acute phase protein and Fpn-1 in rat hepatocytes after IL-6 treatment

Western blot analysis was performed to demonstrate and to compare the changes in acute phase proteins and Fpn-1 (the iron export protein). Acute phase conditions were confirmed by an 
upregulation of positive acute phase protein (APP); alpha-2-macroglobulin and a downregulation of negative APP, albumin. Immunobloting of Fpn-1 showed a downregulation of Fpn-1 protein expression by IL-6 treatment confirming IL-6 mediated regulatory effect on rat hepatocytes. The decrease of Fpn-1 protein expression was comparable to the negative secretory acute phase protein; albumin (Figure 39).
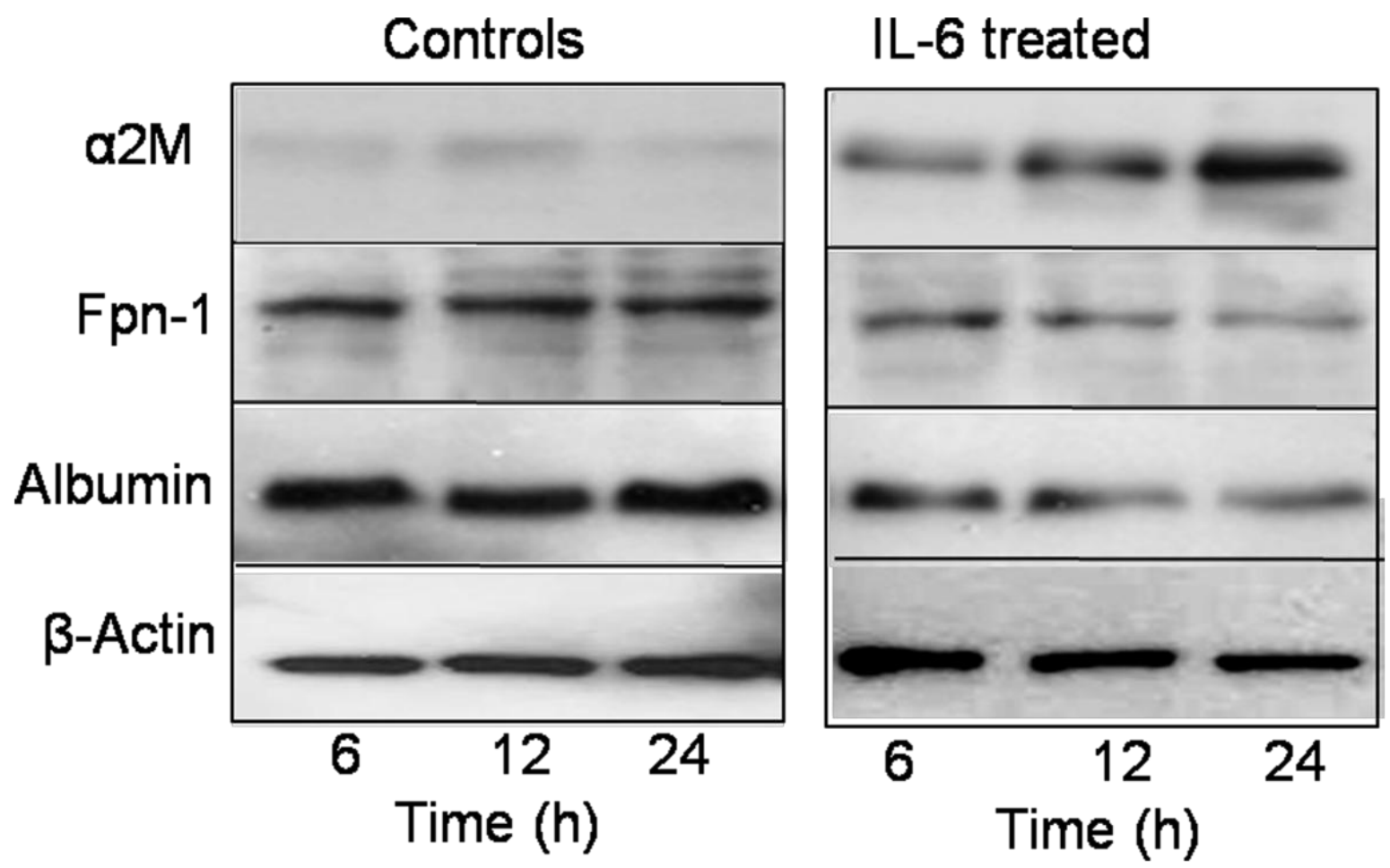

Figure 39: Western blot analysis of total cellular lysates $(50 \mu \mathrm{g})$ from control and IL-6 treated rat hepatocytes for $\alpha-2 \mathrm{M}$, Fpn-1 and albumin protein. Changes in protein expression of $\alpha 2 \mathrm{M}$ (alpha2-macroglobulin; a positive acute phase protein), albumin (a negative acute phase protein) and Fpn-1 (the iron export protein) in control and IL-6 treated hepatocytes. Data represents results from three experiments. 


\section{DISCUSSION}

This study reports and compares the changes in gene-expression (part 1) and cellular localization (part 2) of iron transport proteins (TfR1, TfR2, DMT-1 and Fpn-1) in liver in comparison to brain and spleen in a rat model of acute-phase response. Moreover, it identifies Fpn-1 (the iron export protein) as a negative acute phase protein in hepatocytes (part 3).

\subsection{Turpentine oil induced acute phase response and role of IL-6}

IL-6 gene expression was dramatically upregulated in the injured muscle. Similarly, a significant upregulation of IL-1 $\beta$ in rat muscle was observed during APR although the kinetics of this upregulation was quite less than that of IL-6. Moreover, another remarkable finding of current study was to observe an upregulation of IL- 6 and TNF- $\alpha$ gene expression in the brain while in the liver IL-1 $\beta$ and TNF- $\alpha$ but not the IL-6 gene expression was upregulated. Furthermore, a strong upregulation of serum concentrations of IL-6 and IL- $1 \beta$ are reported whereby the serum level of IL-6 was (at its maximum) 9 times higher than that of IL-1ß (Sheikh et al. 2007) which indicates that IL-6 is the major cytokine induced in the model of study.

TO induced local irritation is a model of sterile inflammation in which the inflammatory agent is restricted to a specific area i.e. the muscle and the local inflammation results in the recruitment of the inflammatory cells as well the upregulation of the IL-6 in the injured muscle. As the inflammatory stimulus is localized which could not approach the liver where it could cause the IL-6 upregulation. Moreover, TO is a lipophilic substance which readily accumulates in fatty tissues. The highest concentrations of turpentine following inhalation by rats were found in the kidneys and brain (Sperling et al., 1969; cited by ACGIH, 1991; Savolainen and Pfäffli, 1978) which might be a possible cause of local production of acute phase cytokines in relative organ of accumulation i.e. brain in the present study. Moreover, the induction of cytokines in the 


\section{Discussion}

brain could also be due to ROS production generated by oxidative stress as a result of increased iron concentration, as it has been observed in other neurodegenerative disorders (Mancuso et al. 2006). On the other hand, at the moment we can suppose (at least for IL-6 gene expression) a positive feedback mechanism which would be specific for the brain. It also suggests that the concentration of IL-6 reaching the brain may not be enough to modulate gene-expression under acute phase condition.

To demonstrate that acute-phase changes of gene-expression in the brain take place under the experimental conditions used we could show behavior of HO-1 gene similar to that observed in liver tissue. HO-1 is a positive acute phase protein and its expression significantly increased in the liver during localized inflammation as it was the case for hepcidin (Sheikh et al. 2007). Kartikasari et al. observed low hepcidin concentrations in the HO-1-deficient patient, suggesting a direct regulatory effect of HO-1 on hepcidin gene expression. However, they also showed that HO-1 activity did not have an effect on hepcidin gene expression in human hepatoma cells (Kartikasari et al. 2009). This suggests that IL-6 (main mediator in TO-induced APR released into the blood from the site of inflammation (skeletal muscle) independently upregulated HO-1 and hepcidin gene expression in liver and brain.

\subsection{Changes in serum and tissue iron concentration; a significant role of liver under APR}

Serum iron concentrations were reduced significantly during APR with a progressive and significant increase of liver iron concentration and a moderate increase in brain iron concentration. Moreover, one of the remarkable findings of the present study is that for the first time an increase in liver cytoplasmic and an even stronger increase of liver nuclear iron concentration during APR is shown. However, in the spleen the iron concentration decreased during APR. As a bacteriostatic response, decrease in serum iron concentration is a characteristic 
response of infection and endotoxin induced APR (Chlosta et al. 2006;Nairz et al. 2007; Wessling-Resnick 2010). The increased concentration of iron in rat liver and brain tissue during acute-phase reaction in a model of sterile inflammation could suggest an increased need of iron supply to satisfy the increased metabolic work under acute-phase conditions as it is known for liver (Ramadori and Christ 1999). The previous studies show that in iron-loading in HFE knockout mice suffering with hemochromatosis was associated with limited iron deposition into the spleen (Ahmad et al. 2002;Zhou et al. 1998). Prussian blue staining however was not sensitive enough to detect the increased hepatic iron concentration. A significant overload of iron has been reported in liver samples from Smad4Co/Co Alb-Cre mutant mice. Prussian blue staining showed that beginning at the age of two months, iron accumulated in the liver with pigmentation. Quantitative measurement showed a nine-fold increase in iron concentrations in the liver samples and confirmed alteration of iron levels in these organs (Wang et al. 2005).

\subsection{Expressional changes of iron transport proteins during APR; a comparison between}

\section{liver, brain and spleen}

In rat liver and brain, apart from the difference of magnitude, the gene expression of iron export proteins (Fpn-1, Fpn-1a, Fpn-1b) was downregulated during APR. Moreover, an upregulation of gene expression of iron import proteins (Tf, TfR1, TfR2 and DMT-1) and iron storage proteins (ferritin $\mathrm{H}$ and $\mathrm{L}$ ) was observed in rat liver with an exception of DMT-1 which showed a downregulation in brain. Moreover, the expression of other iron metabolism genes (HFE, HJV and Dcytb) was downregulated in liver and brain after the onset of APR. However, in liver, the gene expression of hephastin was regulated in a manner opposite to that of brain during APR. In accordance with the mRNA data, in the liver, the protein expression of Fpn-1and hephastin (iron export proteins) was decreased with an almost diminished expression of Fpn-1 at 


\section{Discussion}

24h after APR. Similarly, an increase in DMT-1, Tf, TfR1, TfR2 (iron import proteins) protein amount was observed. In spleen, a significant downregulation of mRNA expression of proteins involved in iron uptake (DMT-1, TfR1 and TfR2) together with a decrease in iron export gene (Fpn-1, Fpn-1a and Fpn-1b) was detected. Taken together, this data indicates that iron from the blood accumulates significantly in the liver and to some extent in the brain as is observed by increased liver and brain iron concentrations. It also indicates that iron is temporarily sequestered in the liver as Fpn-1 and hephastin (the iron exporters) gene expression in this tissue is dramatically down-regulated during APR. This also suggests that extra iron may be needed to satisfy the increased metabolic work under acute-phase conditions, as is known for the liver (Ramadori and Christ 1999). The increased gene expression of the transport molecules may be due to the action of the major acute phase cytokine (IL-6), as shown in-vitro (Sheikh et al. 2006) and the increased iron concentration, may on its own, further induces an upregulation of gene expression of the some proteins such as DMT-1, TfR1 and TfR2 (Tacchini et al. 2002; Trinder et al. 2000).

Although the gene expression of some iron regulatory proteins has been described in the murine CNS (Zechel et al. 2006), to our knowledge, this is the first attempt to determine the relationship between inflammation and regulation of iron metabolism genes in the rat liver and brain. Induction of a sterile abscess by intra-muscular administration can modulate the gene expression of iron-regulatory proteins at mRNA and protein concentration, not only in peripheral organs such as the liver, but also in the brain. Additionally, apart from the difference in magnitude, the pattern of change in major iron regulatory proteins is almost similar in both organs. Transferrin binding maintains iron in a soluble form and serves as a major vehicle of plasma iron delivery into cells via TfR1. Diferric Tf has a high affinity for the TfR1 and this has 
important physiological implications in terms of the mechanism of Tf uptake by cells (Herbison et al. 2009). A recent study on hepatoma cell line showed that increased expression of TfR1 has significant effects on transferrin-bound iron uptake at low transferrin concentrations, suggesting that TfR1 is the major $\mathrm{Tf}$ receptor responsible for iron transport

Although it is supposed that the TfR 1 is inversely regulated by cellular iron status via the posttranscriptional iron responsive element-iron regulatory protein (IRE-IRP) mechanism (Levy et al. 1999) we detected an early increase in the TfR1 protein expression parallel to increase in tissue iron concentration; this upregulation of TfR 1 could be due to either activation of IRP-1 (Caltagirone et al. 2001) or hypoxia-inducible factor $1 \alpha$ (HIF-1 $\alpha$ ), which binds to a conserved binding site within the TfR1 promoter (Tacchini et al. 1999) as induction of hepatic HIF-1 $\alpha$ was also observed in our model (Ramadori et al. 2010) This suggests that acute phase mediators may counteract the downregulating effect of iron on TfR1. Although previous reports showed decreased TfR1 mRNA expression in the liver and hepatocytes of HFE-knockout mice (Chua et al. 2008; Ludwiczek et al. 2005), downregulation of HFE gene in brain and liver during APR was not accompanied by a downregulation of TfR1 suggesting an independent regulation at least in this rat model. A very recent study identified TfR1 as a receptor of ferritin- $\mathrm{H}$ and mediates most of ferritin-H binding in human cells ( $\mathrm{Li}$ et al. 2010).

The presence of DMT1 in brain cerebrospinal fluid barriers is functionally important with regard to the necessity of stable homeostasis of essential elements in brain extracellular fluids for normal brain function (Wang et al. 2006; Rouault and Cooperman 2006). Hephastin is a ferroxidase associated with iron export by interacting with the Fpn1 and its expression has been reported in brain. Hephastin mRNA expression is influenced by the tissue iron status and is probably regulated at the transcriptional concentration by the metal (Qian et al. 2007). IRPs are 
critical determinants of the post-transcriptional regulation of TfR expression. Besides ferritin and TfR1, DMT1 and Fpn1 mRNA contain IRE-like sequences, suggesting that IRPs might be involved in the regulation of the mRNA expression (Gunshin et al. 1997;McKie et al. 2001). Its role is still unclear and further investigation is required. A very recent case reported a reduction in iron overload in the liver but not in the brain, where an iron chelator was used in a neurodegenerative disorder, this was due to incomplete penetration of chelator through the blood brain barrier (Finkenstedt et al. 2010). This suggests that some differences may exist in iron handling between liver and brain. In addition to what happens in the liver, the changes observed in the brain may be due to the local production of acute-phase cytokines.

\subsection{The differential cellular localization of iron transport proteins in rat liver, brain and} spleen

By means of immunohistochemical analysis we reported on the nuclear expression of TfR1 in brain tissue as compared to the liver and spleen where a membranous and cytoplasmic expression was observed. Similar to in vivo data, liver cells (Kupffer cells and hepatocytes) and human hepatoma cell (HepG2) showed a strong membranous and cytoplasmic positivity for TfR1 in contrast to brain cells where an abundant nuclear detection was observed. Moreover, in rat liver, brain and spleen we clearly show that TfR 2 and DMT- 1 are exclusively located in the nuclei of the cells. Similarly, Fpn-1 was localized to the nuclei of liver and brain cells however, in spleen Fpn-1 was detected in the plasma membrane of white and red pulp cell population.

These findings were further elaborated and confirmed by western blot analysis of the nuclear, cytoplasmic and membrane fractions obtained from liver tissue lysates. Moreover, in accordance to in vivo data, cultured Kupffer cells and hepatocytes showed a strong nuclear positivity for TfR2, DMT-1 and Fpn-1. Western blot analysis demonstrated that with a difference 
in intensity of expression, these iron transport proteins were expressed in hepatocytes and Kupffer cells but not in myofibroblasts.

Though, the nuclear expression of ferritin- $\mathrm{H}$ has been described in hepatocytes only under supra-physiological conditions (Smith et al. 1990). To the best of our knowledge, the nuclear expression of DMT-1, TfR2 and Fpn-1 in rat liver has not been described so far. This may suggest iron sequestration not only in cytoplasm but also in nucleus of liver cells as observed by the increased cytoplasmic and nuclear iron concentrations in liver and on the other hand, an important role of iron for hepatocytes metabolism under stress conditions. Moreover, an increase in mRNA expression of iron dependent cytoplasmic enzyme ribonucleotide reductase (RNR) in the present model of study supports the increased iron needs during APR. Increased nuclear iron uptake indicates the increased activity of nuclear enzymes for DNA synthesis and repair (Roth et al. 2000) as is demonstrated by increased mRNA and protein concentrations of cyclin E, and/or to regulate the initiation of transcription (Roth et al. 2000). As transcription function is strongly upregulated under stress conditions nuclear uptake of iron may indicate an important role of this metal. A previous study reported the evidence of stainable iron in the nuclei of hepatocytes and kupffer cells in mice liver under iron overload conditions. This finding may support not only the presence of iron transport proteins in the nuclei of liver cells under nonphysiological conditions as a defence mechanism (Magens et al. 2005) but also the need of iron for nuclear metabolism.

DMT-1 and TfR2 nuclear expression has been demonstrated in rat PC12 cells (Roth et al. 2000) and in mice glioblastomas cancer cell lines respectively (Calzolari et al. 2010). Nuclear localization of Fpn-1 in liver and brain tissue is quite surprising and mystifies its function as a membrane iron export protein. There are conflicting reports that demonstrate the localization of 
Fpn-1 protein in different organs of human, rat and mice by means of immunohistochemical analysis. Membrane positivity of Fpn-1 protein was shown in extra-embryonic visceral endoderm and duodenal enterocytes of mice (Donovan et al. 2005). In one study on human lung tissues, the membrane localization of Fpn-1 in airway epithelial cells was described where it was also visible in the nucleoli of these cells. Anyhow, in alveolar macrophages, Fpn-1 was detected only in the membrane, cytoplasm and intracellular vesicles. Moreover, a study by Yang and coworkers demonstrate the tissue specific sub-cellular localization of Fpn-1 in the lung and duodenum of rat (Yang et al. 2005). However, D'Anna et al. reports supranuclear expression of Fpn-1 protein in mice liver macrophages (D'Anna et al. 2009). The differential subcellular localization of Fpn-1 in different organs suggests that it might not only hepcidin which regulates Fpn-1 but different regulatory mechanisms may exist in different organs depending on cellular iron needs. A recent study reports hepcidin independent regulation of Fpn-1 in human embryonic kidney (De, I et al. 2010). Similarly, a study reports on both inflammation-mediated transcriptional and IRE-dependent post-transcriptional mechanisms for inhibiting ferroportin expression in mononuclear phagocyte cells (Liu et al. 2002). However, in contrast to liver and spleen membranous expression, being an iron importer, the nuclear localization of TfR 1 in brain cells needs further insights.

\subsection{Ferroportin-1, a negative acute phase protein; role of IL-6 cytokine}

In the third part of study, the modulation of Fpn-1 expression in liver tissue and cultured hepatocytes was analyzed under the effect of major acute phase cytokine; IL-6. The mRNA expressions, western blot analysis and immunohistochemical identification on liver sections showed an early (1h) and intense decrease of Fpn-1 (before hepcidin-gene expression start to increase; $2 \mathrm{~h}$ ) in liver under the acute phase conditions studied. Under iron overload conditions, 


\section{Discussion}

Fpn-1 is bounded by hepcidin and degraded leading to cellular iron retention (Canonne-Hergaux et al. 2006). Furthermore, the downregulation of Fpn-1 could probably be controlled by acutephase cytokines (mainly IL-6) released at the site of injury during APR as these cytokines are able to modulate the expression of iron transport proteins (Liu et al. 2005;Nemeth et al. 2004). Moreover, in the present study, Fpn-1 protein expression in the liver was almost diminished at $24 \mathrm{~h}$ of APR. A slight upregulation of IL-6 gene expression in liver at $24 \mathrm{~h}$ of APR can possibly justify the intense decrease in Fpn-1 protein expression in the liver at this time point indicating a direct or combination effect (with hepcidin) of acute phase cytokine (IL-6 in this case) on regulating Fpn-1 gene expression. Infact, this finding is consistent with our previous studies, where a downregulation of Fpn-1 gene expression in parallel to an increase in acute phase cytokines (IL-1 $\beta$, IL-6 and TNF- $\alpha$ ) was reported in different rat models (Christiansen et al. 2007; Moriconi et al. 2009; Sheikh et al. 2006;Sheikh et al. 2007). The cytokines induced Fpn-1 downregulation is most probably a mechanism occurring independently of hepcidin, as a downregulation of Fpn-1 gene expression starts before hepcidin gene expression is upregulated.

To investigate the role of IL-6 in changes of Fpn-1 gene expression, the expression pattern of Fpn-1-, Fpn-1a-, Fpn-1b- and hepcidin -mRNA was analyzed in wild type and IL-6 knock-out mice, under the similar acute phase conditions as for rats. RT-PCR demonstrated an upregulation of hepcidin gene expression in wild type and IL-6 knock-out mice. However, in wild type mice, the constitutive expression of hepcidin was higher than in their IL-6 knockout counterparts during APR. Moreover, Fpn-1, Fpn-1a and Fpn-1b gene expression was also downregulated in wild type and IL-6 knock-out mice under acute phase conditions. However, in wild type mice, the decrease in mRNA amount of Fpn-1 and its isoforms was higher and significant compared to their IL-6 knock-out counterparts. The upregulation of hepcidin and a 


\section{Discussion}

slight downregulation of Fpn-1 and its isoforms in IL-6 knockout mice under acute phase conditions might be due to the existence of other acute phase cytokines; IL- $1 \beta$ and TNF- $\alpha$, produced at the site of injury. It might also indicate that depending on the model of study, other cytokines replace the role of IL-6 as an upregulation of IL-1 $\beta$ was more intense in IL-6 knockout mice than their wild type counterparts (Ramadori et al. 2010).

To support the direct role of IL-6 in Fpn-1 regulation, rat hepatocytes were cultured and stimulated with IL-6 and acute phase conditions were confirmed by upregulation of positive acute phase protein (alpha-2-macroglobulin) and down-regulation of the expression of albumin (negative secretory acute phase protein), this decrease was comparable to the decrease in Fpn-1 protein expression. Moreover, at mRNA concentration, Fpn-1 gene expression was decreased together with its isoforms and an increase in hepcidin gene expression was also observed.

To address the question of downregulation of Fpn-1 and its isoforms in IL-6 knock-out mice liver and effect of other acute phase cytokines on Fpn-1 regulation, rat hepatocytes were stimulated with IL-1 $\beta$ and TNF- $\alpha$. The mRNA expression pattern of Fpn-1, its isoforms together with hepcidin was analyzed by RT-PCR. As was observed for IL-6 treated hepatocytes, with a difference of magnitude, the stimulation of hepatocytes with IL- $1 \beta$ and TNF- $\alpha$ lead to a down regulation of Fpn-1 and its isoforms with a slight upregulation of hepcidin gene expression which indicates that these cytokines too, to some extent regulate the gene expression of Fpn-1 and its isoforms as was observed previously (Sheikh et al. 2006). Similarly, a study on rat C6 glioma cells reports the modulation of Fpn-1 synthesis by IL-1 $\beta$ cytokine (di Patti et al. 2004). In fact, similar finding was confirmed in cultured hepatocytes where a dose dependent downregulation of Fpn-1 gene expression was detected after acute phase cytokines treatment (Sheikh et al. 2006) indicating a direct regulative effect. A similar study also reported a direct 
effect of acute inflammation mediators on downregulation of Fpn-1 in reticuloendothelial system (Yang et al. 2002). Taking together, these data may suggest that Fpn-1 can be considered as a negative intracellular (nuclear) acute phase protein (APP).

\section{CONCLUSION}

In conclusion, we propose that under normal conditions, transferrin bound iron of portal blood is taken up by liver cells through TfR1 mediated iron uptake. Once in the cell, it is in part delivered not only to cytoplasmic organelles like mitochondria (Richardson et al. 2010) but also to the nucleus to meet the cellular functional requirements including DNA synthesis. Under acute phase conditions, liver behaves as a "sponge" for iron as the reduction in serum iron concentration is most probably achieved by increased hepatic uptake of transferrin bound iron by TfR1 mediated iron transport into the hepatocytes; increased DMT-1 also serves to transport iron inside the cell nuclei. On the same side, a reduction in Fpn-1 (mediated mainly by IL-6 cytokine) and hephastin leads to transient iron retention inside the cell and/or cell nucleus. All these events lead to iron retention inside the cell most probably to fulfil functional requirements of acute phase situations (Figure 40). Furthermore, we demonstrated that TfR1 and other iron regulatory proteins known to be expressed in the liver are also expressed in the rat brain. Moreover, we showed that the changes in gene expression of several iron regulating proteins during acute-phase reaction observed in the brain tissue are similar to those observed in the liver including accumulation of iron. Our findings have significant implications for further understanding the importance of iron metabolism, not only in the liver but also in the brain. 


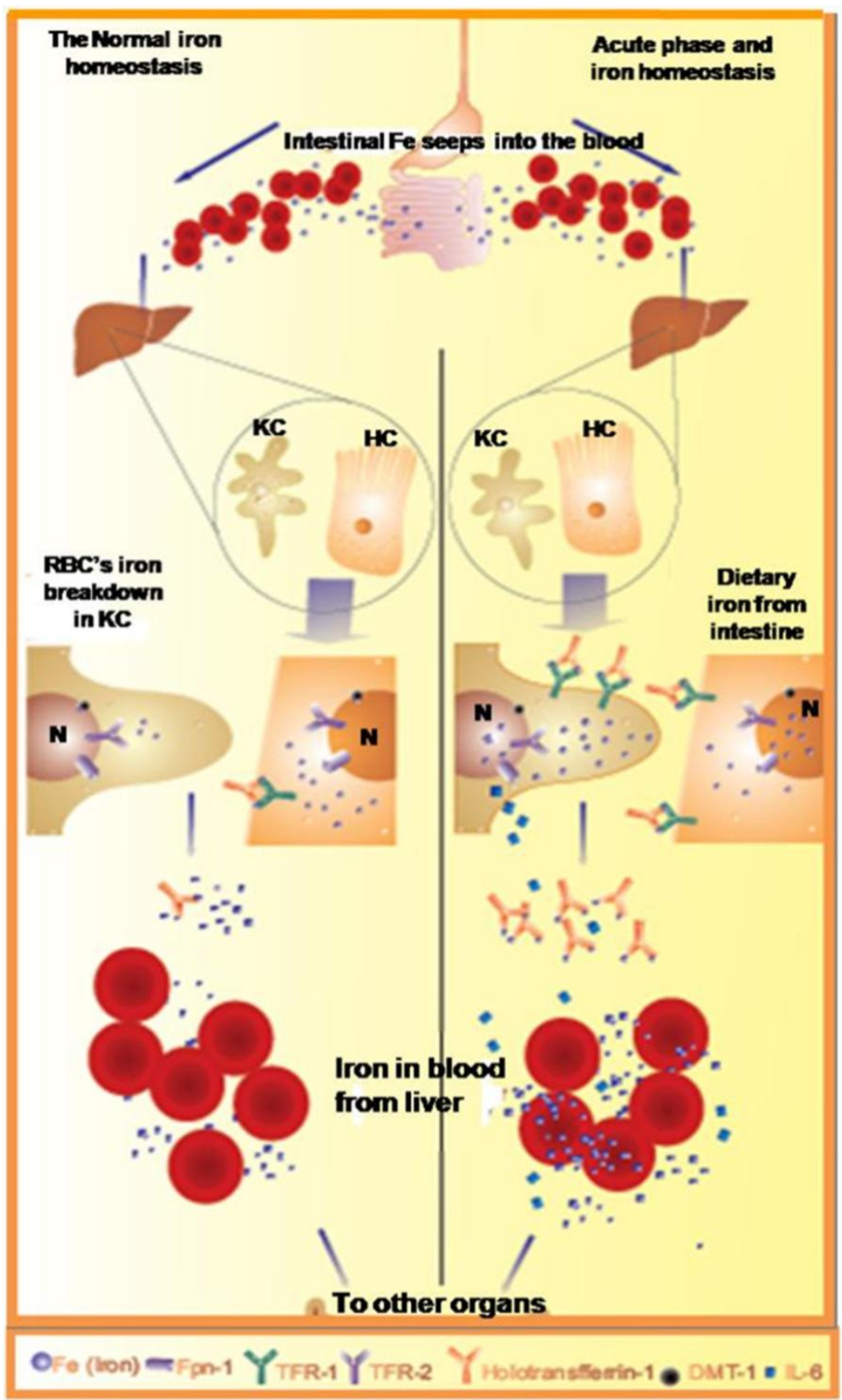

Figure 40: The proposed mechanism of iron metabolism in liver cells (HC: hepatocytes, KC: Kupffer cells) under physiological and acute phase conditions. The iron absorbed at intestinal level seeps into blood and is taken up by Tf which translocates iron inside the cell by TfR1 mediated endocytosis. TfR2 and DMT-1 adds to serve the iron transportation into the cell nuclei $(\mathrm{N})$. During APR, the increased level of serum cytokine (IL-6) induces a downregulation of nuclear iron exporter (Fpn-1) and aids the cells to retain iron inside the cell and cell nuclei to meet the higher metabolic requirements under APR. 
Abboud S, Haile DJ (2000) A novel mammalian iron-regulated protein involved in intracellular iron metabolism. J Biol Chem 275:19906-19912

Ahmad KA, Ahmann JR, Migas MC, Waheed A, Britton RS, Bacon BR, Sly WS, Fleming RE (2002) Decreased liver hepcidin expression in the Hfe knockout mouse. Blood Cells Mol Dis 29:361-366

Anderson GJ, Frazer DM, McKie AT, Wilkins SJ, Vulpe CD (2002) The expression and regulation of the iron transport molecules hephaestin and IREG1: implications for the control of iron export from the small intestine. Cell Biochem Biophys 36:137-146

Aydemir F, Jenkitkasemwong S, Gulec S, Knutson MD (2009) Iron loading increases ferroportin heterogeneous nuclear RNA and mRNA levels in murine J774 macrophages. J Nutr 139:434-438

Benarroch EE (2009) Brain iron homeostasis and neurodegenerative disease. Neurology 72:1436-1440

Boelen A, Kwakkel J, Alkemade A, Renckens R, Kaptein E, Kuiper G, Wiersinga WM, Visser TJ (2005) Induction of type 3 deiodinase activity in inflammatory cells of mice with chronic local inflammation. Endocrinology 146:5128-5134

Bradbury MW (1997) Transport of iron in the blood-brain-cerebrospinal fluid system. J Neurochem 69:443-454

Budick-Harmelin N, Dudas J, Demuth J, Madar Z, Ramadori G, Tirosh O (2008) Triglycerides potentiate the inflammatory response in rat Kupffer cells. Antioxid Redox Signal 10:2009-2022

Cairo G, Recalcati S, Mantovani A, Locati M (2011) Iron trafficking and metabolism in macrophages: contribution to the polarized phenotype. Trends Immunol 32:241-247

Caltagirone A, Weiss G, Pantopoulos K (2001) Modulation of cellular iron metabolism by hydrogen peroxide. Effects of $\mathrm{H} 2 \mathrm{O} 2$ on the expression and function of iron-responsive element-containing mRNAs in B6 fibroblasts. J Biol Chem 276:19738-19745

Calzolari A, Larocca LM, Deaglio S, Finisguerra V, Boe A, Raggi C, Ricci-Vitani L, Pierconti F, Malavasi F, De MR, Testa U, Pallini $R$ (2010) Transferrin receptor 2 is frequently and highly expressed in glioblastomas. Transl Oncol 3:123-134

Camaschella C (2005) Understanding iron homeostasis through genetic analysis of hemochromatosis and related disorders. Blood 106:3710-3717 
Canonne-Hergaux F, Donovan A, Delaby C, Wang HJ, Gros P (2006) Comparative studies of duodenal and macrophage ferroportin proteins. Am J Physiol Gastrointest Liver Physiol 290:G156-G163

Casey JL, Koeller DM, Ramin VC, Klausner RD, Harford JB (1989) Iron regulation of transferrin receptor mRNA levels requires iron-responsive elements and a rapid turnover determinant in the 3' untranslated region of the mRNA. EMBO J 8:3693-3699

Chlosta S, Fishman DS, Harrington L, Johnson EE, Knutson MD, Wessling-Resnick M, Cherayil BJ (2006) The iron efflux protein ferroportin regulates the intracellular growth of Salmonella enterica. Infect Immun 74:3065-3067

Christiansen H, Sheikh N, Saile B, Reuter F, Rave-Frank M, Hermann RM, Dudas J, Hille A, Hess CF, Ramadori G (2007) x-Irradiation in rat liver: consequent upregulation of hepcidin and downregulation of hemojuvelin and ferroportin-1 gene expression. Radiology 242:189-197

Chua AC, Herbison CE, Drake SF, Graham RM, Olynyk JK, Trinder D (2008) The role of Hfe in transferrin-bound iron uptake by hepatocytes. Hepatology 47:1737-1744

Coverley D, Laman H, Laskey RA (2002) Distinct roles for cyclins E and A during DNA replication complex assembly and activation. Nat Cell Biol 4:523-528

Crowe A, Morgan EH (1992) Iron and transferrin uptake by brain and cerebrospinal fluid in the rat. Brain Res 592:8-16

Cui Y, Wu Q, Zhou Y (2009) Iron-refractory iron deficiency anemia: new molecular mechanisms. Kidney Int 76:1137-1141

D'Anna MC, Veuthey TV, Roque ME (2009) Immunolocalization of ferroportin in healthy and anemic mice. J Histochem Cytochem 57:9-16

De D, I, Lo E, Ward DM, Kaplan J (2010) Human mutation D157G in ferroportin leads to hepcidin-independent binding of Jak2 and ferroportin down-regulation. Blood 115:29562959

di Patti MC, Persichini T, Mazzone V, Polticelli F, Colasanti M, Musci G (2004) Interleukin1beta up-regulates iron efflux in rat $\mathrm{C} 6$ glioma cells through modulation of ceruloplasmin and ferroportin-1 synthesis. Neurosci Lett 363:182-186

Donovan A, Brownlie A, Zhou Y, Shepard J, Pratt SJ, Moynihan J, Paw BH, Drejer A, Barut B, Zapata A, Law TC, Brugnara C, Lux SE, Pinkus GS, Pinkus JL, Kingsley PD, Palis J, Fleming MD, Andrews NC, Zon LI (2000) Positional cloning of zebrafish ferroportin1 identifies a conserved vertebrate iron exporter. Nature 403:776-781

Donovan A, Lima CA, Pinkus JL, Pinkus GS, Zon LI, Robine S, Andrews NC (2005) The iron exporter ferroportin/Slc40a1 is essential for iron homeostasis. Cell Metab 1:191-200 
Dudas J, Mansuroglu T, Batusic D, Saile B, Ramadori G (2007) Thy-1 is an in vivo and in vitro marker of liver myofibroblasts. Cell Tissue Res 329:503-514

Elledge SJ, Zhou Z, Allen JB (1992) Ribonucleotide reductase: regulation, regulation, regulation. Trends Biochem Sci 17:119-123

Enerson BE, Drewes LR (2006) The rat blood-brain barrier transcriptome. J Cereb Blood Flow Metab 26:959-973

Finkenstedt A, Wolf E, Hofner E, Gasser BI, Bosch S, Bakry R, Creus M, Kremser C, Schocke M, Theurl M, Moser P, Schranz M, Bonn G, Poewe W, Vogel W, Janecke AR, Zoller $H$ (2010) Hepatic but not brain iron is rapidly chelated by deferasirox in aceruloplasminemia due to a novel gene mutation. J Hepatol 53:1101-1107

Frazer DM, Anderson GJ (2005) Iron imports. I. Intestinal iron absorption and its regulation. Am J Physiol Gastrointest Liver Physiol 289:G631-G635

Ganz T (2005) Cellular iron: ferroportin is the only way out. Cell Metab 1:155-157

Ganz T, Nemeth E (2006) Iron imports. IV. Hepcidin and regulation of body iron metabolism. Am J Physiol Gastrointest Liver Physiol 290:G199-G203

Gruenheid S, Canonne-Hergaux F, Gauthier S, Hackam DJ, Grinstein S, Gros P (1999) The iron transport protein NRAMP2 is an integral membrane glycoprotein that colocalizes with transferrin in recycling endosomes. J Exp Med 189:831-841

Gunshin H, Mackenzie B, Berger UV, Gunshin Y, Romero MF, Boron WF, Nussberger S, Gollan JL, Hediger MA (1997) Cloning and characterization of a mammalian protoncoupled metal-ion transporter. Nature 388:482-488

Han O, Kim EY (2007) Colocalization of ferroportin-1 with hephaestin on the basolateral membrane of human intestinal absorptive cells. J Cell Biochem 101:1000-1010

Hentze MW, Muckenthaler MU, Andrews NC (2004) Balancing acts: molecular control of mammalian iron metabolism. Cell 117:285-297

Hentze MW, Muckenthaler MU, Galy B, Camaschella C (2010) Two to tango: regulation of Mammalian iron metabolism. Cell 142:24-38

Herbison CE, Thorstensen K, Chua AC, Graham RM, Leedman P, Olynyk JK, Trinder D (2009) The role of transferrin receptor 1 and 2 in transferrin-bound iron uptake in human hepatoma cells. Am J Physiol Cell Physiol 297:C1567-C1575

Herrick J, Sclavi B (2007) Ribonucleotide reductase and the regulation of DNA replication: an old story and an ancient heritage. Mol Microbiol 63:22-34

Hogbom M, Andersson ME, Nordlund P (2001) Crystal structures of oxidized dinuclear manganese centres in Mn-substituted class I ribonucleotide reductase from Escherichia 
coli: carboxylate shifts with implications for $\mathrm{O} 2$ activation and radical generation. J Biol Inorg Chem 6:315-323

Kalinowski DS, Richardson DR (2005) The Evolution of Iron Chelators for the Treatment of Iron Overload Disease and Cancer. Pharmacological Reviews 57:547-583

Kartikasari AE, Wagener FA, Yachie A, Wiegerinck ET, Kemna EH, Winkels DW (2009) Hepcidin suppression and defective iron recycling account for dysregulation of iron homeostasis in heme oxygenase-1 deficiency. J Cell Mol Med 13:3091-3102

Knook DL, Sleyster EC (1976) Separation of Kupfer and endothelial cells of the rat liver by centrifugal elutriation. Exp Cell Res 99:444-449

Krause A, Neitz S, Magert HJ, Schulz A, Forssmann WG, Schulz-Knappe P, Adermann K (2000) LEAP-1, a novel highly disulfide-bonded human peptide, exhibits antimicrobial activity. FEBS Lett 480:147-150

Kuo YM, Su T, Chen H, Attieh Z, Syed BA, McKie AT, Anderson GJ, Gitschier J, Vulpe CD (2004) Mislocalisation of hephaestin, a multicopper ferroxidase involved in basolateral intestinal iron transport, in the sex linked anaemia mouse. Gut 53:201-206

Lai CH, Kuo KH (2005) The critical component to establish in vitro BBB model: Pericyte. Brain Res Brain Res Rev 50:258-265

Levy JE, Jin O, Fujiwara Y, Kuo F, Andrews NC (1999) Transferrin receptor is necessary for development of erythrocytes and the nervous system. Nat Genet 21:396-399

Li L, Fang CJ, Ryan JC, Niemi EC, Lebron JA, Bjorkman PJ, Arase H, Torti FM, Torti SV, Nakamura MC, Seaman WE (2010) Binding and uptake of H-ferritin are mediated by human transferrin receptor-1. Proc Natl Acad Sci U S A 107:3505-3510

Liu XB, Hill P, Haile DJ (2002) Role of the ferroportin iron-responsive element in iron and nitric oxide dependent gene regulation. Blood Cells Mol Dis 29:315-326

Liu XB, Nguyen NB, Marquess KD, Yang F, Haile DJ (2005) Regulation of hepcidin and ferroportin expression by lipopolysaccharide in splenic macrophages. Blood Cells Mol Dis 35:47-56

Ludwiczek S, Theurl I, Bahram S, Schumann K, Weiss G (2005) Regulatory networks for the control of body iron homeostasis and their dysregulation in HFE mediated hemochromatosis. J Cell Physiol 204:489-499

Magens B, Dullmann J, Schumann K, Wulfhekel U, Nielsen P (2005) Nuclear iron deposits in hepatocytes of iron-loaded HFE-knock-out mice: a morphometric and immunocytochemical analysis. Acta Histochem 107:57-65 
Malik IA, Baumgartner BG, Naz N, Sheikh N, Moriconi F, Ramadori G (2010) Changes in gene expression of DOR and other thyroid hormone receptors in rat liver during acutephase response. Cell Tissue Res 342:261-272

Malik IA, Naz N, Sheikh N, Khan S, Moriconi F, Blaschke M, Ramadori G (2011) Comparison of changes in gene expression of transferrin receptor-1 and other ironregulatory proteins in rat liver and brain during acute-phase response. Cell Tissue Res

Mancuso M, Coppede F, Migliore L, Siciliano G, Murri L (2006) Mitochondrial dysfunction, oxidative stress and neurodegeneration. J Alzheimers Dis 10:59-73

McGrath H, Rigby PG (2004) Hepcidin: inflammation's iron curtain. Rheumatology 43:1323-1325

McKie AT, Barrow D, Latunde-Dada GO, Rolfs A, Sager G, Mudaly E, Mudaly M, Richardson C, Barlow D, Bomford A, Peters TJ, Raja KB, Shirali S, Hediger MA, Farzaneh F, Simpson RJ (2001) An Iron-Regulated Ferric Reductase Associated with the Absorption of Dietary Iron. Science 291:1755-1759

Moos T, Trinder D, Morgan EH (2000) Cellular distribution of ferric iron, ferritin, transferrin and divalent metal transporter 1 (DMT1) in substantia nigra and basal ganglia of normal and beta2-microglobulin deficient mouse brain. Cell Mol Biol (Noisy -le-grand) 46:549-561

Moriconi F, Ahmad G, Ramadori P, Malik I, Sheikh N, Merli M, Riggio O, Dudas J, Ramadori G (2009) Phagocytosis of gadolinium chloride or zymosan induces simultaneous upregulation of hepcidin- and downregulation of hemojuvelin- and Fpn-1-gene expression in murine liver. Lab Invest 89:1252-1260

Nairz M, Theurl I, Ludwiczek S, Theurl M, Mair SM, Fritsche G, Weiss G (2007) The coordinated regulation of iron homeostasis in murine macrophages limits the availability of iron for intracellular Salmonella typhimurium. Cell Microbiol 9:2126-2140

Napier I, Ponka P, Richardson DR (2005) Iron trafficking in the mitochondrion: novel pathways revealed by disease. Blood 105:1867-1874

Nemeth E, Rivera S, Gabayan V, Keller C, Taudorf S, Pedersen BK, Ganz T (2004) IL-6 mediates hypoferremia of inflammation by inducing the synthesis of the iron regulatory hormone hepcidin. J Clin Invest 113:1271-1276

Oide T, Yoshida K, Kaneko K, Ohta M, Arima K (2006) Iron overload and antioxidative role of perivascular astrocytes in aceruloplasminemia. Neuropathol Appl Neurobiol 32:170176

Pitiero DJ, Connor JR (2000) Iron in the Brain: An Important Contributor in Normal and Diseased States. The Neuroscientist 6:435-453 
Prus E, Fibach E (2011) Uptake of non-transferrin iron by erythroid cells. Anemia 2011:945289

Qian ZM, Chang YZ, Zhu L, Yang L, Du JR, Ho KP, Wang Q, Li LZ, Wang CY, Ge X, Jing NL, Li L, Ke Y (2007) Development and iron-dependent expression of hephaestin in different brain regions of rats. $\mathrm{J}$ Cell Biochem 102:1225-1233

Ramadori G, Christ B (1999) Cytokines and the hepatic acute-phase response. Semin Liver Dis 19:141-155

Ramadori G, Meyer Zum Buschenfelde KH, Tobias PS, Mathison JC, Ulevitch RJ (1990) Biosynthesis of lipopolysaccharide-binding protein in rabbit hepatocytes. Pathobiology 58:89-94

Ramadori G, Sipe JD, Colten HR (1985) Expression and regulation of the murine serum amyloid A (SAA) gene in extrahepatic sites. J Immunol 135:3645-3647

Ramadori P, Ahmad G, Ramadori G (2010) Cellular and molecular mechanisms regulating the hepatic erythropoietin expression during acute-phase response: a role for IL-6. Lab Invest 90:1306-1324

Ramey G, Deschemin JC, Durel B, Canonne-Hergaux F, Nicolas G, Vaulont S (2010) Hepcidin targets ferroportin for degradation in hepatocytes. Haematologica 95:501-504

Richardson DR, Lane DJ, Becker EM, Huang ML, Whitnall M, Suryo RY, Sheftel AD, Ponka P (2010) Mitochondrial iron trafficking and the integration of iron metabolism between the mitochondrion and cytosol. Proc Natl Acad Sci U S A 107:10775-10782

Roetto A, Di CF, Pellegrino RM, Hirsch E, Azzolino O, Bondi A, Defilippi I, Carturan S, Miniscalco B, Riondato F, Cilloni D, Silengo L, Altruda F, Camaschella C, Saglio G (2010) Comparison of 3 Tfr2-deficient murine models suggests distinct functions for Tfr2-alpha and Tfr2-beta isoforms in different tissues. Blood 115:3382-3389

Roth JA, Horbinski C, Feng L, Dolan KG, Higgins D, Garrick MD (2000) Differential localization of divalent metal transporter 1 with and without iron response element in rat PC12 and sympathetic neuronal cells. J Neurosci 20:7595-7601

Rouault TA (2006) The role of iron regulatory proteins in mammalian iron homeostasis and disease. Nat Chem Biol 2:406-414

Rouault TA, Cooperman S (2006) Brain iron metabolism. Semin Pediatr Neurol 13:142-148

Seglen PO (1972) Preparation of rat liver cells. I. Effect of Ca 2+ on enzymatic dispersion of isolated, perfused liver. Exp Cell Res 74:450-454

Sheikh N, Batusic DS, Dudas J, Tron K, Neubauer K, Saile B, Ramadori G (2006) Hepcidin and hemojuvelin gene expression in rat liver damage: in vivo and in vitro studies 42. Am J Physiol Gastrointest Liver Physiol 291:G482-G490 
Sheikh N, Dudas J, Ramadori G (2007) Changes of gene expression of iron regulatory proteins during turpentine oil-induced acute-phase response in the rat

29. Lab Invest 87:713-725

Smith AG, Carthew P, Francis JE, Edwards RE, Dinsdale D (1990) Characterization and accumulation of ferritin in hepatocyte nuclei of mice with iron overload. Hepatology 12:1399-1405

Smith PK, Krohn RI, Hermanson GT, Mallia AK, Gartner FH, Provenzano MD, Fujimoto EK, Goeke NM, Olson BJ, Klenk DC (1985) Measurement of protein using bicinchoninic acid. Anal Biochem 150:76-85

Song N, Wang J, Jiang H, Xie J (2010) Ferroportin 1 but not hephaestin contributes to iron accumulation in a cell model of Parkinson's disease. Free Radic Biol Med 48:332-341

Stankiewicz J, Panter SS, Neema M, Arora A, Batt CE, Bakshi R (2007) Iron in chronic brain disorders: imaging and neurotherapeutic implications. Neurotherapeutics 4:371-386

Tabuchi M, Yoshimori T, Yamaguchi K, Yoshida T, Kishi F (2000) Human NRAMP2/DMT1, which mediates iron transport across endosomal membranes, is localized to late endosomes and lysosomes in HEp-2 cells. J Biol Chem 275:22220-22228

Tacchini L, Bianchi L, Bernelli-Zazzera A, Cairo G (1999) Transferrin receptor induction by hypoxia. HIF-1-mediated transcriptional activation and cell-specific post-transcriptional regulation. J Biol Chem 274:24142-24146

Tacchini L, Fusar PD, Bernelli-Zazzera A, Cairo G (2002) Transferrin receptor gene expression and transferrin-bound iron uptake are increased during postischemic rat liver reperfusion. Hepatology 36:103-111

Trinder D, Fox C, Vautier G, Olynyk JK (2002) Molecular pathogenesis of iron overload. Gut 51:290-295

Trinder D, Oates PS, Thomas C, Sadleir J, Morgan EH (2000) Localisation of divalent metal transporter 1 (DMT1) to the microvillus membrane of rat duodenal enterocytes in iron deficiency, but to hepatocytes in iron overload. Gut 46:270-276

Tron K, Novosyadlyy R, Dudas J, Samoylenko A, Kietzmann T, Ramadori G (2005) Upregulation of heme oxygenase-1 gene by turpentine oil-induced localized inflammation: involvement of interleukin-6. Lab Invest 85:376-387

Vulpe CD, Kuo YM, Murphy TL, Cowley L, Askwith C, Libina N, Gitschier J, Anderson GJ (1999) Hephaestin, a ceruloplasmin homologue implicated in intestinal iron transport, is defective in the sla mouse. Nat Genet 21:195-199

Wang RH, Li C, Xu X, Zheng Y, Xiao C, Zerfas P, Cooperman S, Eckhaus M, Rouault T, Mishra L, Deng CX (2005) A role of SMAD4 in iron metabolism through the positive regulation of hepcidin expression. Cell Metab 2:399-409 
Wang X, Li GJ, Zheng W (2006) Upregulation of DMT1 expression in choroidal epithelia of the blood-CSF barrier following manganese exposure in vitro. Brain Res 1097:1-10

Weiss G (2005) Modification of iron regulation by the inflammatory response. Best Pract Res Clin Haematol 18:183-201

Wessling-Resnick M (2010) Iron homeostasis and the inflammatory response. Annu Rev Nutr 30:105-122

Wusteman M, Wight DG, Elia M (1990) Protein metabolism after injury with turpentine: a rat model for clinical trauma. Am J Physiol 259:E763-E769

Yang F, Haile DJ, Wang X, Dailey LA, Stonehuerner JG, Ghio AJ (2005) Apical location of ferroportin 1 in airway epithelia and its role in iron detoxification in the lung. Am J Physiol Lung Cell Mol Physiol 289:L14-L23

Yang F, Liu XB, Quinones M, Melby PC, Ghio A, Haile DJ (2002) Regulation of reticuloendothelial iron transporter MTP1 (Slc11a3) by inflammation. J Biol Chem 277:39786-39791

Yeh KY, Yeh M, Mims L, Glass J (2009) Iron feeding induces ferroportin 1 and hephaestin migration and interaction in rat duodenal epithelium. Am J Physiol Gastrointest Liver Physiol 296:G55-G65

Zechel S, Huber-Wittmer K, von Bohlen Und HO (2006) Distribution of the iron-regulating protein hepcidin in the murine central nervous system. J Neurosci Res 84:790-800

Zhang DL, Hughes RM, Ollivierre-Wilson H, Ghosh MC, Rouault TA (2009) A ferroportin transcript that lacks an iron-responsive element enables duodenal and erythroid precursor cells to evade translational repression. Cell Metab 9:461-473

Zhou XY, Tomatsu S, Fleming RE, Parkkila S, Waheed A, Jiang J, Fei Y, Brunt EM, Ruddy DA, Prass CE, Schatzman RC, ОГÇÖNeill R, Britton RS, Bacon BR, Sly WS (1998) HFE gene knockout produces mouse model of hereditary $Г$ Çëhemochromatosis. Proceedings of the National Academy of Sciences 95:2492-2497 


\section{LIST OF PUBLICATIONS}

1. *Malik, I.A., *Naz N., Sheikh, N., Khan S., Moriconi, F., Blaschke M. Comparison of changes in gene expression of transferrin receptor-1 and other iron-regulatory proteins in rat liver and brain during acute-phase response. Cell Tissue Res. 2011 May; 344(2):299312.

*(share the first authorship).

2. Naz N., Malik I., Sheikh N., Ahmad S, Khan S., Ramadori G., Ferroporti-1 is a negative acute phase protein in rat hepatocytes. A comparison with other iron transporters. Lab. Invest. 2011 (under revision).

3. Ahmad A., Malik I.A., Nischwitz M., Sultan S., Naz N., Ramadori G. Myeloperoxidase and elastase are only expressed by neutrophils in normal and in inflammed liver. Histochem Cell Biol. 2011 Mar; 135(3):305-15.

4. Sheikh N., Naz N., Qureshi A.W. Impact of work place environment on the hematology and serology of steel industry workers. Health MED, 2011 5(1)35-40.

5. Sheikh N., Masood M., Naz N. Hematological and serological changes in the pre- and post-treatment breast cancer patients. Health MED. 2011. In press.

6. Wójcik M, Ramadori P, Blaschke M, Sultan S, Khan S, Malik IA, Naz N, Martius G, Ramadori G, Schultze FC. Expression of cyclooxygenase-2 (COX-2) is restricted to "resident" tissue macrophages in rat liver injury and cholangiocarcinoma development. Histochem Cell Biol. 2011 Dec 1. [Epub ahead of print].

7. Malik, I.A., Baumgartner BG., Naz N., Sheikh, N., Moriconi, F., Ramadori G. Changes in gene expression of DOR and other thyroid hormone receptors in rat liver during acutephase response. Cell Tissue Res. 2010 Nov; 342(2):261-72.

8. Malik, I.A., Moriconi, F., Sheikh, N. Naz N. Dudas, J. Mansuroglu, T., Hess, C.F., Rave-Fränk MChristiansen, H., Giuliano Ramadori. Single-dose gamma-irradiation induces up-regulation of chemokine- gene expression and recruitment of granulocytes into the portal area but not into other region of rat hepatic tissue. Am J Pathol. 2010 Apr; 176(4):1801-15.

9. Sheikh N., Manzoor F., Ahmed R., Naz N. and. Malik S.A. Laboratory study of repellency and toxicity of Tenekil, Termidor and Terminus against subterranean termite Heterotermes indicola (Wasmann) in Pakistan. Sociobiology 2008 51(3) 749-764. 


\section{ACKNOWLEDGEMENTS}

First and foremost I would like to thank Allah. In the process to get my $\mathrm{PhD}$ I realized $\mathrm{He}$ has given me the power to believe in my passion and pursue my dreams.

I feel enormous intensity of obligation and heights of gratefulness to my learned supervisor Professor Dr. Giuliano Ramadori for his valuable guidance, positive criticism, stimulating ideas and extreme patience with my work which proved to be a panacea in the completion of this dissertation. I deeply appreciate the time he spent supervising and teaching me. I express my particular gratitude to my scientific supervisors; Prof. Dr. Jürgen Wienands and Professor Dr. Lutz Walter for their outstanding supervision, support and contribution to my success. Their constructive criticism and suggestions are highly appreciated.

My sincere thanks to my co-guide Dr. Ihtzaz Malik for his practical advices and the time he spent for time to time discussion, valuable suggestions to my work and my colleague Dr. Martina Blaschke for her constructive critics on my thesis.

I am very grateful for all other colleagues Dr. Silke Cameron, Sajjad Khan, Shakil Ahmad, Sadaf Sultan, Gesa Martius, Martina Blaschke, Ghayyor Ahmad, and Pierlugi Ramadori in the department for providing me nice and friendly working atmosphere. I am also grateful to the technical personnel of the department, especially S. Zachmann, C. Dunaiski, D, Gercke, S. Heyroth, A. Herbst and E. Neumann for their significant help during these years.

A special thanks to my brother Dr. Nadeem Sheikh without whom I could never think to conquer this entire break, a special gratitude to him. Words are inadequate to convey sincere gratitude to Dr. Ahmed Shariq, Dr. Ihtzaz Malik, Dr. Saima Zafar and Dr. Saadia Zahid who was always there to built up my hope and courage whenever I felt down to earth.

Last but not the least; I must not miss the opportunity to acknowledge the role of my parents and family in my success. Without their support it would have been a dream which became a reality today and I finished my Ph.D. Thank you all.

Naila 
10. DEDICATION

1 dedicate my thesis to my adored parents Mr. \&Mrs. Sheikh Hadayat Wllah and to my lovely family. 


\section{CURRICULUM VITAE}

Family Name

First name

Date of birth

Place of birth

Citizenship

2002-2004

2004-2008

2008-2009

2008-2009
$\mathrm{Naz}$

Naila

08.02.1986

Lahore, Pakistan

Pakistani

College Education

Lahore, Pakistan

Degree: FSc (Pre-medical)

Kinnaird College University, Lahore, Pakistan.

University Education

Degree: Bachelors (Hons.) of Zoology

University of Punjab, Lahore, Pakistan

Project leaders: Dr.Nabila Roohi/Dr. Nadeem Sheikh

University of Punjab, Lahore, Pakistan

Guest Scientist (6 months)

Department of Internal medicine

Division of Gastroenterology and Endocrinology

University hospital Göttingen, Germany.

Project leader: Prof. Dr. Giuliano Ramadori

Diplom practical work

Department of Primate Genetics, 
German Primate Center, Göttingen, Germany.

Project leader: Prof. Dr. Lutz Walter

Sep. 2009-January. 2012

Degree: Ph.D. in biology

Department of Gastroenterology and Endocrinology of

University Hospital, Georg-August University, Göttingen

Project leader: Prof. Dr. Giuliano Ramadori

Title: "Comparison of expression pattern and localization of iron transport proteins in rat liver, brain and spleen during acute phase response: in-vivo and in-vitro studies". 